\title{
Stereoselective Synthesis and Biological Evaluation as Inhibitors of Hepatitis C virus RNA polymerase of GSK3082 Analogues with Structural Diversity at the 5- Position
}

José A. Gálvez ${ }^{\mathrm{a}, *}$, Rafael Clavería-Gimeno ${ }^{\mathrm{b}, \mathrm{c}}$, Juan J. Galano-Frutos ${ }^{\mathrm{c}, \mathrm{de}}$, Javier Sancho ${ }^{\mathrm{cd,}, \mathrm{e}}$, Adrian Velázquez-Campoy, ${ }^{\mathrm{cffg}}$, Olga Abian ${ }^{\mathrm{b}, \mathrm{cd}, \mathrm{g}}$, and María D. Díaz-de-Villegas ${ }^{\mathrm{a}, *}$

a Instituto de Síntesis Química y Catálisis Homogénea (ISQCH), CSIC - Universidad de Zaragoza, Departamento de Química Orgánica, Pedro Cerbuna 12, 50009 Zaragoza, Spain.

${ }^{\mathrm{b}}$ Instituto Aragonés de Ciencias de la Salud (IACS), 50009 Zaragoza, Spain.

${ }^{\mathrm{c}}$ Biocomputation and Complex Systems Physics Institute (BIFI)-Joint Units: BIF GBsC-CSIC, University of Zaragoza, Zaragoza 50018, Spain.

${ }^{d}$ Aragon Institute for Health Research (IIS Aragon), 50009 Zaragoza, Spain.

e Departamento de Bioquímica y Biología Molecular y Celular, Facultad de Ciencias, Universidad de Zaragoza, Zaragoza 50009, Spain

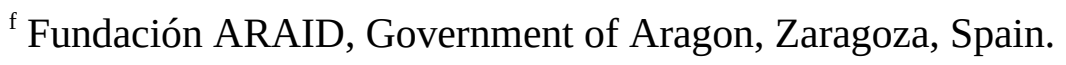

${ }^{g}$ Centro de Investigación Biomédica en Red en el Área Temática de Enfermedades Hepáticas y Digestivas (CIBERehd), Barcelona, Spain.

Corresponding Author: jagl@unizar.es, loladiaz@unizar.es

\begin{abstract}
:
GSK3082 - a hepatitis C virus RNA polymerase inhibitor - and a series of analogues with structural diversity at the 5-position were prepared from a 2,2,4,5-tetrasubstituted pyrrolidine obtained with a well-defined stereochemistry from the 1,3-dipolar cycloaddition of the chiral imino ester derived from leucine tert-butyl ester and (R)-2,3-O-isopropylideneglyceraldehyde with methyl acrylate. The chiral 2,2-dimethyl-1,3-dioxolane moiety provided by the glyceraldehyde served as a synthetic equivalent for different substituents and functional groups and these transformations usually required mild reaction conditions and simple work-up procedures. The inhibitory activity of the resulting GSK3082 analogues
\end{abstract}


was studied in vitro in a cell-based assay of the subgenomic HCV RNA replication system. Some of the analogues showed good inhibitory activity with IC50 values in the nanomolar concentration range.

Key words: Hepatitis C virus (HCV), N-Acylpyrrolidines, HCV replication inhibitors, StructureActivity relationshiphs

\section{Introduction}

Hepatitis $\mathrm{C}$ virus (HCV) is a biological pathogenic agent and it is considered to be the most common cause of chronic liver disease worldwide [1]. The progressive destruction and regeneration of the liver parenchyma caused by chronic liver disease is associated with the development of fibrosis, liver cirrhosis, hepatocellular carcinoma and eventually liver failure and death [2]. HCV infection constitutes a major public health problem: a large number of people - about 325 million worldwide in 2015 - are carriers of hepatitis B or C virus infections, each year 1.75 million people newly acquire hepatitis C virus infection and in 2015 alone viral hepatitis caused 1.34 million deaths, most of which were due to chronic liver disease and primary liver cancer [3].

Inhibition of HCV NS5B polymerase, a key enzyme for HVC replication with RNA-dependent RNA polymerase function [4], has proven to be a goal of paramount importance for the development of specifically targeted antiviral therapy for HCV [5]. The potent antiviral effect of polymerase inhibitors has led to the development of nucleos(t)ide and non-nucleoside analogues for the treatment of chronic hepatitis C patients [6].

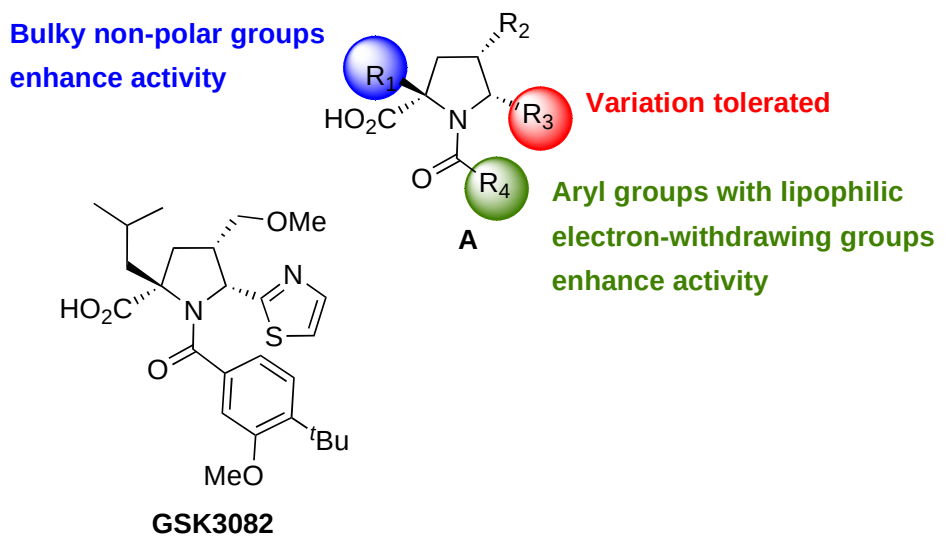

Figure 1. General structure of $N$-acylpyrrolidines identified as of HCV NS5B polymerase inhibitors.

In the above context, $N$-acylpyrrolidines with the general structure $\mathbf{A}$ (Figure 1 ) have been identified as reversible, non-competitive inhibitors of HCV NS5B polymerase [7]. Structural analyses have shown 
that compounds from Mhacylpyrrolidine series

bind in the palm pocket

I

active site of the polymerase [6h,8].

Optimization of the structure based on the analysis of structure-activity relationships (GlaxoSmithKline) led to the identification of GSK3082 [7c], a potent inhibitor of RNA-dependent RNA polymerase (NS5B) in enzymatic assays that also inhibits viral RNA replication in cell-based replicon assays. These SAR studies showed that (i) the presence of a bulky non-polar group in the 2-position increases activity, (ii) aryl groups with lipophilic electron-withdrawing groups in the acyl moiety enhance activity, with the 4-(tert-butyl)-3-methoxybenzoyl group being optimal, and (iii) that the substituent at the 5-position can be widely varied.

1,3-Dipolar cycloaddition has proven to be a flexible and versatile synthetic strategy to gain access to the pyrrolidine core of biologically active compounds [8]. Previously described non-stereoselective [7], diastereoselective [9] and enantioselective [10] syntheses of antiviral compounds with the general structure A have been performed using 1,3-dipolar cycloaddition of iminoglycinates and acrylates as the key step. Substituents $\mathrm{R}_{1}$ and $\mathrm{R}_{3}$ are provided by the amino acid and the aldehyde from which the iminoglycinate is obtained and substituent $\mathrm{R}_{2}$ is generated from the carboxylate moiety in the acrylate (Scheme 1).

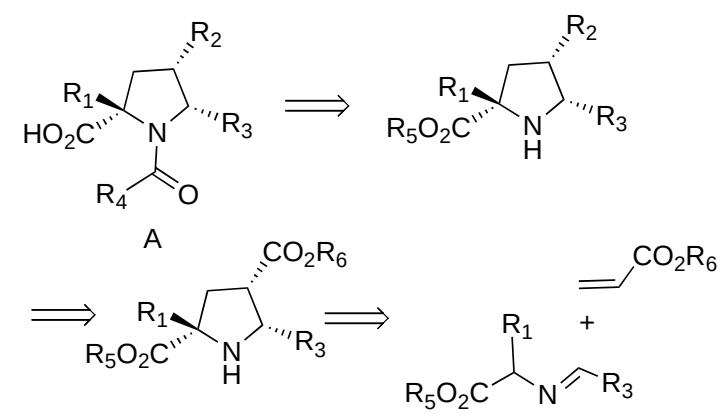

Scheme 1. Strategy for synthesis of $N$-acylpyrrolidines.

One of our research goals is the synthesis of versatile chiral intermediates from imines derived from glyceraldehyde - which is readily accessible from inexpensive D-mannitol - and the development of synthetic routes to obtain bioactive compounds in enantiomerically pure form from these chiral intermediates [11]. With this aim in mind, we studied the behaviour of chiral iminoesters derived from glyceraldehyde acetonide in azomethine ylide cycloadditions and developed a stereoselective and flexible methodology for the synthesis of 2,2,4,5-tetrasubstituted pyrrolidines with a well-defined stereochemistry [12]. We presume that this methodology would be amenable to the synthesis of HCV NS5B polymerase inhibitors and related structural analogues. In the work reported here, we synthesised 
a series of novel $N$-acylpyrrolidines - in which the substituent at 5-position in GSK3082 was varied starting from a common precursor. The target compounds are potential HCV polymerase inhibitors and their inhibitory activities were evaluated in vitro in a cell-based assay of the subgenomic HCV RNA replication system.

\section{Results and discussion}

\subsection{Chemistry}

Based on our previous experience we envisaged that the pyrrolidine core of structural analogues of GSK3082 with different substituents in the 5-position could be obtained by the 1,3-dipolar cycloaddition between an acrylate and an iminoester derived fromD-glyceraldehyde acetonide and leucine using silver acetate for metallation. In this way the 2,2,4,5-tetrasubstituted pyrrolidine with the appropriate configuration would be obtained. The chiral 2,2-dimethyl-1,3-dioxolane moiety provided by the glyceraldehyde has a double role: (i) to control the stereochemical course of the reaction and (ii) to serve as a synthetic equivalent for different substituents and functional groups (Scheme 2). The tertbutylimino ester $\mathbf{1}$ and methyl acrylate were selected as reagents to obtain an orthogonally protected pyrrolidine.

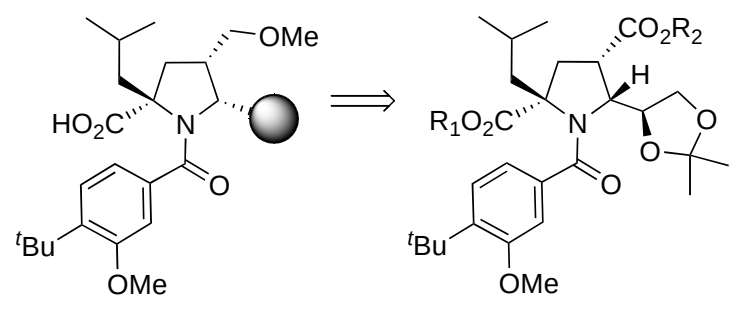

GSK3082 analogues

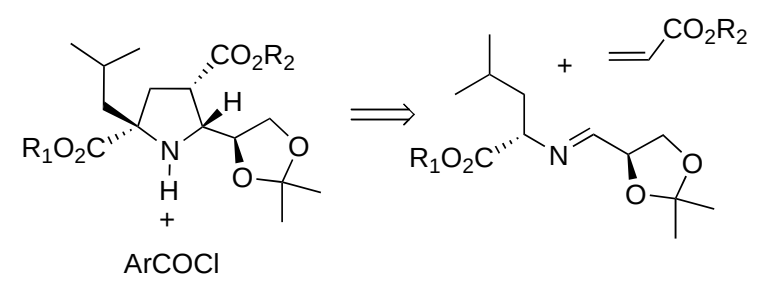

Scheme 2. Strategy for synthesis GSK3082 analogues.

Starting imino ester 1 was prepared by reaction of (S)-leucine tert-butyl ester with (R)-2,3-Oisopropylideneglyceraldehyde in ether at room temperature for $2 \mathrm{~h}$ in the presence of anhydrous $\mathrm{MgSO}_{4}$ as a dehydrating agent. The crude imino ester was directly submitted to a 1,3-dipolar cycloaddition reaction with methyl acrylate without any purification. Reaction using silver acetate (20 
mol\%) as the catalyst and DBU (20 mol\%) as the base in toluene at room temperature for $24 \mathrm{~h}$ led to an

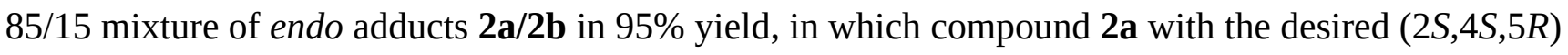
configuration was in excess. The absolute configuration of the major endo adduct was unambiguously established by a single-crystal X-ray diffraction study on compound $\mathbf{4 a}$, which was obtained from $\mathbf{2 a}$ as shown below. Acylation of the mixture with 4-(tert-butyl)-3-methoxybenzoyl chloride provided the corresponding $N$-acyl pyrrolidines $\mathbf{3 a / 3 b}$ as an 85/15 mixture of diastereoisomers in $96 \%$ yield (Scheme 3).
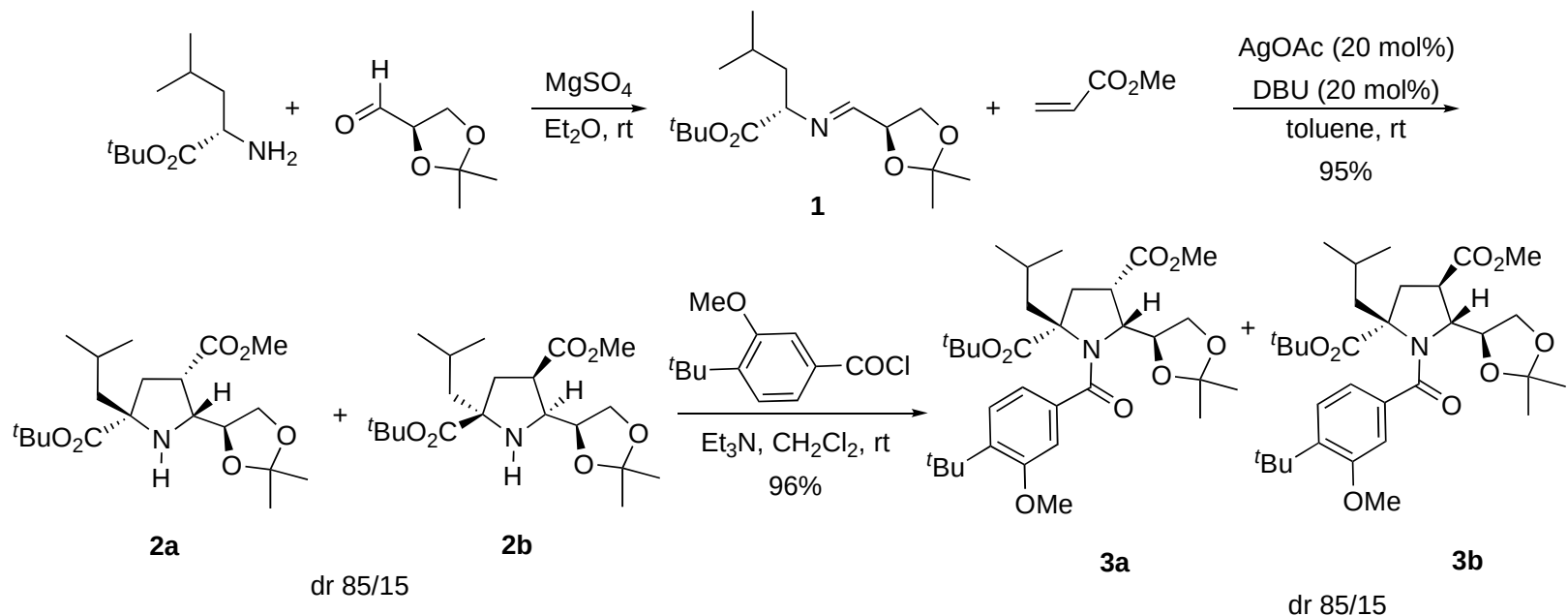

Scheme 3. Synthesis of $N$-acylpyrrolidine 3a.

The synthesis of GSK3082 was completed as shown in Schemes 4 and 5. Reduction of the methyl ester was achieved with a combination of $\mathrm{NaBH}-\mathrm{MeOH}(1: 2)$ in the presence of a catalytic amount of $\mathrm{NaB}(\mathrm{OAc})_{3} \mathrm{H}$ (2.5 mol \% relative to $\mathrm{NaBH}$ [10a]. After stirring 3a/3b in THF for 4 days at room temperature the corresponding 4-hydroxymethylpyrrolidines were obtained as an 85/15 diastereomeric mixture, from which $\mathbf{4 a}$ and $\mathbf{4 b}$ were isolated as diastereomerically pure compounds in $81 \%$ and $12 \%$ yield, respectively.

The $O$-methylation of $\mathbf{4 a}$ with an excess of methyl iodide in the presence of potassium tert-butoxide in THF at room temperature was complete after $18 \mathrm{~h}$ and provided compound 5 in $88 \%$ yield. The 2,2dimethyl-1,3-dioxolane moiety was converted into the required thiazol-2-yl substituent at the 5position by first converting the acetonide 5 into the aldehyde 7 . Chemoselective deprotection using $\mathrm{BiCl}_{3}$ in dry acetonitrile provided diol 6 in 81\% yield [13] and this was subsequently converted into the aldehyde 7 in $94 \%$ yield by oxidation with sodium periodate. 


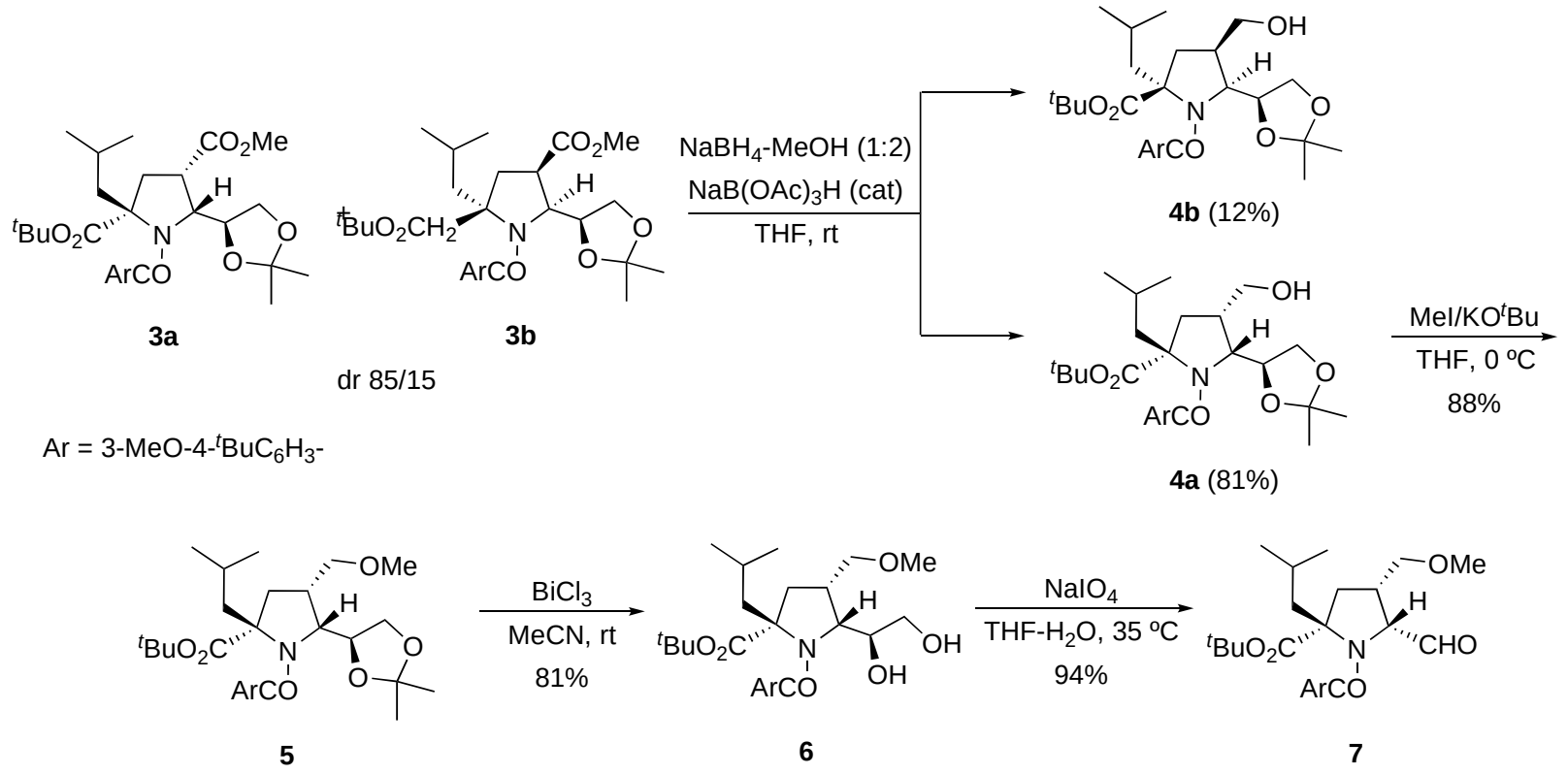

Scheme 4. The synthetic route for key intermediate 7.

Further oxidation of aldehyde 7 with potassium permanganate using a mixture of tert-butanol and aqueous $\mathrm{NaH}_{2} \mathrm{PO}_{4}$ as the reaction medium [14], followed by treatment with of isopropyl chloroformate in the presence of $N$-methylmorpholine in THF at room temperature and subsequent reaction with ammonium hydroxide gave a 79\% yield of formamide 8. Direct conversion of formamide 8 into thioamide 10 using Lawesson's reagent was unsuccessful and we evaluated a two-step procedure using nitrile 9 as the intermediate. Reaction of formamide 8 with POsCin pyridine [15] provided a 51\% yield of the nitrile intermediate $\mathbf{9}$, which was subsequently converted into thioamide $\mathbf{1 0}$ (95\% yield) by the action of $40-44 \%$ aqueous ammonium sulfide solution in methanol. At this point we evaluated the direct conversion of aldehyde $\mathbf{7}$ to nitrile $\mathbf{9}$. This transformation was successfully achieved in $99 \%$ yield using iodine in ammonia water [16]. In an effort to prevent epimerization, the final thiazol-2-yl substituent at the 5-position in GSK3082 was prepared via a modified Hantzsch method [15] that involved the cyclocondensation of thioamide $\mathbf{1 0}$ with bromoacetaldehyde in dry dimethoxyethane using $\mathrm{NaHCO}_{3}$ as base followed by dehydratation of the hydroxythiazoline intermediate by treatment with trifluoroacetic anhydride-pyridine. In this way compound $\mathbf{1 1}$ was obtained in 87\% yield with complete stereocontrol. Finally, hydrolysis of the tert-butyl ester with trifluoroacetic acid in dichloromethane at 0 ${ }^{\circ} \mathrm{C}$ yielded GSK3082 in 95\% yield. GSK3082 was obtained from $\mathbf{1}$ in 10 steps with a good overall yield of $38 \%$. 

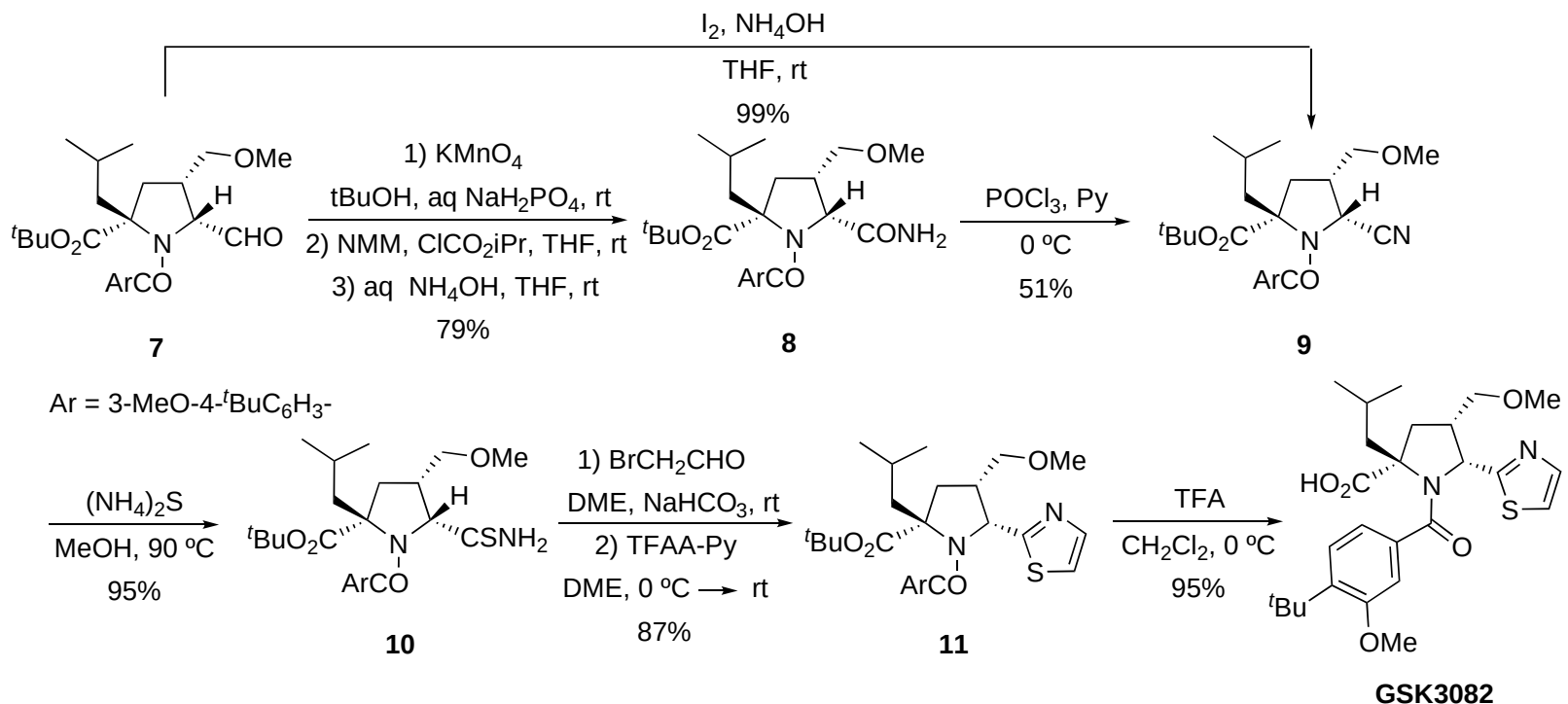

Scheme 5. The synthetic route for target compound GSK3082.

Cyclocondensation of thioamide $\mathbf{1 0}$ with ethyl bromopyruvate using this protocol led to an $88 \%$ yield of compound 12, which upon hydrolysis with trifluoroacetic acid in dichloromethane at $0{ }^{\circ} \mathrm{C}$ afforded GSK3082 analogue 13 in 95\% yield without detectable epimerization (Scheme 6).

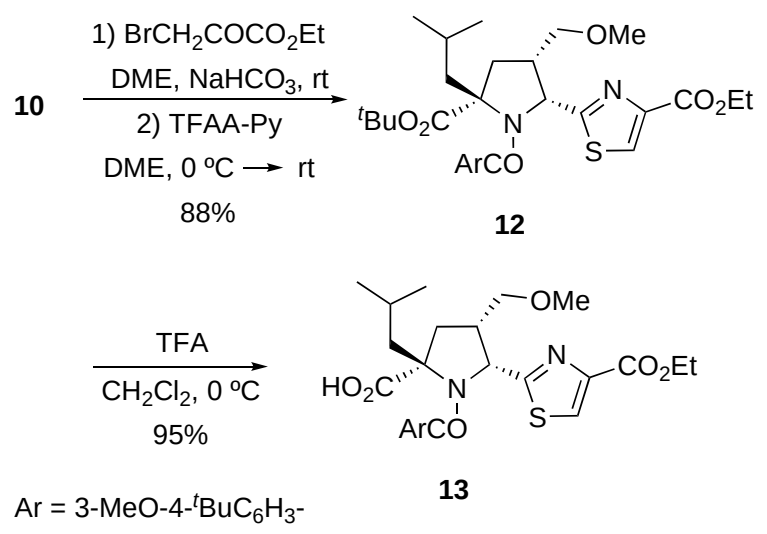

Scheme 6. The synthetic route for GSK3082 analogue 13.

Alternatively, the thiazol-2-yl substituent at the 5-position was installed by reaction of thioamide $\mathbf{1 0}$ with $\alpha$-bromoacetaldehyde diethyl acetal in THF under reflux and in the presence of a catalytic amount of $\mathrm{HCl}$ in dioxane [17]. In this way compound $\mathbf{1 4}$ - the epimer of $\mathbf{1 1}$ at C5 - was obtained in 51\% yield, again with complete stereocontrol. tert-Butyl ester $\mathbf{1 4}$ was readily hydrolysed to the corresponding acid $\mathbf{1 5}$ in 96\% yield under the same conditions as above (Scheme 7). 


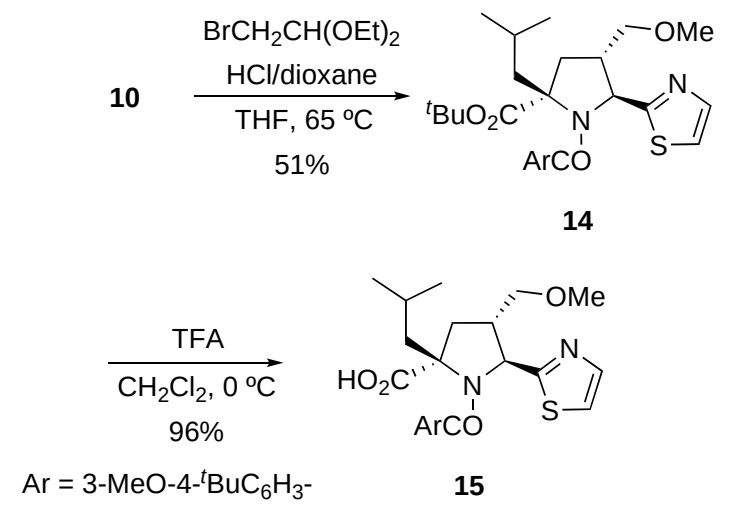

Scheme 7. The synthetic route for GSK3082 analogue 15.

The synthesis of the first set of structural analogues of GSK3082 with substituents with different structural characteristics in the 5-position was readily achieved from intermediates 5, 6 and 8 as detailed below. The chemoselective hydrolysis of the tert-butyl ester compound $\mathbf{5}$ was carried out under reflux with a methanolic solution of potassium hydroxide and this gave analogue $\mathbf{1 6}$ in nearly quantitative yield. Compound 6 was reacted with 1,1'-carbonyldiimidazole in THF at $60{ }^{\circ} \mathrm{C}$ to produce carbonate 17 in $90 \%$ yield, which upon hydrolysis with trifluoroacetic acid in dichloromethane at $0{ }^{\circ} \mathrm{C}$ led to analogue 18 in 94\% yield. GSK3082 analogue 19 was obtained in 96\% yield by treatment of amide 8 with trifluoroacetic acid in dichloromethane at $0{ }^{\circ} \mathrm{C}$ (Scheme 8).

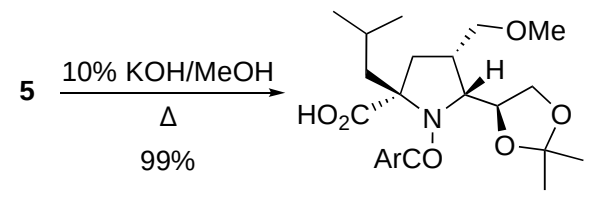

16

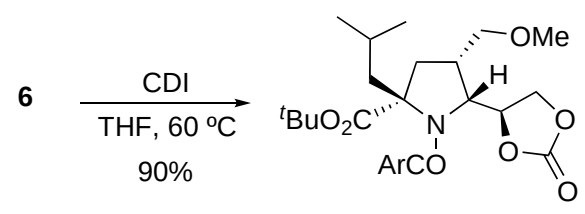

17

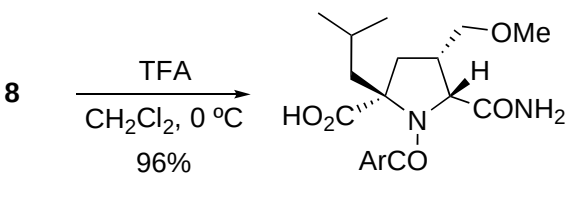

$\mathrm{Ar}=3-\mathrm{MeO}-4-{ }^{t} \mathrm{BuC}_{6} \mathrm{H}_{3}-$

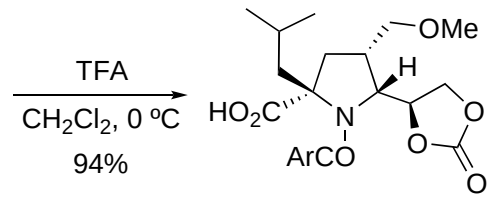

18

Scheme 8. The synthetic route for GSK3082 analogues 16, 18 and 19. 
Other GSK3082 analogues were obtained from versatile chiral intermediate 7 by transformation of the formyl group into methoxymethyl, ethyl and methoxycarbonyl groups, as shown in Scheme 9. Reaction of compound 7 with sodium borohydride in ethanol reduced the C5 formyl group to a hydroxymethyl group, which in turn reacted with methyl iodide to give compound 20 in 85\% yield over the two steps. Subsequent hydrolysis of $\mathbf{2 0}$ with trifluoroacetic acid in dichloromethane at $0{ }^{\circ} \mathrm{C}$ gave GSK3082 analogue 21 in 98\% yield. Synthesis of analogue 23 involved oxidation of the formyl group, which was performed with potassium permanganate using a mixture of tert-butanol and aqueous $\mathrm{N}_{2} \mathbb{O}_{4}$ as a reaction medium as above. The resulting carboxylic acid was immediately converted into its methyl ester using trimethylsilyldiazomethane. Transformation of aldehyde $\mathbf{7}$ into methyl ester $\mathbf{2 2}$ took place to give $89 \%$ yield over the two steps and final hydrolysis with trifluoroacetic acid in dichloromethane at 0 ${ }^{\circ} \mathrm{C}$ afforded a 97\% yield of analogue 23. Wittig reaction of 7 and the unstabilised ylide derived from triphenylphosphonium methyl bromide gave olefin 24 in 91\% yield. Compound 24 was hydrogenated to 25 (93\%) with molecular hydrogen using $\mathrm{Pd} / \mathrm{C}$ as the catalyst. Hydrolysis of the tert-butyl ester under the usual acidic conditions afforded analogue $\mathbf{2 6}$ in $97 \%$ yield.

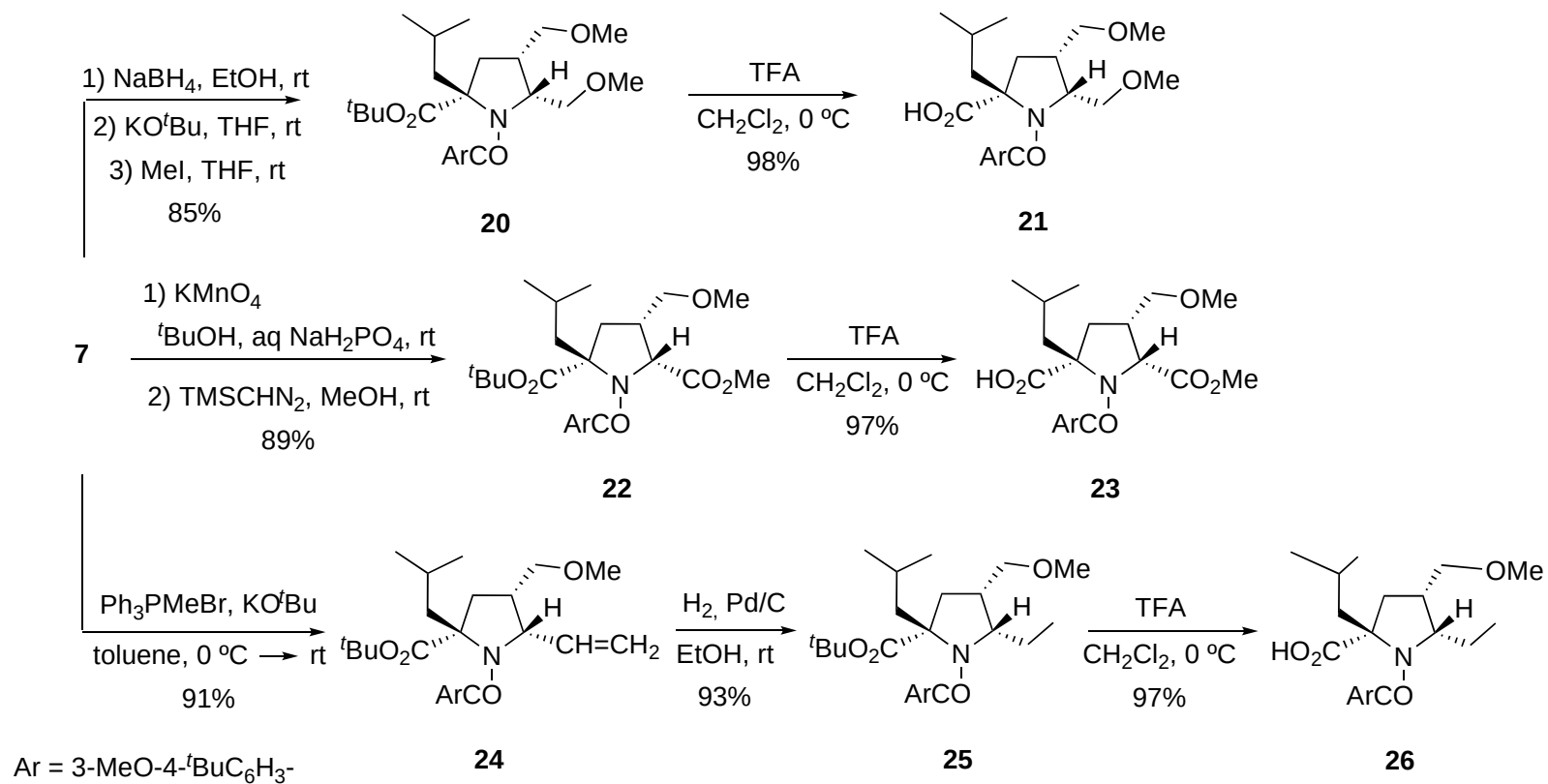

Scheme 9. The synthetic route for GSK3082 analogues 21, 23 and 26.

Compounds 13, 15, 16, 18, 19, 21, 23 and 26 were tested as inhibitors by mimicking HCV viral replication in cells using a subgenomic HCV RNA replication system and, on the basis of their in vitro activity (see below), we prepared a second set of structural analogues of GSK3082 taking into account the beneficial effect of the presence of a heteromethyl side chain at C5. Firstly, aldehyde 7 was 
efficiently converted into acetate $\mathbf{2 7}$, allyl ether $\mathbf{2 9}$ or methylcarbonate 31 by reduction $\mathbf{7}$ with sodium borohydride in ethanol followed by the immediate dimethylaminopyridine-catalysed acetylation with acetic anhydride, reaction with allyl bromide in the presence of sodium hydride or treatment with methyl chloroformate in the presence of a catalytic amount of dimethylaminopyridine. Subsequent hydrolysis of these compounds with trifluoroacetic acid in dichloromethane at $0{ }^{\circ} \mathrm{C}$ yielded GSK3082 analogues 28, 30 and 32 in 94-95\% yields from starting aldehyde 7 (Scheme 10).

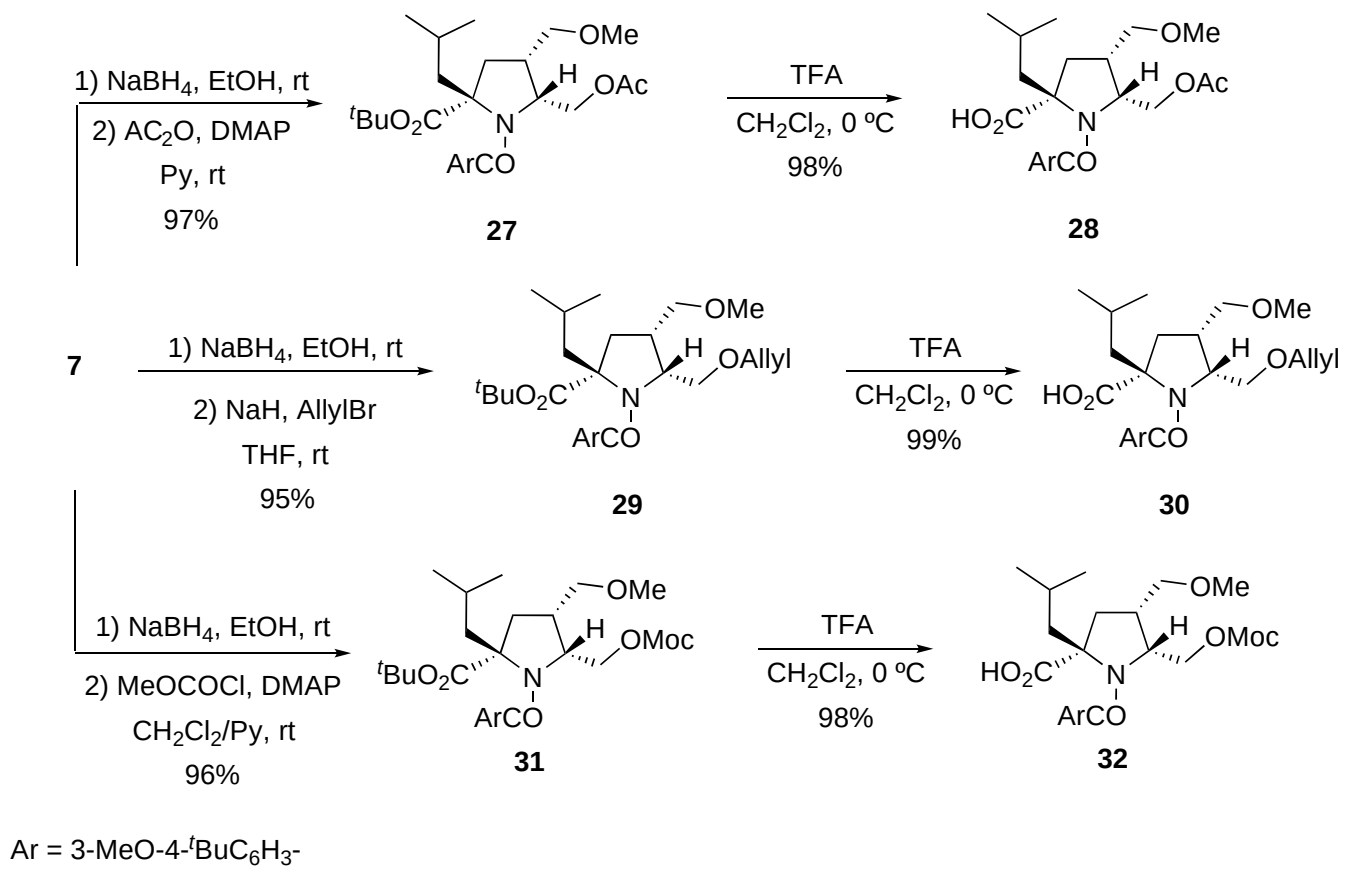

Scheme 10. The synthetic route for GSK3082 analogues 28, 30 and 32.

Compound 7 was also converted into GSK3082 analogues 34, 36 and 38 with a fluoromethyl, azidomethyl or acetylaminometyl side chain at C5 (Scheme 11). Access to the fluoromethyl side chain was achieved by sequential treatment of aldehyde 7 with sodium borohydride in ethanol and the fluorinating agent diethylaminosulfur trifluoride (DAST). Compound 33, obtained in 52\% yield, was hydrolysed with trifluoroacetic acid in dichloromethane at $0{ }^{\circ} \mathrm{C}$ to afford analogue 34 in almost quantitative yield. The intermediate hydroxymethyl derivative obtained in the reduction of $\mathbf{7}$ with sodium borohydride in ethanol was immediately reacted first with methanesulfonyl chloride in the presence of triethylamine and then with sodium azide in the presence of a catalytic amount of sodium iodide to afford 35. Hydrolysis of this compound under the usual conditions gave analogue $\mathbf{3 6}$ in 95\% from aldehyde 7. Catalytic reduction of azide 35 gave the corresponding amine, which was 
immediately acetylated with acetic anhydride-triethylamine to produce acetylamino derivative $\mathbf{3 7}$ in $65 \%$ yield. Subsequent hydrolysis with trifluoroacetic acid in dichloromethane at $0{ }^{\circ} \mathrm{C}$ yielded analogue 38 in $95 \%$ yield.

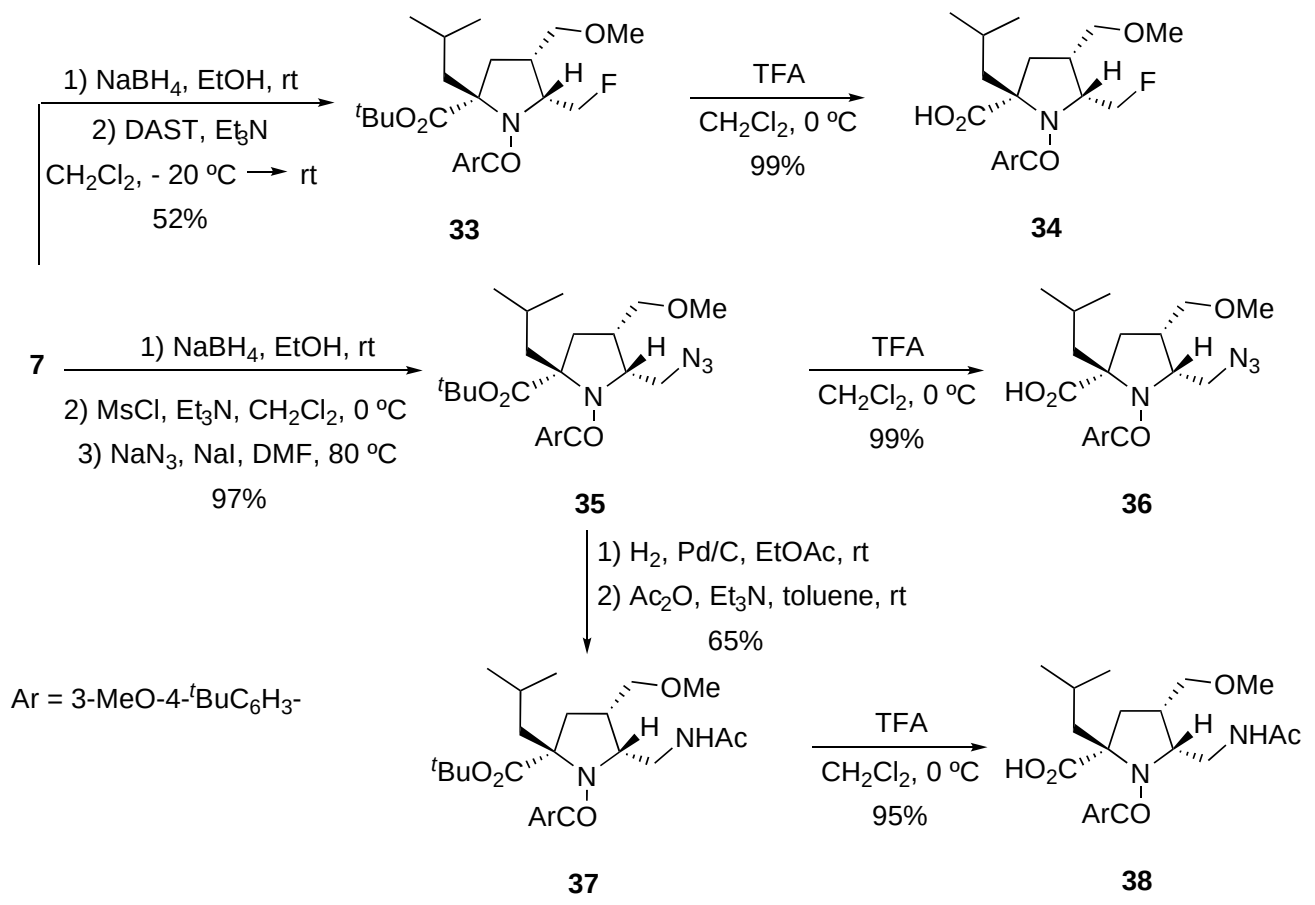

Scheme 11. The synthetic route for GSK3082 analogues 34, 36 and 38.

\subsection{Biological evaluation}

In order to evaluate the potency and cytotoxicity of the 14 synthesised compounds, viral replication was assessed by in vitro HCV replication assays with genotype 1b Con1 HCV subgenomic replicons (Huh 5-2) [18] and the results were compared to those obtained for GSK3082. All of the compounds inhibited HCV replicon replication (measured as the luciferase signal) in a dose-dependent manner, with EC50 values lower than 100 microM (Table 1, Figure 2). The estimated EC50 values for these compounds ranged from nanomolar to micromolar. The anti-HCV activity was not the result of a cytostatic effect [19], since the CC50 values for these compounds were significantly higher than the EC50 values. 
Table 1. Evaluation of the potency and cytotoxicity of the obtained compounds in cell assays

\begin{tabular}{|c|c|c|c|}
\hline Compound & $\mathbf{R}$ & $\mathrm{EC50}^{a}(\mathbf{M})$ & $\mathrm{CC50}^{b}(\mathrm{M})$ \\
\hline GSK3082 & & 0.1 & $>120$ \\
\hline 13 & & 60 & 200 \\
\hline 15 & & 15 & 200 \\
\hline 16 & & 60 & $>120$ \\
\hline 18 & & 2 & $>120$ \\
\hline 19 & $\mathrm{CONH}_{2}$ & 2 & $>120$ \\
\hline 21 & $\mathrm{CH}_{2} \mathrm{OMe}$ & 0.6 & $>120$ \\
\hline 23 & $\mathrm{CO}_{2} \mathrm{Me}$ & 7 & $>120$ \\
\hline 26 & Et & 40 & 200 \\
\hline 28 & $\mathrm{CH}_{2} \mathrm{OAc}$ & 30 & $>120$ \\
\hline 30 & $\mathrm{CH}_{2} \mathrm{OAllyl}$ & 7.5 & $>120$ \\
\hline 32 & $\mathrm{CH}_{2} \mathrm{OMoc}$ & 30 & $>120$ \\
\hline 34 & $\mathrm{CH}_{2} \mathrm{~F}$ & 45 & $>120$ \\
\hline 36 & $\mathrm{CH}_{2} \mathrm{~N}_{3}$ & 100 & $>120$ \\
\hline 38 & $\mathrm{CH}_{2} \mathrm{NHAC}$ & 15 & $>120$ \\
\hline
\end{tabular}

${ }^{a}$ EC50, effective concentration 50\%; ${ }^{b}$ CC50, cytotoxic concentration 50\%. Relative error in the parameters is $15 \%$. 

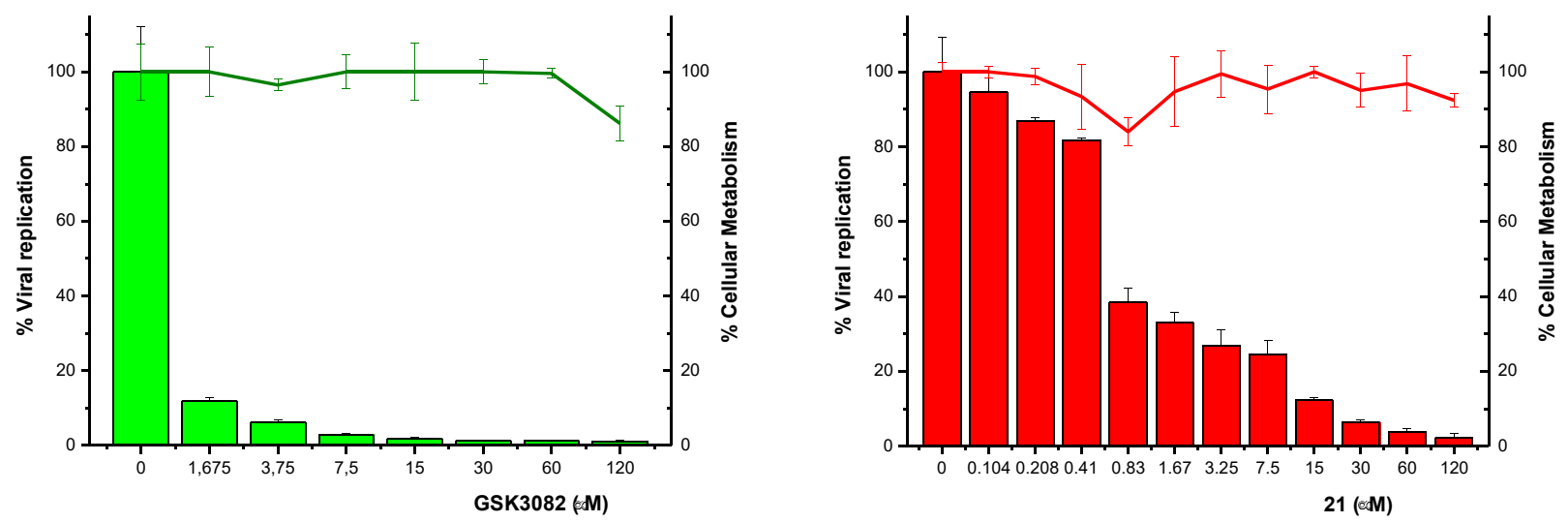

Figure 2. Evaluation of viral load reduction (bars) of the HCV replicon system in human hepatoma cells (Huh5-2) with cell growth (lines) upon increasing the concentration of compound GSK3082 (green) and 21 (red). *UTC: untreated controls.

\subsection{SAR analysis}

To uncover relationships between EC50 activities and structural features or physical-chemical properties in the compound series, a simple SAR (Structure-Activity Relationship) analysis was performed. The compound structures were optimized and 36 molecular descriptors were calculated. Then, we sought for linear correlations between effectiveness of compounds against HCV NS5B polymerase $(-\log (\mathrm{EC} 50))$ and any of the previously calculated molecular descriptors. Although this analysis did not show any high correlation between any of the molecular descriptors selected and the biological activity (not shown) it provided some clues. It was noticed that GSK3082, the most effective compound, presented marked differences with most other compounds in regard to properties such as aromatic ratio (ARR) and reactivity (Re) (Figure 3 panels A and B). According to these plots, only compounds 15 and 13 differentiated from the group in the same direction as GSK3082. This was somewhat expected due to their close structural similarity (15 is a GSK3082's estereoisomer and 13 presents the same thiazole ring but ramified with an ethyl carboxylate) but did not allow us to explain their lower activity compared to that of GSK3082. On the other hand, compound 13 was that with highest molecular weight (Figure 3 panel C) and displayed one of the lowest activities. Thus, we thought the activity could be qualitatively correlated with structural features of the complexes formed by the compounds and the target enzyme. Based on the availability of a 3D structure for the complex between HCV NS5B polymerase and a ligand structurally close to GSK3082 (PDB code: 2jc1) [7c], we modeled the binding of all the compounds. As shown in SI Figure S1 (panels B and C) both compounds 15 and 13 appear to face steric problems (clashes) to fit in the putative binding site. As for 
the remaining compounds, the lower activity of $\mathbf{1 6}, \mathbf{2 3}, \mathbf{2 8}, \mathbf{3 0}, \mathbf{3 2}$ and $\mathbf{3 8}$ could also be related to steric issues (SI Figure S2 panel A), while that of the others (e.g. 18, 19, 21, 26, 34 and 36, SI Figure S2 panel B) appears related to loss of polar and/or hydrophobic interactions with the protein binding pocket.
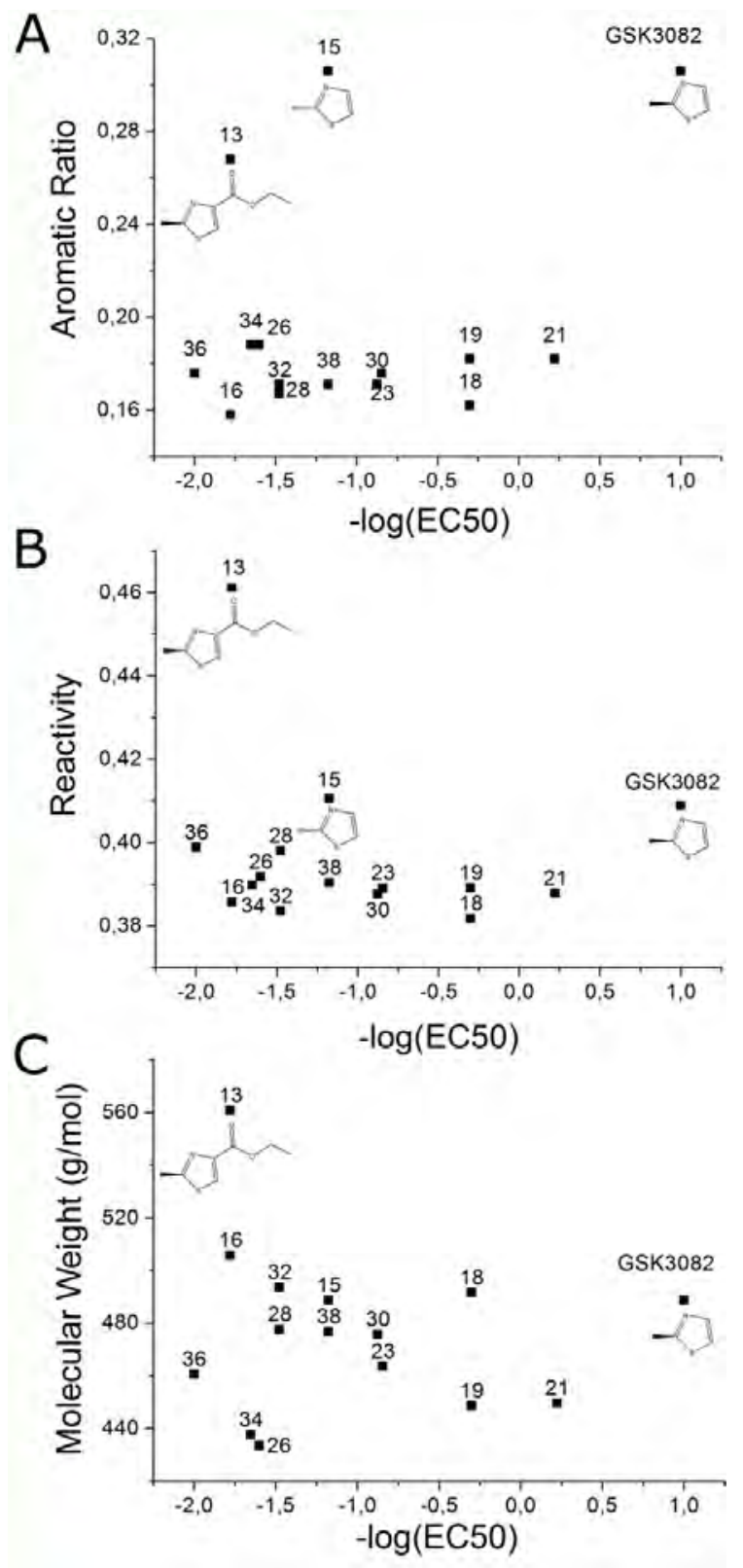

Figure 3. Scatter plots of molecular descriptor values versus the assayed biological activities: (A) aromatic ratio, (B) reactivity and (C) molecular weight values versus the effectiveness of compounds against HCV NS5B polymerase. Substituent structures $\left(\mathrm{R}_{3}\right)$ at the 5-position in compounds GSK3082, 13 and 15 are shown. 


\section{Conclusions}

In summary, we have developed a very efficient diastereoselective approach to novel 2,2,4,5tetrasubstituted $N$-acyl pyrrolidines with a well-defined stereochemistry starting from a chiral iminoester derived from leucine tert-butyl ester and (R)-2,3-O-isopropylideneglyceraldehyde. The cycloadduct derived from the 1,3-dipolar cycloaddition with methyl acrylate has served as a common precursor for the synthesis of GSK3082 and structurally related compounds with different substituents at C5, with the chiral 2,2-dimethyl-1,3-dioxolane moiety provided by the glyceraldehyde acting as a synthetic equivalent for structural diversity. The inhibitory activity of the obtained GSK3082 analogues has been studied in vitro in a cell-based assay of a subgenomic HCV RNA replication system and some of the analogues have shown a good inhibitory activity with estimated IC50 values ranging from nanomolar to micromolar.

\section{Experimental Section}

\subsection{Chemistry}

\subsubsection{General Details}

Unless otherwise specified, all reagents were obtained from commercial suppliers and were used as received without further purification. For anhydrous conditions, reactions were carried out under $\mathrm{Ar}$ in solvents dried using a Solvent Purification System (SPS). TLC was performed on precoated silica gel $60 \mathrm{~F}_{254}$ polyester plates and products were visualised using UV light (254 nm) and potassium permanganate solutions followed by heating. Column chromatography was performed on silica gel (60, 40-63 $\mu \mathrm{m}$ ) with air pressure. Melting points were determined in open capillary tubes and are not corrected. FT-IR spectra were recorded as thin films on $\mathrm{NaCl}$ plates, $\quad v_{\max }$ values expressed in $\mathrm{cm}^{-1}$ are given for the main absorption bands. Optical rotations were measured on a digital polarimeter at $\lambda 589$ $\mathrm{nm}$ and $25{ }^{\circ} \mathrm{C}$ in cells with 1 or $10 \mathrm{~cm}$ path length $\alpha I_{D}$ values are given in $10^{1} \mathrm{deg} \cdot \mathrm{cm}^{2} \cdot \mathrm{g}^{-1}$ and concentrations are given in g/100 mL. ${ }^{1} \mathrm{H},{ }^{19} \mathrm{~F}$ and ${ }^{13} \mathrm{C}$ NMR spectra were acquired on a $400 \mathrm{MHz}$ spectrometer in the stated deuterated solvent at room temperature unless otherwise stated using a 5-mm probe. ${ }^{13} \mathrm{C}$ NMR spectra were acquired with the ${ }^{1} \mathrm{H}$ broad-band decoupled mode, chemical shifts $(\delta)$ are reported in parts per million (ppm) with the solvent resonance as the internal standard [20], and coupling constants $(\mathrm{J})$ in hertz $(\mathrm{Hz})$. High-resolution mass spectra were recorded from methanolic solutions on a MICROTOF-Q (quadrupole time-of-flight) micro instrument using the positive electrospray ionization mode (ESI+). The X-ray diffraction data were collected at room temperature on a four-circle diffractometer, using graphite-monochromated Mo-Ka radiation $(\mathrm{l}=0.71073 \AA$ ) . 


\subsubsection{Synthesis of crude (E)-tert-butyl $N$-\{[(S)-2,2-dimethyl-1,3-dioxolan-4-yl]methylidene $\}-(S)$ -}

leucinate (1)

To a solution of (S)-leucine tert-butyl ester hydrochloride $(1,79 \mathrm{~g}, 8.0 \mathrm{mmol})$ in water $(5 \mathrm{~mL})$ at room temperature was added a solution of potassium carbonate (2.21 g, $16.0 \mathrm{mmol})$ in water $(5 \mathrm{~mL})$. The resulting solution was extracted with dichloromethane $(3 \times 20 \mathrm{~mL})$ and the combined organic layers were dried over anhydrous $\mathrm{MgSO}_{4}$, filtered and evaporated under reduced pressure to give crude tertbutyl (S)-leucinate. In the meantime to a stirred solution of 1,2:5,6-di-O-isopropyliden@-mannitol $(1.31 \mathrm{~g}, 5.0 \mathrm{mmol})$ in dichloromethane $(20 \mathrm{~mL})$ at room temperature was added saturated aqueous solution of sodium hydrogen carbonate $(1 \mathrm{~mL})$. Then, sodium metaperiodate $(2.14 \mathrm{~g}, 10.0 \mathrm{mmol})$ was added with vigorous agitation and the reaction was allowed to proceed for $1 \mathrm{~h}$ at $35^{\circ} \mathrm{C}$. The solids were removed by filtration and washed with dichloromethane $(30 \mathrm{~mL})$. The combined organic solutions were dried over anhydrous $\mathrm{MgSO}_{4}$, filtered and evaporated under reduced pressure at less than $30{ }^{\circ} \mathrm{C}$ to give crude (R)-2,3-O-isopropylideneglyceraldehyde, which was used immediately in the condensation reaction with tert-butyl (S)-leucinate. To a solution containing crude tert-butyl (S)-leucinate and $(R)$ 2,3-O-isopropylideneglyceraldehyde in dry diethyl ether $(20 \mathrm{~mL})$ at room temperature was added anhydrous $\mathrm{MgSO}_{4}(1.0 \mathrm{~g})$ and the resulting suspension was stirred for $2 \mathrm{~h}$. The reaction mixture was then filtered and the solid residue was washed with diethyl ether $(20 \mathrm{~mL})$. The combined organic filtrates were evaporated under reduced pressure to afford $2.60 \mathrm{~g}$ of crude imine $\mathbf{2}$ of $65 \%$ purity, as determined by ${ }^{1} \mathrm{H}$ NMR using 1,3,5-trimethoxybenzene as an internal standard [21]. Crude imine 2 was used without further purification in the next reaction. Oil; ${ }^{1} \mathrm{H}$ NMR $\left(400 \mathrm{MHz}, \mathrm{CDCl}_{3}\right) \delta 0.85$ (d, $J=$ $6.6 \mathrm{~Hz}, 3 \mathrm{H}), 0.92$ (d, $J=6.6 \mathrm{~Hz}, 3 \mathrm{H}), 1.39$ (s, 3H), 1.41-1.43 (m, 1H), 1.44 (s, 3H), 1.45 (s, 9H), 1.63-1.99 (m, 2H), 3.78 (dd, $J=8.2,6.2 \mathrm{~Hz}, 1 \mathrm{H}$ ), 3.94 (dd, $J=8.5,5.9 \mathrm{~Hz}, 1 \mathrm{H}$ ), 4.20 (dd, $J=8.5,6.9$ $\mathrm{Hz}, 1 \mathrm{H}$ ), 4.65 (ddd, $J=6.9,5.9,4.7 \mathrm{~Hz}, 1 \mathrm{H}), 7.66$ (d, $J=4.7 \mathrm{~Hz}, 1 \mathrm{H}$ ).

\subsubsection{2-(tert-Butyl) 4-methyl (2S,4S,5R)-5-((S)-2,2-dimethyl-1,3-dioxolan-4-yl)-2-isobutylpyrrolidine-}

\section{2,4-dicarboxylate (2a)}

To a stirred suspension of crude imine 1 of $65 \%$ purity ( $2.60 \mathrm{~g}, 5.6 \mathrm{mmol}$ ) and silver acetate (183 $\mathrm{mg}$, $1.1 \mathrm{mmol})$ in dry toluene $(30 \mathrm{~mL})$ under argon at room temperature were sequentially added ethyl acrylate (966 mg, $11.2 \mathrm{mmol}$ ) and DBU (171 mg, $1.1 \mathrm{mmol}$ ), both of them previously solved in dry toluene $(1 \mathrm{~mL})$. The reaction mixture was stirred in the dark at room temperature for $24 \mathrm{~h}$. The mixture was quenched with water $(5 \mathrm{~mL})$ and filtered through a short Celite ${ }^{\circledR}$ pad. Celite ${ }^{\circledR}$ residues were 
thoroughly washed with diethyl ether $(50 \mathrm{~mL})$ and the combined organic filtrates were dried over anhydrous $\mathrm{MgSO}_{4}$, filtered and concentrated under reduced pressure. The crude cycloadducts were purified by flash chromatography (eluent: diethyl ether/hexane, 1/2) to afford 2 (2.05 g, 95\% yield) as a mixture of endo diasteroisomers $2 \mathbf{a}$ and $\mathbf{2 b}(\mathbf{b} \mathbf{a} / \mathbf{2} \mathbf{b}=85 / 15)$. Some column chromatography fractions containing exclusively major cycloadduct 2a were used for characterization purposes. Colourless oil; $[\alpha]_{\mathrm{D}}{ }^{24}=-39.23\left(c=1.11\right.$ in $\left.\mathrm{CHCl}_{3}\right)$; IR (neat) 3341, 3308, $1734 \mathrm{~cm}^{-1} ;{ }^{1} \mathrm{H} \mathrm{NMR}\left(400 \mathrm{MHz}, \mathrm{CDCl}_{3}\right) \delta$ 0.83 (d, $J=6.4$ Hz, 3H), 0.90 (d, $J=6.5$ Hz, 3H), 1.29 (s, 3H), 1.39 (s, 3H), 1.41-1.45 (m, 1H), 1.46 (s, 9H), 1.61-1.74 (m, 2H), 1.81 (dd, $J=13.7,7.9 \mathrm{~Hz}, 1 \mathrm{H}), 2.48$ (dd, $J=13.7,5.5 \mathrm{~Hz}, 1 \mathrm{H}$ ), 2.92 (ddd, $J=7.9,6.9,5.5 \mathrm{~Hz}, 1 \mathrm{H}$ ), 3.00 (bs, 1H), 3.26 (dd, $J=6.9,5.3 \mathrm{~Hz}, 1 \mathrm{H}$ ), 3.60 (s, 3H), 3.71 (dd, $J=8.0$, $7.1 \mathrm{~Hz}, 1 \mathrm{H}), 3.93$ (dd, $J=8.0,6.4 \mathrm{~Hz}, 1 \mathrm{H}), 4.12-4.20(\mathrm{~m}, 1 \mathrm{H}) ;{ }^{13} \mathrm{C}-\mathrm{APT}\left\{{ }^{1} \mathrm{H}\right\} \mathrm{NMR}\left(100 \mathrm{MHz}, \mathrm{CDCl}_{3}\right)$

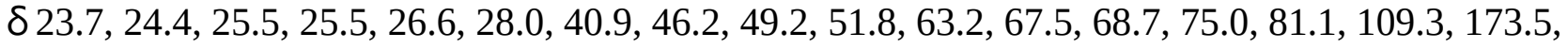
175.1; HRMS(ESI $\left.{ }^{+}\right) \mathrm{m} / \mathrm{z}[\mathrm{M}+\mathrm{H}]^{+}$calcd for $\mathrm{C}_{20} \mathrm{H}_{36} \mathrm{NO}_{6}$ 386.2538, found 386.2546.

\subsubsection{2-(tert-Butyl) 4-methyl (2S,4S,5R)-1-(4-(tert-butyl)-3-methoxybenzoyl)-5-((S)-2,2-dimethyl-1,3-} dioxolan-4-yl)-2-isobutylpyrrolidine-2,4-dicarboxylate (3a)

A mixture of 4-tert-butyl-3-methoxybenzoic acid (1.56 g, $7.5 \mathrm{mmol})$ and thionyl chloride (12 mL) was refluxed for 4 hours. Thionyl choride in excess was removed by evaporation under reduced pressure and the residue was solved in toluene $(5 \mathrm{~mL})$. The organic solvent was evaporated under reduced pressure to remove thionyl chloride traces and the crude 4-tert-butyl-3-methoxybenzoyl chloride was solved in anhydrous dichloromethane $(10 \mathrm{~mL})$. To this stirred solution at $0{ }^{\circ} \mathrm{C}$ was added a solution of compound 2 as an 85/15 mixture of diastereoisomers $2 \mathbf{a}$ and $\mathbf{2 b}$ (1.93 g, $5.0 \mathrm{mmol}$ ) in dichloromethane $(10 \mathrm{~mL})$ followed by triethylamine $(2.8 \mathrm{~mL}, 20.1 \mathrm{mmol})$ and this mixture was stirred at room temperature for 36 hours. After that, the reaction mixture was washed with saturated aqueous sodium bicarbonate solution ( 2 x $20 \mathrm{~mL}$ ). The organic layer was dried over MgSO $\quad$ 4, filtered and evaporated under reduced pressure. The residue was purified by flash chromatography ( $1^{\text {st }}$ eluent: diethyl ether/hexane, 1/3; $2^{\text {nd }}$ eluent: diethyl ether/hexane 1/1) to afford 3 (2.76 g, 96\% yield) as a mixture of endo diastereoisomers $\mathbf{3 a}$ and $\mathbf{3 b}(\mathbf{3} \mathbf{a} / \mathbf{3 b}=85 / 15)$. Following the same experimental procedure starting from major diastereoisomer 2a, diastereomerically pure compound 3a was obtained and fully characterised. Colourless oil; [ $\alpha]_{\mathrm{D}}{ }^{24}=0.65$ ( $c=1.94$ in $\mathrm{CHCl}{ }_{3}$ ); IR (neat) 1734, 1636, $1567 \mathrm{~cm}^{-1} ;{ }^{1} \mathrm{H}$ NMR (400 MHz, CDCl $) \delta 0.52$ (s, 3H), 0.97 (d, $J=6.6 \mathrm{~Hz}, 3 \mathrm{H}), 1.00$ (d, $J=6.6 \mathrm{~Hz}, 3 \mathrm{H}), 1.12$ (s, 3H), 1.32 (s, 9H), 1.52 (s, 9H), 1.72-1.83 (m, 1H), 2.00 (dd, $J=15.1,4.4$ Hz, 1H), 2.25 (dd, $J=13.4,6.9$ Hz, 1H), 2.24-2.32 (m, 1H), 2.64 (dd, $J=13.4,13.4$ Hz, 1H), 3.28 (dd, $J=7.7,7.7$ Hz, 1H), 3.47 (ddd, 
$J=13.4,7.3,6.9 \mathrm{~Hz}, 1 \mathrm{H}), 3.67-3.73$ (m, 1H); 3.71 (s, 3H), 3.84 (s, 3H), $4.32-4.42$ (m, 1H), 4.73 (dd, $J=9.3,7.3 \mathrm{~Hz}, 1 \mathrm{H}), 6.92$ (dd, $J=7.9,1.6 \mathrm{~Hz}, 1 \mathrm{H}), 7.04$ (d, $J=1.6 \mathrm{~Hz}, 1 \mathrm{H}), 7.18$ (d, $J=7.9 \mathrm{~Hz}, 1 \mathrm{H})$; ${ }^{13} \mathrm{C}-\mathrm{APT}\left\{{ }^{1} \mathrm{H}\right\} \mathrm{NMR}\left(100 \mathrm{MHz}, \mathrm{CDCl}_{3}\right) \delta 24.4,24.7,24.9,25.3,25.7,28.2,29.6,35.0,36.1,41.6,44.6$, 52.3, 55.1, 65.3, 66.4, 69.3, 75.2, 81.5, 108.6, 112.6, 118.5, 125.7, 137.0, 140.4, 158.8, 169.7, 170.8, 172.8; HRMS(ESI ${ }^{+}$) m/z [M+H] $]^{+}$calcd for $\mathrm{C}_{32} \mathrm{H}_{50} \mathrm{NO}_{8}$ 576.3531, found 576.3518.

4.1.5. tert-Butyl (2S,4S,5R)-1-(4-(tert-butyl)-3-methoxybenzoyl)-5-((S)-2,2-dimethyl-1,3-dioxolan-4-yl)4-(hydroxymethyl)-2-isobutylpyrrolidine-2-carboxylate (4a)

To a stirred solution of compound 3 as an 85/15 mixture of diastereoisomers 3a and $3 \mathbf{b}$ (2.30 g, 4.0 mmol) in dry THF (40 mL) were sequentially added $\mathrm{NaBH} \quad{ }_{4}(606 \mathrm{mg}, 16.0 \mathrm{mmol})$ and $\mathrm{NaB}(\mathrm{OAc}){ }_{3} \mathrm{H}$ (172 mg, $0.8 \mathrm{mmol})$. To the white slurry under argon at $0{ }^{\circ} \mathrm{C}$ dry methanol $(1.3 \mathrm{~mL}, 32.1 \mathrm{mmol})$ was added and the mixture was stirred at room temperature for 4 days until complete disappearance of the starting material was observed by TLC. The resulting reaction mixture was quenched with saturated aqueous $\mathrm{NH}_{4} \mathrm{Cl}$ solution $(20 \mathrm{~mL}$ ) and the organic solvents were evaporated under reduced pressure. The aqueous layer was extracted with dichloromethane (3 x $20 \mathrm{~mL})$ and the combined organic layers were dried over anhydrous $\mathrm{MgSO}_{4}$, filtered and concentrated under reduced pressure. The crude product was purified by flash chromatography ( $1{ }^{\text {st }}$ eluent: diethyl ether/hexane, $1 / 1 ; 2$ nd eluent: diethyl ether) to provide diastereomerically pure $4 \mathbf{a}\left(1.78 \mathrm{~g}, 81 \% \text { yield) as a white solid. M.p. }=204{ }^{\circ} \mathrm{C} \text {; } \alpha\right]_{\mathrm{D}}{ }^{24}$ $=-3.07$ ( $c=0.99$ in $\mathrm{CHCl}_{3}$ ); IR (nujol) 3379, 1730, 1593, $1563 \mathrm{~cm}^{-1}$; ${ }^{1} \mathrm{H} \mathrm{NMR}\left(400 \mathrm{MHz}, \mathrm{CDCl}_{3}\right)$ $\delta 0.73$ (s, 3H), 0.97 (d, $J=6.6 \mathrm{~Hz}, 3 \mathrm{H}), 1.00$ (d, $J=6.6 \mathrm{~Hz}, 3 \mathrm{H}), 1.11$ (s, 3H), 1.32 (s, 9H) 1.50 (s, 9H), 1.77-1.89 (m, 1H), 1.93 (dd, $J=12.9,12.9 \mathrm{~Hz}, 1 \mathrm{H}$ ), 2.01 (dd, $J=14.9,4.4 \mathrm{~Hz}, 1 \mathrm{H}), 2.14$ (dd, $J=12.9$, $6.8 \mathrm{~Hz}, 1 \mathrm{H}$ ), 2.25 (dd, $J=14.9,6.0 \mathrm{~Hz}, 1 \mathrm{H}), 2.68$ (bs, 1H), 2.80-2.94 (m, 1H), 3.48-3.63 (m, 2H), 3.67 (dd, $J=8.8,8.8 \mathrm{~Hz}, 1 \mathrm{H}), 3.83$ (s, 3H), 3.98 (dd, $J=8.8,6.5 \mathrm{~Hz}, 1 \mathrm{H}), 4.14-4.23$ (m, 1H), 4.61 (dd, $J=$ 7.5, $7.5 \mathrm{~Hz}, 1 \mathrm{H}), 6.93$ (dd, $J=7.9,1.7 \mathrm{~Hz}, 1 \mathrm{H}), 7.01$ (d, $J=1.7 \mathrm{~Hz}, 1 \mathrm{H}), 7.18(\mathrm{~d}, J=7.9 \mathrm{~Hz}, 1 \mathrm{H}) ;{ }^{13} \mathrm{C}-$ APT $\left\{{ }^{1} \mathrm{H}\right\}$ NMR (100 MHz, $\left.\mathrm{CDCl}_{3}\right) \delta$ 24.5, 24.9, 25.0, 25.7, 28.2, 29.7, 35.0, 37.1, 41.9, 43.4, 55.2, 61.1, 63.9, 66.9, 69.7, 75.5, 81.2, 108.0, 112.0, 118.5, 125.9, 137.0, 140.3, 158.7, 170.0, 173.2; $\operatorname{HRMS}\left(\mathrm{ESI}^{+}\right) \mathrm{m} / \mathrm{z}[\mathrm{M}+\mathrm{H}]^{+}$calcd for $\mathrm{C}_{31} \mathrm{H}_{50} \mathrm{NO}_{7}$ 548.3582, found 548.3598.

4.1.6. tert-Butyl (2S,4S,5R)-1-(4-(tert-butyl)-3-methoxybenzoyl)-5-((S)-2,2-dimethyl-1,3-dioxolan-4-yl)2-isobutyl-4-(methoxymethyl)pyrrolidine-2-carboxylate (5)

To a stirred solution of compound $4 \mathbf{a}(1.64 \mathrm{~g}, 3.0 \mathrm{mmol})$ in dry THF $(30 \mathrm{~mL})$ under argon at $0{ }^{\circ} \mathrm{C}$ was added $\mathrm{KO}^{t} \mathrm{Bu}(673.3 \mathrm{mg}, 6.0 \mathrm{mmol})$ and the mixture was stirred at room temperature for $15 \mathrm{~min}$. Then, 
iodomethane $(0.94 \mathrm{~mL}, 15.1 \mathrm{mmol})$ was added and the slurry was stirred for 18 hours at room temperature. The resulting reaction mixture was quenched with saturated aqueous $\mathrm{NH}{ }_{4} \mathrm{Cl}$ solution (20 $\mathrm{mL}$ ) and the organic solvent was evaporated under reduced pressure. The aqueous layer was extracted with dichloromethane ( $3 \times 20 \mathrm{~mL}$ ) and the combined organic layers were dried over anhydrous $\mathrm{MgSO}_{4}$, filtered and concentrated under reduced pressure. The crude product was purified by flash chromatography (eluent: diethyl ether/hexane: 1/1), to provide compound 5 (1.78 g, 88\% yield) as a white solid. M.p. $=109{ }^{\circ} \mathrm{C} ;[\alpha]_{\mathrm{D}}{ }^{24}=-13.72\left(c=1.45\right.$ in $\mathrm{CHCl}_{3}$ ); IR (nujol) 1729, $1612 \mathrm{~cm}^{-1}$; ${ }^{1} \mathrm{H}$ NMR (400 MHz, $\left.\mathrm{CDCl}_{3}\right) \delta 0.54$ (s, 3H), 0.96 (d, $\left.J=6.6 \mathrm{~Hz}, 3 \mathrm{H}\right), 1.00$ (d, $\left.J=6.6 \mathrm{~Hz}, 3 \mathrm{H}\right), 1.15$ (s, 3H), 1.32 (s, 9H), 1.50 (s, 9H), 1.81-1.99 (m, 1H), 1.93-2.05 (m, 2H), 2.13 (dd, $J=12.8,6.8 \mathrm{~Hz}, 1 \mathrm{H}), 2.28$ (dd, $J=14.8,6.5$ Hz, 1H), 2.83-2.96 (m, 1H), 3.17 (dd, $J=9.7,9.2$ Hz, 1H), 3.30 (s, 3H), 3.34 (dd, $J=9.7$, $5.1 \mathrm{~Hz}, 1 \mathrm{H}$ ), 3.58 (dd, $J=8.6,7.4 \mathrm{~Hz}, 1 \mathrm{H}$ ), 3.83 (s, 3H), 3.87 (dd, $J=8.6,6.4 \mathrm{~Hz}, 1 \mathrm{H}$ ), 4.26 (ddd, $J=$ 9.3, 7.4, $6.4 \mathrm{~Hz}, 1 \mathrm{H}), 4.55$ (dd, $J=9.3,6.9 \mathrm{~Hz}, 1 \mathrm{H}), 6.92$ (dd, $J=8.0,1.7 \mathrm{~Hz}, 1 \mathrm{H}), 7.06$ (d, $J=1.7 \mathrm{~Hz}$, 1H), 7.15 (d, $J=8.0 \mathrm{~Hz}, 1 \mathrm{H}) ;{ }^{13} \mathrm{C}-\mathrm{APT}\left\{{ }^{1} \mathrm{H}\right\}$ NMR $\left(100 \mathrm{MHz}, \mathrm{CDCl}_{3}\right) \delta 24.4,24.7,25.0,25.4,25.7$, 28.2, 29.7, 34.9, 36.8, 40.9, 41.8, 55.1, 58.8, 65.2, 67.0, 69.2, 71.2, 75.3, 81.0, 108.1, 112.7, 118.8, 125.6, 137.5, 140.1, 158.7, 170.1, 173.4; HRMS(ESI) $\mathrm{m} / \mathrm{z}[\mathrm{M}+\mathrm{H}]^{+}$calcd for $\mathrm{C}_{32} \mathrm{H}_{52} \mathrm{NO}_{7}$ 562.3739, found 562.3751 .

\subsection{7. tert-Butyl (2S,4S,5R)-1-(4-(tert-butyl)-3-methoxybenzoyl)-5-((S)-1,2-dihydroxyethyl)-2-isobutyl-} 4-(methoxymethyl)pyrrolidine-2-carboxylate (6)

Compound 5 (1.40 g, $2.5 \mathrm{mmol}$ ) and bismuth(III) chloride (79 $\mathrm{mg}, 0.25 \mathrm{mmol}$ ) were mixed in wet acetonitrile $(50 \mathrm{~mL})$ and the mixture was stirred at room temperature for 4 hours. The resulting reaction mixture was quenched with saturated aqueous sodium bicarbonate solution (20 mL) and the organic solvent was evaporated under reduced pressure. The aqueous layer was extracted with dichloromethane (3 x $20 \mathrm{~mL}$ ) and the combined organic layers were dried over anhydrous $\mathrm{Mg}$ \$̧ filtered and concentrated under reduced pressure. The crude product was purified by flash chromatography chromatography ( $1^{\text {st }}$ eluent: diethyl ether/hexane, $1 / 1$; $2^{\text {nd }}$ eluent: diethyl ether) to

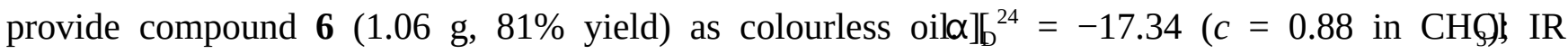
(nujol) 3579, 3411, 1737, 1699, 1639, $1566 \mathrm{~cm}^{-1}$; ${ }^{1} \mathrm{H}$ NMR (400 MHz, CDCl $\left.{ }_{3}\right) \delta 0.99$ (d, $J=6.6 \mathrm{~Hz}$, 3H), 1.03 (d, $J=6.6 \mathrm{~Hz}, 3 \mathrm{H}), 1.34$ (s, 9H), 1.53 (s, 9H), 1.78-1.90 (m, 1H), 1.95 (dd, $J=14.8,5.0 \mathrm{~Hz}$, 1H), 2.00 (dd, $J=13.0,13.0 \mathrm{~Hz}, 1 \mathrm{H}$ ), 2.20 (dd, $J=13.0,6.9 \mathrm{~Hz}, 1 \mathrm{H}$ ), 2.37 (dd, $J=14.8,6.0 \mathrm{~Hz}, 1 \mathrm{H}$ ), 2.83-2.98 (m, 1H), 3.02-3.14 (m, 1H), 3.20-3.29 (m, 1H), 3.30 (s, 3H), 3.33-3.42 (m, 3H), 3.57-3.66 (m, 1H), 3.83 (s, 3H), 4.36 (dd, $J=6.7,6.7 \mathrm{~Hz}, 1 \mathrm{H}), 5.26$ (d, $J=5.4 \mathrm{~Hz}, 1 \mathrm{H}), 6.93$ (dd, $J=7.9,1.7 \mathrm{~Hz}$, 
1H), 7.04 (d, $J=1.7 \mathrm{~Hz}, 1 \mathrm{H}), 7.21$ (d, $J=7.9 \mathrm{~Hz}, 1 \mathrm{H}) ;{ }^{13} \mathrm{C}-\mathrm{APT}\left\{{ }^{1} \mathrm{H}\right\}$ NMR $\left(100 \mathrm{MHz}, \mathrm{CDCl}_{3}\right) \delta 24.5$, 25.1, 25.7, 28.1, 29.7, 35.0, 37.8, 41.6, 41.7, 55.3, 59.0, 62.0, 64.9, 70.0, 70.4, 70.8, 83.3, 112.1, 119.1, 126.0, 136.2, 140.4, 158.6, 171.2, 176.6; HRMS(ESI ${ }^{+}$) $\mathrm{m} / \mathrm{z}[\mathrm{M}+\mathrm{Na}]^{+}$calcd for $\mathrm{C}_{29} \mathrm{H}_{47} \mathrm{NNaO}_{7}$ 544.3245, found 544.3256.

4.1.8. tert-Butyl (2S,4S,5R)-1-(4-(tert-butyl)-3-methoxybenzoyl)-5-formyl-2-isobutyl-4(methoxymethyl)pyrrolidine-2-carboxylate (7)

To a stirred solution of compound $6(1.04 \mathrm{~g}, 2.0 \mathrm{mmol})$ in THF (30 mL) at room temperature was added water $(6 \mathrm{~mL})$ followed by sodium metaperiodate $(1.71 \mathrm{~g}, 8.0 \mathrm{mmol})$ and the mixture was vigorously stirred at $35{ }^{\circ} \mathrm{C}$ for 16 hours. After that, the solvents were evaporated under reduced pressure and the residue was partitioned between a mixture of dichloromethane $(30 \mathrm{~mL})$ and water $(10$ $\mathrm{mL})$. The aqueous layer was extracted with dichloromethane $(20 \mathrm{~mL})$ and the combined organic layers were dried over anhydrous $\mathrm{MgSO}_{4}$, filtered and concentrated under reduced pressure. The crude product was purified by flash chromatography (eluent: diethyl ether/hexane, 1/1) to afford compound 7 (921 mg, 94\% yield) as a white solid. M.p. = $175^{\circ} \mathrm{C}$; $[\quad \alpha]_{\mathrm{D}}{ }^{24}=-3.55$ ( $c=1.01$ in $\mathrm{CHCl}{ }_{3}$ ); IR (nujol) 2727, 1728, 1630, $1563 \mathrm{~cm}^{-1}$; ${ }^{1} \mathrm{H}$ NMR (400 MHz, CDCl 3 ) $\delta 1.03$ (d, $\left.J=6.5 \mathrm{~Hz}, 6 \mathrm{H}\right), 1.32$ (s, 9H), 1.53 (s, 9H), 1.77-1.91 (m, 1H), 2.07 (dd, $J=14.9,3.7$ Hz, 1H), 2.17 (dd, $J=13.1,7.6$ Hz, 1H), 2.26 (dd, $J=13.1,13.1 \mathrm{~Hz}, 1 \mathrm{H}$ ), 2.35 (dd, $J=14.9,8.2 \mathrm{~Hz}, 1 \mathrm{H}), 2.88-2.99$ (m, 1H), 3.19 (s, $3 \mathrm{H}$ ), 3.24 (dd, $J=9.8,4.8 \mathrm{~Hz}, 1 \mathrm{H}), 3.43$ (dd, $J=9.8,5.2 \mathrm{~Hz}, 1 \mathrm{H}), 3.80$ (s, 3H), 4.38 (dd, $J=9.1,3.7 \mathrm{~Hz}, 1 \mathrm{H}), 6.75$ (d, $J=1.7 \mathrm{~Hz}, 1 \mathrm{H}), 6.77$ (dd, $J=7.8,1.7 \mathrm{~Hz}, 1 \mathrm{H}), 7.22$ (d, $J=7.8 \mathrm{~Hz}, 1 \mathrm{H}), 9.67$ (d, $J=3.7,1 \mathrm{H})$; $\quad{ }^{13} \mathrm{C}-$ APT $\left\{{ }^{1} \mathrm{H}\right\}$ NMR (100 MHz, $\left.\mathrm{CDCl}_{3}\right) \delta$ 24.0, 24.7, 25.8, 28.1, 29.6, 35.1, 38.0, 41.8, 43.2, 55.1, 58.7, 69.6, 70.2, 70.9, 81.7, 109.6, 117.9, 127.0, 135.0, 140.6, 158.8, 169.5, 172.7, 200.1; HRMS(ESI ${ }^{+}$) $\mathrm{m} / \mathrm{z}$ $[\mathrm{M}+\mathrm{H}]^{+}$calcd for $\mathrm{C}_{28} \mathrm{H}_{44} \mathrm{NO}_{6} 490.3164$, found 490.3149 .

4.1.9. tert-Butyl (2S,4S,5R)-1-(4-(tert-butyl)-3-methoxybenzoyl)-5-carbamoyl-2-isobutyl-4(methoxymethyl)pyrrolidine -2-carboxylate (8)

A solution of compound 7 (146.9 mg, $0.3 \mathrm{mmol})$ in tert-butanol (12 mL) was diluted with an aqueous $1.25 \mathrm{M}$ sodium phosphate buffer $(4 \mathrm{~mL})$ and the resulting mixture was treated with an aqueous $1 \mathrm{M}$ potassium permanganate solution $(1.8 \mathrm{~mL}, 1.8 \mathrm{mmol})$ at room temperature and vigorously stirred for 2 hours. Then, saturated aqueous sodium sulfite solution $(4 \mathrm{~mL})$ was added and the $\mathrm{pH}$ of the mixture was adjusted to 3 with $1 \mathrm{M}$ hydrochloric acid. The reaction mixture was extracted with dichloromethane (3 x $20 \mathrm{~mL}$ ) and the combined organic extracts were dried over MgSO ${ }_{4}$ and evaporated under reduced 
pressure to afford a residue containing the crude acid. To a stirred solution of the resulting crude acid and $N$-methylmorpholine (30.5 mg, $0.3 \mathrm{mmol})$ in anhydrous THF (10 mL) at room temperature was added a $1 \mathrm{M}$ solution of isopropyl chloroformate in toluene $(0.45 \mathrm{~mL}, 0.45 \mathrm{mmol}$ ) and the mixture stirred for 30 minutes. Then, 28\% ammonium hydroxide solution (1 mL) was added and the reaction mixture was stirred for 2 hours. The organic solvent was removed under reduced pressure and the resulting aqueous solution was extracted with dichloromethane (3 x $20 \mathrm{~mL}$ ). The combined organic extracts were dried over anhydrous $\mathrm{MgSO}_{4}$, filtered and evaporated under reduced pressure. The residue was purified by flash chromatography (eluent: diethyl ether/hexane, 1/1) to afford compound 8 (119.5 mg, 79\% yield) as colourless oil. [ $\alpha]_{\mathrm{D}}^{24}=7.83\left(c=1.01\right.$ in $\left.\mathrm{CHCl}_{3}\right)$; IR (neat) 3324, 3189, 1697, 1650, $1563 \mathrm{~cm}^{-1}$; ${ }^{1} \mathrm{H}$ NMR (400 MHz, $\mathrm{CDCl}_{3}$ ) $\delta 1.00$ (d, $\left.J=6.6 \mathrm{~Hz}, 3 \mathrm{H}\right), 1.02$ (d, $\left.J=6.7 \mathrm{~Hz}, 3 \mathrm{H}\right), 1.32$ (s, 9H), 1.55 (s, 9H), 1.76-1.88 (m, 1H), 2.02 (dd, $J=13.1,13.1 \mathrm{~Hz}, 1 \mathrm{H}), 2.08-2.19$ (m, 2H), 2.41 (dd, $J=13.1,6.4 \mathrm{~Hz}, 1 \mathrm{H}), 2.82-2.99$ (m, $1 \mathrm{H}), 3.14$ (dd, $J=9.6,8.4 \mathrm{~Hz}, 1 \mathrm{H}), 3.29$ (s, 3H), 3.59 (dd, $J=9.6$, $4.9 \mathrm{~Hz}, 1 \mathrm{H}), 3.80$ (s, 3H), 4.44 (d, $J=9.0 \mathrm{~Hz}, 1 \mathrm{H}), 5.58$ (bs, 1H), 6.86 (d, $J=1.7 \mathrm{~Hz}, 1 \mathrm{H}), 6.89$ (dd, $J=$ 7.9, $1.7 \mathrm{~Hz}, 1 \mathrm{H}), 7.22$ (d, $J=7.9 \mathrm{~Hz}, 1 \mathrm{H}), 9.25$ (bs, 1H); $\quad{ }^{13} \mathrm{C}-\mathrm{APT}\left\{{ }^{1} \mathrm{H}\right\} \operatorname{NMR}\left(100 \mathrm{MHz}, \mathrm{CDCl}{ }_{3}\right) \delta$ 24.3, 25.0, 25.7, 28.1, 29.6, 35.0, 39.0, 41.3, 41.7, 55.1, 59.2, 65.9, 71.4, 72.3, 83.6, 109.8, 118.1, 126.8, 134.7, 140.4, 158.5, 169.8, 173.0, 175.8; HRMS(ESI ${ }^{+}$) m/z $[\mathrm{M}+\mathrm{H}]^{+}$calcd for $\mathrm{C}_{28} \mathrm{H}_{45} \mathrm{~N}_{2} \mathrm{O}_{6}$ 505.3273, found 505.3290.

4.1.10. tert-Butyl (2S,4S,5R)-1-(4-(tert-butyl)-3-methoxybenzoyl)-5-cyano-2-isobutyl-4(methoxymethyl)pyrrolidine -2-carboxylate (9)

Method A: Phosphorus oxychloride (192 mg, $1.25 \mathrm{mmol}$ ) was added to a stirred solution of compound 8 (252 mg, $0.5 \mathrm{mmol})$ in pyridine $(3 \mathrm{~mL})$ at $0{ }^{\circ} \mathrm{C}$ and the solution was stirred for 6 hours at the same temperature. The resulting solution was poured into ice, diluted with water ( $3 \mathrm{~mL})$ and extracted with diethyl ether (3 x $10 \mathrm{~mL}$ ). The combined organic extracts were dried over anhydrous $\mathrm{MgSO}{ }_{4}$, filtered and evaporated under reduced pressure. The residue was purified by flash chromatography (eluent: diethyl ether/hexane, 1/2) to yield compound 9 (124 mg, 51\% yield) as colourless oil.

Method B: Iodine $(1.27 \mathrm{~g}, 5.0 \mathrm{mmol})$ was added to a stirred solution of compound 7 (245 mg, 0.5 $\mathrm{mmol})$ in aqueous 28\% ammonium hydroxide solution $(20 \mathrm{~mL})$ and THF (5 mL) at room temperature and the reaction mixture was stirred for 16 hours. After that, the resulting dark mixture was treated with saturated aqueous sodium sulfite solution ( $5 \mathrm{~mL}$ ), followed by extraction with dichloromethane (2 x $20 \mathrm{~mL}$ ). The combined organic extracts were dried over anhydrous MgSO ${ }_{4}$, filtered and evaporated under reduced pressure. The residue was purified by flash chromatography (eluent: diethyl 
ether/hexane, 1/2) to afford compound 9 (240.9 mg, 99\% yield) as colourless oil. [ $\alpha]_{\mathrm{D}}{ }^{24}=32.95(c=$ 1.01 in $\mathrm{CHCl}_{3}$ ); IR (neat) 2250, 1734, 1657, $1565 \mathrm{~cm}^{-1} ;{ }^{1} \mathrm{H}$ NMR (400 MHz, $\left.\mathrm{CDCl}_{3}\right) \delta 0.98$ (d, $J=6.6$ Hz, 3H), 1.01 (d, $J=6.6$ Hz, 3H), 1.36 (s, 9H), 1.55 (s, 9H), 1.70-1.82 (m, 1H), 2.00 (dd, $J=13.1$, $13.1 \mathrm{~Hz}, 1 \mathrm{H}$ ); 2.05 (dd, $J=15.0,3.4 \mathrm{~Hz}, 1 \mathrm{H}$ ), 2.20 (dd, $J=13.1,6.5 \mathrm{~Hz}, 1 \mathrm{H}), 2.39$ (dd, $J=15.0,8.8$ Hz, 1H), 2.83-2.96 (m, 1H), 3.33 (s, 3H), 3.47 (dd, $J=9.6,9.6 \mathrm{~Hz}, 1 \mathrm{H}), 3.58$ (dd, $J=9.6,5.0 \mathrm{~Hz}, 1 \mathrm{H}$ ), 3.86 (s, 3H), 4.76 (d, $J=7.2 \mathrm{~Hz}, 1 \mathrm{H}), 6.92$ (dd, $J=7.9,1.7 \mathrm{~Hz}, 1 \mathrm{H}), 6.97$ (d, $J=1.7 \mathrm{~Hz}, 1 \mathrm{H}), 7.30$ (d, $J$ $=7.9 \mathrm{~Hz}, 1 \mathrm{H}) ;{ }^{13} \mathrm{C}-\mathrm{APT}\left\{{ }^{1} \mathrm{H}\right\} \operatorname{NMR}\left(100 \mathrm{MHz} \mathrm{CDCl}_{3}\right) \delta$ 23.5, 24.4, 25.7, 28.1, 29.6, 35.1, 37.4, 41.2, 41.7, 55.1, 55.1, 59.4, 70.2, 72.0, 82.4, 109.3, 116.1, 117.3, 127.1, 134.7, 140.5, 158.7, 169.4, 171.9; $\operatorname{HRMS}\left(\mathrm{ESI}^{+}\right) \mathrm{m} / \mathrm{z}[\mathrm{M}+\mathrm{H}]^{+}$calcd for $\mathrm{C}_{28} \mathrm{H}_{43} \mathrm{~N}_{2} \mathrm{O}_{5}$ 487.3167, found 487.3171.

\subsubsection{1. tert-Butyl (2S,4S,5R)-1-(4-(tert-butyl)-3-methoxybenzoyl)-5-carbamothioyl-2-isobutyl-4-} (methoxymethyl)pyrrolidine -2-carboxylate (10)

Compound 9 (195.7 mg, $0.4 \mathrm{mmol}$ ) was solved in methanol (6 mL) and aqueous 40-44\% ammonium sulfide solution ( $3 \mathrm{~mL}$ ) was added. The reaction mixture was stirred at $90{ }^{\circ} \mathrm{C}$ for 4 days in an autoclave. The resulting mixture was concentrated under reduced pressure and the residue was partitioned between dichloromethane $(20 \mathrm{~mL})$ and water $(20 \mathrm{~mL})$. The aqueous layer was further extracted with dichloromethane (2 x $20 \mathrm{~mL})$ and the combined organic extracts were dried over anhydrous MgSO 4 , filtered and evaporated under reduced pressure. The residue was purified by flash chromatography (eluent: diethyl ether/hexane, 1/2) to yield compound 10 (197.9 mg, 95\% yield) as a white solid. M.p. =

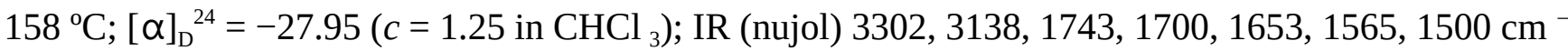

1, ${ }^{1} \mathrm{H}$ NMR (400 MHz, $\mathrm{CDCl}_{3}$ ) $\delta 1.00$ (d, $\left.J=6.6 \mathrm{~Hz}, 3 \mathrm{H}\right), 1.01$ (d, $\left.J=6.6 \mathrm{~Hz}, 3 \mathrm{H}\right), 1.32$ (s, 9H), 1.55 (s, 9H), 1.75-1.90 (m, 1H), 1.99 (dd, $J=13.2,13.2 \mathrm{~Hz}, 1 \mathrm{H}), 2.11$ (d, $J=5.7 \mathrm{~Hz}, 2 \mathrm{H}), 2.42$ (dd, $J=$ 13.2, $6.4 \mathrm{~Hz}, 1 \mathrm{H}), 2.85-2.98$ (m, 1H), 3.12 (dd, $J=9.5,9.2 \mathrm{~Hz}, 1 \mathrm{H}), 3.28$ (s, 3H), 3.74 (dd, $J=9.5,4.6$ Hz, 1H), 3.81 (s, 3H), 5.06 (d, $J=9.1 \mathrm{~Hz}, 1 \mathrm{H}), 6.79$ (d, $J=1.7 \mathrm{~Hz}, 1 \mathrm{H}), 6.85$ (dd, $J=7.9,1.7 \mathrm{~Hz}, 1 \mathrm{H}$ ), 7.21 (d, $J=8.0 \mathrm{~Hz}, 1 \mathrm{H}), 7.62$ (bs, $1 \mathrm{H}), 10.66$ (bs, $1 \mathrm{H}) ;{ }^{13} \mathrm{C}-\mathrm{APT}\left\{{ }^{1} \mathrm{H}\right\}$ NMR $\left(100 \mathrm{MHz}, \mathrm{CDCl}_{3}\right) \delta 24.3$, 25.0, 25.7, 28.0, 29.6, 35.0, 39.0, 41.2, 41.6, 55.2, 59.1, 70.9, 72.3, 72.8, 83.9, 109.9, 118.2, 126.7, 134.2, 140.4, 158.5, 170.0, 176.6, 205.2; $\mathrm{HRMS}\left(\mathrm{ESI}^{+}\right) \mathrm{m} / \mathrm{z}[\mathrm{M}+\mathrm{H}]^{+}$calcd for $\mathrm{C}_{28} \mathrm{H}_{45} \mathrm{~N}_{2} \mathrm{O}_{5} \mathrm{~S} 521.3044$, found 521.3058 .

4.1.12. tert-Butyl (2S,4S,5R)-1-(4-(tert-butyl)-3-methoxybenzoyl)-2-isobutyl-4-(methoxymethyl)-5(thiazol-2-yl)pyrrolidine -2-carboxylate (11)

To a solution of thioamide 10 (52.1 mg, $0.1 \mathrm{mmol})$ and crude bromoacetaldehyde with a $21.5 \%$ purity 
[22] (228.7 $\mathrm{mg}, 0.4 \mathrm{mmol})$ in dry dimethoxyethane $(2 \mathrm{~mL})$ was added sodium hydrogen carbonate (67.2 $\mathrm{mg}, 0,8 \mathrm{mmol}$ ) and the mixture was stirred at room temperature for 18 hours. The reaction mixture was concentrated under reduced pressure and the residue was partitioned between dichloromethane $(10 \mathrm{~mL})$ and water $(10 \mathrm{~mL})$. The aqueous layer was further extracted with dichloromethane (2 x $10 \mathrm{~mL})$ and the combined organic extracts were dried over anhydrous MgSO 4, filtered and evaporated under reduced pressure. The residue was solved in dry dimethoxiethane (1mL) and cooled to $0{ }^{\circ} \mathrm{C}$. A solution of trifluoroacetic anhydride (84.1 $\left.\mathrm{mg}, 0,4 \mathrm{mmol}\right)$ in dry dimethoxyetnane $(0.5 \mathrm{~mL})$ was added followed by a solution of pyridine $(63.3 \mathrm{mg}, 0.8 \mathrm{mmol})$ in dry dimethoxyetane $(0.5 \mathrm{~mL})$. The reaction mixture was stirred at room temperature for 24 hours. After that, the resulting mixture was concentrated under reduced pressure and the residue was partitioned between dichloromethane $(20 \mathrm{~mL})$ and water $(10 \mathrm{~mL})$. The aqueous layer was further extracted with dichloromethane (2 x $10 \mathrm{~mL})$ and the combined organic extracts were dried over anhydrous MgSO 4, filtered and evaporated under reduced pressure. The residue was purified by flash chromatography (eluent: diethyl ether/hexane, 1/1) to afford compound 11 (47.4 mg, 87\% yield) as a brown solid. M.p. $=144{ }^{\circ} \mathrm{C} ;[\alpha]_{\mathrm{D}}{ }^{24}=66.42\left(c=0.55\right.$ in $\left.\mathrm{CHCl}_{3}\right)$; IR (neat) 3113, 1713, 1608, 1567, $1502 \mathrm{~cm}^{-1} ;{ }^{1} \mathrm{H}$ NMR (400 MHz, $\mathrm{CDCl}_{3}$ ) $\delta 1.06$ (d, $\left.J=6.6 \mathrm{~Hz}, 3 \mathrm{H}\right), 1.07$ (d, $\left.J=6.6 \mathrm{~Hz}, 3 \mathrm{H}\right), 1.27$ (s, 9H), 1.58 (s, 9H), 1.91-2.02 (m, 1H), 2.10 (dd, $J=14.6,7.0 \mathrm{~Hz}, 1 \mathrm{H}), 2.25-2.35$ (m, 3H), 2.81 (dd, $J=9.4,7.1 \mathrm{~Hz}, 1 \mathrm{H}$ ), 2.95 (dd, $J=9.4,6.6 \mathrm{~Hz}, 1 \mathrm{H}), 3.02-3.14$ (m, 1H), 3.06 (s, 3H), 3.55 (s, 3H), 5.46 (d, $J=8.5 \mathrm{~Hz}, 1 \mathrm{H})$, 6.31 (d, $J=1.7 \mathrm{~Hz}, 1 \mathrm{H}), 6.62$ (dd, $J=7.9,1.7 \mathrm{~Hz}, 1 \mathrm{H}), 7.09$ (d, $J=7.9 \mathrm{~Hz}, 1 \mathrm{H}), 7.19$ (d, $J=3.2 \mathrm{~Hz}$, 1H), 7.48 (d, $J=3.2 \mathrm{~Hz}, 1 \mathrm{H}) ;{ }^{13} \mathrm{C}-\mathrm{APT}\left\{{ }^{1} \mathrm{H}\right\} \mathrm{NMR}\left(100 \mathrm{MHz}, \mathrm{CDCl}_{3}\right) \delta 24.6,25.3,25.6,28.3,29.6$, 34.9, 37.3, 42.7, 42.8, 54.8, 59.0, 63.9, 70.9, 72.0, 81.9, 109.4, 117.1, 119.8, 126.4, 135.9, 139.2, 141.7, 158.3, 169.5, 169.8, 172.2; $\operatorname{HRMS}\left(\mathrm{ESI}^{+}\right) \mathrm{m} / \mathrm{z}[\mathrm{M}+\mathrm{H}]^{+}$calcd for $\mathrm{C}_{30} \mathrm{H}_{45} \mathrm{~N}_{2} \mathrm{O}_{5} \mathrm{~S}$ 545.3044, found 545.3061.

\subsubsection{3. (2S,4S,5R)-1-(4-(tert-Butyl)-3-methoxybenzoyl)-2-isobutyl-4-(methoxymethyl)-5-(thiazol-2-} yl)pyrrolidine -2-carboxylic acid (GSK3082)

To a solution of compound $11(27.2 \mathrm{mg}, 0.05 \mathrm{mmol})$ in dichloromethane $(0.6 \mathrm{~mL})$ at $0{ }^{\circ} \mathrm{C}$ was added trifluoroacetic acid $(0.2 \mathrm{~mL})$ and the resulting solution was stirred at $0{ }^{\circ} \mathrm{C}$ for 14 hours. The reaction mixture was diluted with dichloromethane $(15 \mathrm{~mL})$, neutralised with saturated aqueous sodium hydrogen carbonate solution and carefully acidified at $\mathrm{pH} 1$ with $1 \mathrm{M}$ hydrochloric acid. The organic layer was separated and the aqueous layer was extracted with dichloromethane (2 x $10 \mathrm{~mL})$. The combined organic extracts washed with water $(10 \mathrm{~mL})$, dried over anhydrous MgS@ filtered and 
evaporated under reduced pressure to give compound 1 (23.1 $\mathrm{mg}$, 95\% yield) as a brown solid. All physical and spectroscopic data are in agreement with those previously described in the literature. ${ }^{7 c}$

4.1.14. tert-Butyl (2S,4S,5R)-1-(4-(tert-butyl)-3-methoxybenzoyl)-5-(4-(ethoxycarbonyl)thiazol-2-yl)-2isobutyl-4-(methoxymethyl)pyrrolidine -2-carboxylate (12)

To a solution of thioamide 10 (52.1 mg, $0.1 \mathrm{mmol})$ and ethyl bromopyruvate 85\% (91.8 mg, $0.4 \mathrm{mmol})$ in dry dimethoxyethane (2 mL) was added sodium hydrogen carbonate (67.2 $\mathrm{mg}, 0,8 \mathrm{mmol})$ and the mixture was stirred at room temperature for 18 hours. The reaction mixture was concentrated under reduced pressure and the residue was partitioned between dichloromethane $(10 \mathrm{~mL})$ and water $(10 \mathrm{~mL})$. The aqueous layer was further extracted with dichlorometane (2 x $10 \mathrm{~mL})$ and the combined organic extracts were dried over anhydrous $\mathrm{MgSO}_{4}$, filtered and evaporated under reduced pressure. The residue was solved in dry dimethoxyethane $(1 \mathrm{~mL})$ and cooled to $0{ }^{\circ} \mathrm{C}$. A solution of trifluoroacetic anhydride (84.1 $\mathrm{mg}, 0,4 \mathrm{mmol})$ in dry dimethoxyetnane $(0.5 \mathrm{~mL})$ was added followed by a solution of pyridine $(63.3 \mathrm{mg}, 0.8 \mathrm{mmol})$ in dry dimethoxyetane $(0.5 \mathrm{~mL})$. The reaction mixture was stirred at room temperature for 24 hours. After that, the resulting mixture was concentrated under reduced pressure and the residue was partitioned between dichloromethane $(20 \mathrm{~mL})$ and water $(10 \mathrm{~mL})$. The aqueous layer was further extracted with dichlorometane (2 x $10 \mathrm{~mL})$ and the combined organic extracts were dried over anhydrous $\mathrm{MgSO}_{4}$, filtered and evaporated under reduced pressure. The residue was purified by flash chromatography (eluent: diethyl ether/hexane, 1/1) to afford compound 12 (54.2 mg, 88\% yield) as a brown solid. M.p. $=114^{\circ} \mathrm{C} ;[\alpha]_{\mathrm{D}}{ }^{24}=53.75\left(c=1.05\right.$ in $\left.\mathrm{CHCl}_{3}\right)$; IR (nujol) 3092, 1730, 1653, $1591 \mathrm{~cm}^{-1}$; ${ }^{1} \mathrm{H}$ NMR (400 MHz, $\mathrm{CDCl}_{3}$ ) $\delta 1.07$ (d, $\left.J=6.5,6 \mathrm{H}\right), 1.25$ (s, 9H), 1.34 (t, $J=7.1 \mathrm{~Hz}, 3 \mathrm{H}), 1.59$ (s, 9H), 1.89-2.00 (m, 1H), 2.07 (dd, $J=14.8,7.3 \mathrm{~Hz}, 1 \mathrm{H}), 2.28$ (dd, $J=13.0$, $13.0 \mathrm{~Hz}, 1 \mathrm{H}$ ), 2.28 (dd, $J=14.8,3.9 \mathrm{~Hz}, 1 \mathrm{H}$ ), 2.37 (dd, $J=13.0,6.3 \mathrm{~Hz}, 1 \mathrm{H}$ ), 2.78 (dd, $J=9.2,7.5 \mathrm{~Hz}$, 1H), 3.02-3.12 (m, 1H), 3.06 (s, 3H), 3.16 (dd, $J=9.2,5.4 \mathrm{~Hz}, 1 \mathrm{H}), 3.58$ (s, 3H), 4.26-4.41 (m, 2H), 5.59 (d, $J=8.7 \mathrm{~Hz}, 1 \mathrm{H}), 6.37$ (d, $J=1.7 \mathrm{~Hz}, 1 \mathrm{H}), 6.64$ (dd, $J=7.9,1.7 \mathrm{~Hz}, 1 \mathrm{H}), 7.09$ (d, $J=7.9 \mathrm{~Hz}$, 1H), 8.04 (d, $J=0.7 \mathrm{~Hz}, 1 \mathrm{H}) ;{ }^{13} \mathrm{C}-\mathrm{APT}\left\{{ }^{1} \mathrm{H}\right\} \mathrm{NMR}\left(100 \mathrm{MHz}, \mathrm{CDCl}_{3}\right) \delta 14.5,24.6,25.3,25.6,28.3$, 29.5, 34.9, 37.6, 42.5, 42.7, 54.9, 59.0, 61.5, 64.0, 71.1, 71.8, 82.2, 109.3, 117.3, 126.5, 128.4, 135.4, 139.6, 146.0, 158.2, 161.2, 169.6, 171.0, 172.3; HRMS(ESI) $\mathrm{m} / \mathrm{z}[\mathrm{M}+\mathrm{H}]^{+}$calcd for $\mathrm{C}_{33} \mathrm{H}_{49} \mathrm{~N}_{2} \mathrm{O}_{7} \mathrm{~S}$ 617.3255, found 617.3272.

4.1.15. (2S,4S,5R)-1-(4-(tert-Butyl)-3-methoxybenzoyl)-5-(4-(ethoxycarbonyl)thiazol-2-yl)-2-isobutyl4-(methoxymethyl)pyrrolidine-2-carboxylic acid (13) 
To a solution of compound $12(30.8 \mathrm{mg}, 0.05 \mathrm{mmol})$ in dichloromethane $(0.6 \mathrm{~mL})$ at $0{ }^{\circ} \mathrm{C}$ was added trifluoroacetic acid $(0.2 \mathrm{~mL})$ and the resulting solution was stirred at $0{ }^{\circ} \mathrm{C}$ for 14 hours. The reaction mixture was diluted with dichloromethane $(15 \mathrm{~mL})$, neutralised with saturated aqueous sodium hydrogen carbonate solution and carefully acidified at $\mathrm{pH} 1$ with $1 \mathrm{M}$ hydrochloric acid. The organic layer was separated and the aqueous layer was extracted with dichloromethane (2 x $10 \mathrm{~mL})$. The combined organic extracts were washed with water $(10 \mathrm{~mL})$, dried over anhydrous $\mathrm{MgSO}_{4}$, filtered and evaporated under reduced pressure to give compound 13 (26.5 mg, 95\% yield) as a brown solid. M.p. = $55^{\circ} \mathrm{C} ;[\alpha]_{\mathrm{D}}{ }^{24}=61.89\left(c=0.64 \mathrm{in} \mathrm{CHCl}{ }_{3}\right.$ ); IR (nujol) 3500-2400, 1741, 1653, 1607, $1565 \mathrm{~cm}{ }^{-1} ;{ }^{1} \mathrm{H}$ NMR (400 MHz, CDCl $) \delta 1.09$ (d, $J=6.6 \mathrm{~Hz}, 3 \mathrm{H}), 1.12$ (d, $J=6.6 \mathrm{~Hz}, 3 \mathrm{H}) ; 1.28(\mathrm{~s}, 9 \mathrm{H}), 1.45$ (t, $J=$ $7.1 \mathrm{~Hz}, 3 \mathrm{H}$ ), 1.90-2.00 (m, 1H), 2.17-2.23 (m, 2H), 2.30 (dd, $J=15.0,4.0 \mathrm{~Hz}, 1 \mathrm{H}$ ), 2.40 (dd, $J=15.0$, $8.1 \mathrm{~Hz}, 1 \mathrm{H}$ ), 2.54 (dd, $J=10.3,9.4 \mathrm{~Hz}, 1 \mathrm{H}), 3.11$ (s, 3H), 3.17-3.30 (m, 1H), 3.33 (dd, $J=9.4,4.5 \mathrm{~Hz}$, 1H), 3.56 (s, 3H), 4.44 (q, $J=7.1 \mathrm{~Hz}, 2 \mathrm{H}), 5.50$ (d, $J=8.1 \mathrm{~Hz}, 1 \mathrm{H}), 6.31$ (d, $J=1.7 \mathrm{~Hz}, 1 \mathrm{H}), 6.61$ (dd, $J=7.9,1.7 \mathrm{~Hz}, 1 \mathrm{H}), 7.12(\mathrm{~d}, J=7.9 \mathrm{~Hz}, 1 \mathrm{H}), 8.06(\mathrm{~s}, 1 \mathrm{H}) ;{ }^{13} \mathrm{C}-\mathrm{APT}\left\{{ }^{1} \mathrm{H}\right\} \mathrm{NMR}\left(100 \mathrm{MHz}, \mathrm{CDCl}_{3}\right) \delta$ 14.4, 24.2, 24.9, 25.7, 29.6, 35.0, 35.6, 42.6, 43.5, 55.0, 58.9, 62.4, 64.0, 70.8, 71.3, 109.1, 116.7, 126.6, 128.3, 135.0, 140.2, 145.9, 158.6, 160.4, 169.9, 172.0, 173.6; HRMS(ESI $\left.{ }^{+}\right) \mathrm{m} / \mathrm{z}[\mathrm{M}+\mathrm{Na}]^{+}$calcd $^{2}$ for $\mathrm{C}_{29} \mathrm{H}_{40} \mathrm{~N}_{2} \mathrm{NaO}_{7} \mathrm{~S}$ 583.2449, found 583.2441.

\subsubsection{6. tert-Butyl (2S,4S,5S)-1-(4-(tert-butyl)-3-methoxybenzoyl)-2-isobutyl-4-(methoxymethyl)-5-} (thiazol-2-yl)pyrrolidine-2-carboxylate (14)

To a solution of thioamide 10 (156.2 $\mathrm{mg}, 0.3 \mathrm{mmol})$ and bromoacetaldehyde diethyl acetal (295.6 mg, $1.5 \mathrm{mmol})$ in dry THF $(12 \mathrm{~mL})$ was added $\mathrm{HCl} /$ dioxane $(4 \mathrm{~N}, 0,1 \mathrm{~mL})$ and the mixture was stirred at 65 ${ }^{\circ} \mathrm{C}$ for 24 hours. The reaction mixture was concentrated under reduced pressure and the residue was purified by flash chromatography (eluent: diethyl ether/hexane, 1/1) to afford compound 14 (83.3 mg, $51 \%$ yield) as an oil. $[\alpha]_{\mathrm{D}}{ }^{24}=-28.67\left(c=0.99\right.$ in $\mathrm{CHCl}_{3}$ ); IR (neat) 3082, 1734, 1652, 1610, $1566 \mathrm{~cm}^{-1}$; ${ }^{1} \mathrm{H}$ NMR (400 MHz, $\mathrm{CDCl}_{3}$ ) $\delta 1.05$ (d, $\left.J=6.3 \mathrm{~Hz}, 3 \mathrm{H}\right), 1.07$ (d, $\left.J=6.4 \mathrm{~Hz}, 3 \mathrm{H}\right), 1.28$ (s, 9H), 1.51 (s, 9H), 2.02-2.11 (m, 2H), 2.20 (dd, $J=12.9,10.7$ Hz, 1H), 2.39-2.49 (m, 2H), 2.75-2.86 (m, 1H), 3.28 (s, 3H), 3.34 (dd, $J=9.6,6.4 \mathrm{~Hz}, 1 \mathrm{H}$ ), 3.47 (dd, $J=9.6,5.2 \mathrm{~Hz}, 1 \mathrm{H}), 3.63$ (s, 3H), 5.16 (d, $J=8.3 \mathrm{~Hz}$, 1H), 6.43 (d, $J=1.7 \mathrm{~Hz}, 1 \mathrm{H}), 6.76$ (dd, $J=7.9,1.7 \mathrm{~Hz}, 1 \mathrm{H}), 7.06$ (d, $J=3.2 \mathrm{~Hz}, 1 \mathrm{H}), 7.10$ (d, $J=7.9$ $\mathrm{Hz}, 1 \mathrm{H}), 7.42$ (d, $J=3.2 \mathrm{~Hz}, 1 \mathrm{H}) ; \quad{ }^{13} \mathrm{C}-\mathrm{APT}\left\{{ }^{1} \mathrm{H}\right\}$ NMR (100 MHz, CDCl $\left.{ }_{3}\right) \delta$ 25.4, 25.4, 25.5, 28.1, 29.6, 34.9, 38.2, 44.1, 47.4, 54.9, 59.1, 64.8, 71.6, 72.3, 81.5, 109.6, 117.6, 119.2, 126.4, 135.9, 139.3, 142.1, 158.4, 170.4, 172.0, 172.3; HRMS(ESI ${ }^{+}$) $\mathrm{m} / \mathrm{z}[\mathrm{M}+\mathrm{H}]^{+}$calcd for $\mathrm{C}_{30} \mathrm{H}_{45} \mathrm{~N}_{2} \mathrm{O}_{5} \mathrm{~S} 545.3044$, found 545.3056. 
4.1.17. (2S,4S,5S)-1-(4-(tert-Butyl)-3-methoxybenzoyl)-2-isobutyl-4-(methoxymethyl)-5-(thiazol-2yl)pyrrolidine-2-carboxylic acid (15)

To a solution of compound $14(27.2 \mathrm{mg}, 0.05 \mathrm{mmol})$ in dichloromethane $(0.6 \mathrm{~mL})$ at $0{ }^{\circ} \mathrm{C}$ was added trifluoroacetic acid $(0.2 \mathrm{~mL})$ and the resulting solution was stirred at $0{ }^{\circ} \mathrm{C}$ for 14 hours. The reaction mixture was diluted with dichloromethane $(15 \mathrm{~mL})$, neutralised with saturated aqueous sodium hydrogen carbonate solution and carefully acidified at $\mathrm{pH} 1$ with $1 \mathrm{M}$ hydrochloric acid. The organic layer was separated and the aqueous layer was extracted with dichloromethane ( $2 \times 10 \mathrm{~mL})$. The combined organic extracts washed with water $(10 \mathrm{~mL})$, dried over anhydrous MgSQ filtered and evaporated under reduced pressure to give compound 15 (23.5 mg, 96\% yield) as a brown oil. [ $\alpha]_{D}{ }^{24}=$ -52.63 ( $c=0.90$ in $\mathrm{CHCl}_{3}$ ); IR (neat) 3500-2400, 1728, 1650, 1607, 1566, $1501 \mathrm{~cm}^{-1}$; ${ }^{1} \mathrm{H}$ NMR (400 $\mathrm{MHz}, \mathrm{CDCl}_{3}$ ) $\delta 1.03$ (d, $\left.J=6.6 \mathrm{~Hz}, 3 \mathrm{H}\right), 1.04$ (d, $\left.J=6.6 \mathrm{~Hz}, 3 \mathrm{H}\right), 1.29$ (s, 9H), 1.79-1.91 (m, 1H), 2.20 (dd, $J=14.0,6.2 \mathrm{~Hz}, 1 \mathrm{H}$ ), 2.42 (dd, $J=13.2,7.2 \mathrm{~Hz}, 1 \mathrm{H}$ ), 2.48-2.58 (m, 1H), 2.83 (dd, $J=13.2$, $3.5 \mathrm{~Hz}, 1 \mathrm{H}$ ), 2.87 (dd, $J=14.0,5.8 \mathrm{~Hz}, 1 \mathrm{H}$ ); 3.33 (s, 3H), 3.34 (dd, $J=9.8,8.3 \mathrm{~Hz}, 1 \mathrm{H}$ ), 3.42 (dd, $J=$ 9.8, $5.1 \mathrm{~Hz}, 1 \mathrm{H}$ ), 3.61 (s, 3H), 5.26 (d, $J=3.3 \mathrm{~Hz}, 1 \mathrm{H}$ ), 6.38 (d, $J=1.6 \mathrm{~Hz}, 1 \mathrm{H}), 6.63$ (dd, $J=7.9,1.6$ Hz, 1H), 7.13 (d, $J=7.9 \mathrm{~Hz}, 1 \mathrm{H}), 7.15$ (d, $J=3.3 \mathrm{~Hz}, 1 \mathrm{H}$ ), 7.60 (d, $J=3.3 \mathrm{~Hz}, 1 \mathrm{H}$ ), 8.51 (bs, $1 \mathrm{H}) ;{ }^{13} \mathrm{C}-$ APT $\left\{{ }^{1} \mathrm{H}\right\}$ NMR (100 MHz, $\left.\mathrm{CDCl}_{3}\right) \delta$ 24.0, 24.8, 25.2, 29.5, 35.0, 36.6, 43.8, 46.0, 55.0, 59.1, 65.6, 72.8, 74.5, 108.8, 117.3, 119.6, 126.7, 135.0, 140.1, 142.3, 158.3, 170.9, 173.9, 174.6; HRMS(ESI + $\left.{ }^{+}\right)$ $\mathrm{m} / \mathrm{z}[\mathrm{M}+\mathrm{Na}]^{+} \mathrm{C}_{26} \mathrm{H}_{36} \mathrm{~N}_{2} \mathrm{NaO}_{5} \mathrm{~S} 511.2238$, found 511.2251.

4.1.18. (2S,4S,5R)-1-(4-(tert-butyl)-3-methoxybenzoyl)-5-((S)-2,2-dimethyl-1,3-dioxolan-4-yl)-2isobutyl-4-(methoxymethyl)pyrrolidine-2-carboxylic acid (16)

A solution of compound 5 (112.4 mg, $0.2 \mathrm{mmol}$ ) in $10 \% \mathrm{KOH} / \mathrm{methanol} \mathrm{(5} \mathrm{mL)} \mathrm{was} \mathrm{refluxed} \mathrm{for} 5$ days. The resulting mixture was cooled and the solvent evaporated under reduced pressure. The residue was diluted in water $(10 \mathrm{~mL})$ and washed with dichloromethane $(5 \mathrm{~mL})$. The aqueous layer was then acidified with $1 \mathrm{M}$ hydrochloric acid and extracted with dichloromethane (2 x $20 \mathrm{~mL}$ ). The combined organic extracts were dried over anhydrous $\mathrm{MgSO}_{4}$, filtered and concentrated under reduced pressure to provide compound 16 (100.1 mg, 99\% yield) as a white solid. M.p. $=155{ }^{\circ} \mathrm{Qj}_{\mathrm{D}} \mathrm{F}^{4}=$ -99.59 (c = 1.11 in CHCl); IR (nujol) 3400-2200, 1739, 1605, $1558 \mathrm{~cm}^{-1}$; ${ }^{1} \mathrm{H}$ NMR (400 MHz, $\left.\mathrm{CDCl}_{3}\right) \delta 0.96$ (d, $J=6.4 \mathrm{~Hz}, 3 \mathrm{H}$ ), 0.98 (d, $\left.J=6.3 \mathrm{~Hz}, 3 \mathrm{H}\right), 1.15$ (s, 3H), 1.22 (s, 3H), 1.34 (s, 9H), 1.73-1.85 (m, 2H), 2.18 (dd, $J=12.6,6.5 \mathrm{~Hz}, 1 \mathrm{H}), 2.36$ (dd, $J=15.4,7.7 \mathrm{~Hz}, 1 \mathrm{H}$ ), 2.70-2.82 (m, 1H), 2.82 (dd, $J=12.6,12.6 \mathrm{~Hz}, 1 \mathrm{H}$ ), 3.24 (dd, $J=9.6,9.6 \mathrm{~Hz}, 1 \mathrm{H}$ ), 3.29 (s, 3H), 3.38 (dd, $J=8.0,8.0 \mathrm{~Hz}$, 
1H), 3.46 (dd, $J=9.6,4.4 \mathrm{~Hz}, 1 \mathrm{H}$ ), 3.67 (dd, $J=8.0,6.0 \mathrm{~Hz}, 1 \mathrm{H}$ ), 3.35 (s, 3H), 3.88-3.95 (m, 1H), 4.49 (dd, $J=6.2,6.2 \mathrm{~Hz}, 1 \mathrm{H}), 6.91$ (dd, $J=7.9,1.7 \mathrm{~Hz}, 1 \mathrm{H}), 7.04$ (bs, 1H), 7.26 (d, $J=7.9 \mathrm{~Hz}, 1 \mathrm{H}$ ); ${ }^{13} \mathrm{C}-\mathrm{APT}\left\{{ }^{1} \mathrm{H}\right\}$ NMR $\left(100 \mathrm{MHz}, \mathrm{CDCl}_{3}\right)$ $\delta$ 23.9, 24.7, 24.9, 25.1, 25.9, 29.5, 35.3, 35.8, 39.2, 42.7, 55.2, 59.0, 65.1, 66.3, 71.2, 73.0, 73.7, 109.1, 112.1, 119.3, 126.7, 134.1, 142.5, 150.0, 174.0, 175.4; $\operatorname{HRMS}\left(\mathrm{ESI}^{+}\right) \mathrm{m} / \mathrm{z}[\mathrm{M}+\mathrm{Na}]^{+}$calcd for $\mathrm{C}_{28} \mathrm{H}_{43} \mathrm{NNaO}_{7}$ 528.2932, found 528.2919.

4.1.19. tert-Butyl (2S,4S,5R)-1-(4-(tert-butyl)-3-methoxybenzoyl)-2-isobutyl-4-(methoxymethyl)-5-((S)2-oxo-1,3-dioxolan-4-yl)pyrrolidine-2-carboxylate (17)

To a solution of compound 6 (104.3 mg, $0.2 \mathrm{mmol})$ in THF (5 mL) was added 1,1'carbonyldiimidazole ( $97.3 \mathrm{mg}, 0.6 \mathrm{mmol}$ ) and the mixture was stirred at $60{ }^{\circ} \mathrm{C}$ for 24 hours. After that, the solvent was evaporated under reduced pressure and the residue was purified by flash chromatography (eluent: diethyl ether/hexane, 3/1) to afford compound 17 (98.5 mg, 90\% yield) as a white solid. M.p. $=90^{\circ} \mathrm{C} ;[\alpha]_{\mathrm{D}}{ }^{24}=-37.76\left(c=1.01\right.$ in $\mathrm{CHCl}_{3}$ ); IR (nujol) 1815, 1729, 1639, $1565 \mathrm{~cm}^{-1}$; ${ }^{1} \mathrm{H}$ NMR (400 MHz, $\mathrm{CDCl}_{3}$ ) $\delta$ 0.93-1.00 (m, 3H), 1.03 (d, $\left.J=6.6 \mathrm{~Hz}, 3 \mathrm{H}\right), 1.34$ (s, 9H), 1.52 (s, 9H), 1.76-1.90 (m, 1H), 1.91-2.05 (m, 1H), 2.10-2.22 (m, 2H), 2.28-2.42 (m, 1H), 2.86-3.02 (m, 1H), 3.15-3.26 (m, 1H), 3.29 (s, 3H), 3.46 (dd, $J=10.2,4.0 \mathrm{~Hz}, 1 \mathrm{H}), 3.88(\mathrm{~s}, 3 \mathrm{H}) ; 4.03-4.15(\mathrm{~m}, 1 \mathrm{H})$, 4.20-4.31 (m, 1H), 4.55-4.68 (m, 1H), 4.84-4.95 (m, 1H), 6.84 (bd, $J=7.9$ Hz, 1H), 7.08 (d, $J=1.7$ $\mathrm{Hz}, 1 \mathrm{H}), 7.17$ (d, $J=7.9 \mathrm{~Hz}, 1 \mathrm{H}) ; \quad{ }^{13} \mathrm{C}\left\{{ }^{1} \mathrm{H}\right\} \mathrm{NMR}\left(100 \mathrm{MHz}, \mathrm{CDCl}_{3}\right.$ ) $\delta 24.4,25.2$, 25.6, 28.1, 29.6, 35.0, 36.5, 40.8, 41.7, 55.1, 59.1, 63.6, 67.3, 69.3, 70.3, 75.7, 77.4, 82.1, 112.4, 117.8, 125.8, 135.8, 140.4, 153.4, 159.1, 170.5, 173.1; HRMS(ESI) $\mathrm{m} / \mathrm{z}[\mathrm{M}+\mathrm{H}]^{+}$calcd for $\mathrm{C}_{30} \mathrm{H}_{46} \mathrm{NO}_{8}$ 548.3218, found 548.3232.

4.1.20. (2S,4S,5R)-1-(4-(tert-Butyl)-3-methoxybenzoyl)-2-isobutyl-4-(methoxymethyl)-5-((S)-2-oxo-1,3dioxolan-4-yl)pyrrolidine-2-carboxylic acid (18)

To a solution of compound $17(54.7 \mathrm{mg}, 0.1 \mathrm{mmol})$ in dichloromethane $(1.2 \mathrm{~mL})$ at $0{ }^{\circ} \mathrm{C}$ was added trifluoroacetic acid $(0.4 \mathrm{~mL})$ and the resulting solution was stirred at $0{ }^{\circ} \mathrm{C}$ for 14 hours. The reaction mixture was diluted with dichloromethane $(15 \mathrm{~mL})$, neutralised with saturated aqueous sodium hydrogen carbonate solution and carefully acidified at pH 1 with $1 \mathrm{M}$ hydrochloric acid. The organic layer was separated and the aqueous layer was extracted with dichloromethane ( $2 \mathrm{x} 15 \mathrm{~mL})$. The combined organic extracts washed with water $(10 \mathrm{~mL})$, dried over anhydrous MgS@ filtered and evaporated under reduced pressure to give compound 18 (46.1 mg, 94\% yield) as a brown solid. M.p. = $194{ }^{\circ} \mathrm{C} ;[\alpha]_{\mathrm{D}}{ }^{24}=-146.28\left(c=0.92\right.$ in $\mathrm{CHCl}_{3}$ ); IR (nujol) 3700-2500, 1818, 1691, 1653, 1608, 1572 
$\mathrm{cm}^{-1}$; ${ }^{1} \mathrm{H}$ NMR (400 MHz, $\left.\mathrm{CDCl}_{3}\right) \delta 1.00$ (d, $\left.J=6.7 \mathrm{~Hz}, 3 \mathrm{H}\right), 1.02$ (d, $\left.J=6.7 \mathrm{~Hz}, 3 \mathrm{H}\right), 1.36$ (s, 9H), 1.76-1.85 (m, 2H), 2.25 (dd, $J=13.9,7.8$ Hz, 1H), 2.41-2.52 (m, 1H), 2.72-2.84 (m, 1H), 2.98 (dd, $J$ = 13.9, $13.9 \mathrm{~Hz}, 1 \mathrm{H}), 3.18$ (dd, $J=10.5,7.8 \mathrm{~Hz}, 1 \mathrm{H}), 3.28$ (s, 3H), 3.52 (dd, $J=10.5,3.5 \mathrm{~Hz}, 1 \mathrm{H}), 3.89$ (s, 3H), 3.95 (dd, $J=9.2,5.8 \mathrm{~Hz}, 1 \mathrm{H}), 4.32$ (dd, $J=9.2,8.0 \mathrm{~Hz}, 1 \mathrm{H}), 4.45$ (dd, $J=9.9,6.2 \mathrm{~Hz}, 1 \mathrm{H}$ ), 4.58 (ddd, $J=9.9,8.0,5.8 \mathrm{~Hz}, 1 \mathrm{H}), 6.79$ (dd, $J=7.9,1.7 \mathrm{~Hz}, 1 \mathrm{H}), 7.10$ (d, $J=1.7 \mathrm{~Hz}, 1 \mathrm{H}), 7.26$ (d, $J=$ $7.9 \mathrm{~Hz}, 1 \mathrm{H}) ;{ }^{13} \mathrm{C}\left\{{ }^{1} \mathrm{H}\right\} \mathrm{NMR}\left(100 \mathrm{MHz}, \mathrm{CDCl}_{3}\right) \delta$ 23.8, 24.7, 25.1, 29.5, 34.7, 35.5, 39.1, 42.6, 55.3, 59.1, 66.3, 67.0, 69.7, 71.9, 74.1, 112.0, 117.6, 126.6, 133.7, 142.3, 153.1, 159.5, 173.8, 176.1; $\operatorname{HRMS}\left(\mathrm{ESI}^{+}\right) \mathrm{m} / \mathrm{z}[\mathrm{M}+\mathrm{Na}]^{+}$calcd for calcd for $\mathrm{C}_{26} \mathrm{H}_{37} \mathrm{NNaO}_{8}$ 514.2412, found 514.2425.

4.1.21. (2S,4S,5R)-1-(4-(tert-Butyl)-3-methoxybenzoyl)-5-carbamoyl-2-isobutyl-4(methoxymethyl)pyrrolidine-2-carboxylic acid (19)

To a solution of compound 8 (50.4 mg, $0.1 \mathrm{mmol})$ in dichloromethane $(1.2 \mathrm{~mL})$ at $0{ }^{\circ} \mathrm{C}$ was added trifluoroacetic acid $(0.4 \mathrm{~mL})$ and the resulting solution was stirred at $0{ }^{\circ} \mathrm{C}$ for 8 hours. The reaction mixture was diluted with dichloromethane $(15 \mathrm{~mL})$, neutralised with saturated aqueous sodium hydrogen carbonate solution and carefully acidified at $\mathrm{pH} 1$ with $1 \mathrm{M}$ hydrochloric acid. The organic layer was separated and the aqueous layer was extracted with dichloromethane (2 x $20 \mathrm{~mL})$. The combined organic extracts were washed with water $(10 \mathrm{~mL})$, dried over anhydrous $\mathrm{MgSO}_{4}$, filtered and evaporated under reduced pressure to give compound 19 (43.1 mg, 96\% yield) as a brownish solid. M.p. $=253^{\circ} \mathrm{C} ;[\alpha]_{\mathrm{D}}{ }^{24}=7.12\left(c=1.01\right.$ in $\mathrm{CHCl}_{3}$ ); IR (nujol) 3600-2200, 3433, 3337, 3209, 1720, 1650, 1608, $1570 \mathrm{~cm}^{-1}$; ${ }^{1} \mathrm{H}$ NMR (400 MHz, $\mathrm{CDCl}_{3}$ ) $\delta 1.01$ (d, $\left.J=6.7 \mathrm{~Hz}, 3 \mathrm{H}\right), 1.01$ (d, $\left.J=6.7 \mathrm{~Hz}, 3 \mathrm{H}\right), 1.31$ (s, 9H), 1.75-1.89 (m, 1H), 2.01 (dd, $J=13.4,13.4 \mathrm{~Hz}, 1 \mathrm{H}), 2.16$ (dd, $J=15.1,3.6 \mathrm{~Hz}, 1 \mathrm{H}), 2.20$ (dd, $J=13.4,6.7 \mathrm{~Hz}, 1 \mathrm{H}), 2.34$ (dd, $J=15.1,8.3 \mathrm{~Hz}, 1 \mathrm{H}), 2.94-3.14$ (m, 1H), 3.28 (s, 3H), 3.31-3.40 (m, 2H), 3.77 (s, 3H), 4.64 (d, $J=8.5$ Hz, 1H), 6.45 (bs, 1H), 6.80-6.84 (m, 2H), 7.05 (bs, 1H), 7.22 (d, $J=$ 8.0 Hz, 1H); ${ }^{13} \mathrm{C}-\mathrm{APT}\left\{{ }^{1} \mathrm{H}\right\} \mathrm{NMR}\left(100 \mathrm{MHz} \mathrm{CDCl}_{3}\right) \delta$ 23.9, 24.6, 25.7, 29.6, 35.1, 37.0, 41.5, 41.9, 55.2, 59.1, 65.4, 70.6, 71.5, 109.8, 117.6, 126.8, 134.3, 140.6, 158.7, 170.4, 175.4, 175.4; $\mathrm{HRMS}_{\left(\mathrm{ESI}^{+}\right)}$ $\mathrm{m} / \mathrm{z}[\mathrm{M}+\mathrm{Na}]^{+}$calcd for calcd for $\mathrm{C}_{24} \mathrm{H}_{36} \mathrm{~N}_{2} \mathrm{NaO}_{6}$ 471.2466, found 471.2481.

4.1.22. tert-Butyl (2S,4S,5R)-1-(4-(tert-butyl)-3-methoxybenzoyl)-2-isobutyl-4,5bis(methoxymethyl)pyrrolidine-2-carboxylate (20)

A solution of compound $7(97.9 \mathrm{mg}, 0.2 \mathrm{mmol})$ in ethanol $(2 \mathrm{~mL})$ was reacted with sodium borohydride (75.7 mg, $2 \mathrm{mmol}$ ) for 16 hours at room temperature. The reaction was quenched with saturated aqueous ammonium chloride solution $(2 \mathrm{~mL})$ and concentrated under reduced pressure. The 
residue was partitioned between dichloromethane $(20 \mathrm{~mL})$ and water $(10 \mathrm{~mL})$, the organic layer was separated and the aqueous layer extracted with dichloromethane (2 x $10 \mathrm{~mL})$. The combined organic extracts were dried over anhydrous $\mathrm{MgSO}_{4}$, filtered and evaporated under reduced pressure to afford a residue containing the crude alcohol. To a stirred solution of the crude alcohol in dry THF (5 mL) under argon at $0{ }^{\circ} \mathrm{C} \mathrm{KOBu}(44.9 \mathrm{mg}, 0.4 \mathrm{mmol}$ ) was added and the mixture was stirred at room temperature for $15 \mathrm{~min}$. Then, iodomethane $(172 \mathrm{mg}, 1.0 \mathrm{mmol})$ was added and the slurry was stirred for 18 hours at room temperature. The resulting reaction mixture was quenched with saturated aqueous $\mathrm{NH}_{4} \mathrm{Cl}$ solution $(10 \mathrm{~mL})$ and the organic solvent was evaporated under reduced pressure. The aqueous layer was extracted with dichloromethane $(3 \times 20 \mathrm{~mL})$ and the combined organic extracts were dried over anhydrous $\mathrm{MgSO}_{4}$, filtered and concentrated under reduced pressure. The crude product was purified by flash chromatography (eluent: diethyl ether/hexane, 1/1) to provide compound 20 (85.9 mg, $85 \%$ yield) as a white solid. M.p. $=157^{\circ} \mathrm{C} ;[\alpha]_{\mathrm{D}}{ }^{24}=29.15\left(c=1.04\right.$ in $\left.\mathrm{CHCl}_{3}\right)$; IR (nujol) 1727, 1620, $1566 \mathrm{~cm}^{-1}$; ${ }^{1} \mathrm{H}$ NMR (400 MHz, $\mathrm{CDCl}_{3}$ ) $\delta 1.00$ (d, $\left.J=6.6 \mathrm{~Hz}, 3 \mathrm{H}\right), 1.03$ (d, $\left.J=6.6 \mathrm{~Hz}, 3 \mathrm{H}\right), 1.33$ (s, 9H), 1.50 (s, 9H), 1.78-1.89 (m, 1H), 1.91 (dd, $J=13.0,13.0 \mathrm{~Hz}, 1 \mathrm{H}), 1.99$ (dd, $J=14.8,3.6 \mathrm{~Hz}, 1 \mathrm{H}$ ), 2.22 (dd, $J=13.0,6.8 \mathrm{~Hz}, 1 \mathrm{H}), 2.30$ (dd, $J=14.8,8.2 \mathrm{~Hz}, 1 \mathrm{H}), 2.78-2.91$ (m, 1H), 2.85 (s, 3H), 3.09 (dd, $J=10.8,2.8 \mathrm{~Hz}, 1 \mathrm{H}), 3.25$ (dd, $J=9.5,7.7 \mathrm{~Hz}, 1 \mathrm{H}), 3.31$ (s, 1H), 3.52 (dd, $J=9.5,6.2 \mathrm{~Hz}, 1 \mathrm{H}$ ), 3.60 (dd, $J=10.8,9.8 \mathrm{~Hz}, 1 \mathrm{H}), 3.84$ (s, 3H), 4.32 (ddd, $J=9.8,7.0,2.8 \mathrm{~Hz}, 1 \mathrm{H}), 6.93$ (d, $J=1.7 \mathrm{~Hz}$, 1H), 6.96 (dd, $J=7.9,1.7 \mathrm{~Hz}, 1 \mathrm{H}), 7.25$ (d, $J=7.9 \mathrm{~Hz}, 1 \mathrm{H}) ;{ }^{13} \mathrm{C}-\mathrm{APT}\left\{{ }^{1} \mathrm{H}\right\} \mathrm{NMR}\left(100 \mathrm{MHz}, \mathrm{CDCl}_{3}\right) \delta$ 24.1, 24.5, 25.8, 28.1, 29.7, 35.0, 38.0, 41.4, 41.7, 55.2, 57.9, 59.0, 60.2, 69.4, 72.0, 72.1, 81.1, 110.4, 118.4, 126.5, 136.0, 140.3, 158.6, 169.2, 173.3; HRMS(ESI ${ }^{+}$) m/z $[\mathrm{M}+\mathrm{H}]^{+}$calcd for $\mathrm{C}_{29} \mathrm{H}_{48} \mathrm{NO}_{6}$ 506.3477, found 506.3488.

\subsubsection{3. (2S,4S,5R)-1-(4-(tert-Butyl)-3-methoxybenzoyl)-2-isobutyl-4,5-bis(methoxymethyl)pyrrolidine-} 2-carboxylic acid (21)

To a solution of compound $20(50.5 \mathrm{mg}, 0.1 \mathrm{mmol})$ in dichloromethane $(1.2 \mathrm{~mL})$ at $0{ }^{\circ} \mathrm{C}$ was added trifluoroacetic acid $(0.4 \mathrm{~mL})$ and the resulting solution was stirred at $0{ }^{\circ} \mathrm{C}$ for 14 hours. The reaction mixture was diluted with dichloromethane $(15 \mathrm{~mL})$, neutralised with saturated aqueous sodium hydrogen carbonate solution and carefully acidified at pH 1 with $1 \mathrm{M}$ hydrochloric acid. The organic layer was separated and the aqueous layer was extracted with dichloromethane (2 x $20 \mathrm{~mL})$. The combined organic extracts were washed with water $(10 \mathrm{~mL})$, dried over anhydrous $\mathrm{MgSO}_{4}$, filtered and evaporated under reduced pressure to give compound 21 (44.0 mg, 98\% yield) as a brown oil. [ $\alpha]_{D}{ }^{24}=$ -53.18 ( $c=1.00$ in $\mathrm{CHCl}_{3}$ ); IR (neat) 3400-2400, 1734, 1636, 1608, $1558 \mathrm{~cm}^{-1}$; ${ }^{1} \mathrm{H} \mathrm{NMR}(400 \mathrm{MHz}$, 
$\left.\mathrm{CDCl}_{3}\right) \delta 1.01$ (d, $\left.J=6.7 \mathrm{~Hz}, 3 \mathrm{H}\right), 1.02$ (d, $\left.J=6.6 \mathrm{~Hz}, 3 \mathrm{H}\right), 1.36$ (s, 9H), 1.75-1.89 (m, 1H), 2.00 (dd, $J=14.2,6.1 \mathrm{~Hz}, 1 \mathrm{H}), 2.19$ (dd, $J=13.4,8.0 \mathrm{~Hz}, 1 \mathrm{H}), 2.29$ (dd, $J=14.2,5.5 \mathrm{~Hz}, 1 \mathrm{H}), 2.59$ (dd, $J=$ 13.4, $13.4 \mathrm{~Hz}, 1 \mathrm{H}), 2.72-2.85$ (m, 1H), 3.18 (dd, $J=10.2,4.5 \mathrm{~Hz}, 1 \mathrm{H}), 3.21$ (s, 3H), 3.25 (dd, $J=10.2$, $4.5 \mathrm{~Hz}, 1 \mathrm{H}), 3.31$ (s, 3H), 3.31 (dd, $J=9.5,9.5 \mathrm{~Hz} 1 \mathrm{H}), 3.42$ (dd, $J=9.5,5.5 \mathrm{~Hz}, 1 \mathrm{H}), 3.85$ (s, 3H), 4.42 (ddd, $\mathrm{J}=7.6,4.5,4.5 \mathrm{~Hz}, 1 \mathrm{H}$ ), 6.91 (dd, $J=8.0,1.7 \mathrm{~Hz}, 1 \mathrm{H}), 6.96$ (d, $J=1.7 \mathrm{~Hz}, 1 \mathrm{H}$ ), 7.27 (d, $J=$ 8.0 Hz, 1H); ${ }^{13} \mathrm{C}-\mathrm{APT}\left\{{ }^{1} \mathrm{H}\right\} \mathrm{NMR}\left(100 \mathrm{MHz} \mathrm{CDCl}_{3}\right) \delta 24.5,24.6,24.9,29.6,35.2,36.7,39.2,42.5$, 55.4, 59.1, 59.2, 63.1, 71.4, 71.9, 72.6, 110.9, 118.5, 126.8, 134.6, 141.6, 159.0, 173.8, 174.2; HRMS(ESI $\left.{ }^{+}\right) \mathrm{m} / \mathrm{z}[\mathrm{M}+\mathrm{Na}]^{+}$calcd for $\mathrm{C}_{25} \mathrm{H}_{39} \mathrm{NNaO}_{6}$ 472.2670, found 472.2687.

\subsubsection{2-(tert-Butyl) 5-methyl (2S,4S,5R)-1-(4-(tert-butyl)-3-methoxybenzoyl)-2-isobutyl-4-} (methoxymethyl)pyrrolidine-2,5-dicarboxylate (22)

A solution of compound 7 (97.9 mg, $0.2 \mathrm{mmol})$ in tert-butanol $(8 \mathrm{~mL})$ was diluted with an aqueous 1.25 $\mathrm{M}$ sodium phosphate buffer $(2 \mathrm{~mL})$ and the resulting mixture at room temperature was treated with an aqueous $1 \mathrm{M}$ potassium permanganate solution $(1.2 \mathrm{~mL}, 1.2 \mathrm{mmol})$ and vigorously stirred for 2 hours. Then, saturated aqueous sodium sulfite solution $(4 \mathrm{~m}<\mathrm{l})$ was added and the $\mathrm{pH}$ of the mixture was adjusted to 3 with $1 \mathrm{M}$ hydrochloric acid. The reaction mixture was diluted with diethyl ether (20 $\mathrm{mL}$ ) and the organic layer was separated. The aqueous layer was extracted with diethyl ether (2 x 20 $\mathrm{mL}$ ) and the combined organic extracts were dried over anhydrous MgS $\mathrm{O}$ filtered and evaporated under reduced pressure to afford a residue containing the crude acid. A stirred solution of the resulting crude acid in methanol (5 mL) was treated with a $2 \mathrm{M}$ solution of (trimethylsilyl)diazomethane in diethyl ether at room temperature until yellow color persisted. The reaction mixture was stirred for 1 hour and then quenched with a few drops of acetic acid until yellow color disappeared. The solvent was removed under reduced pressure and the residue was purified by flash chromatography (eluent: diethyl ether/hexane, 1/2) to afford compound 22 (92.5 mg, 89\% yield) as a white solid. M.p. $=154{ }^{\circ} \mathrm{C}$; $\left.\alpha\right]_{\mathrm{D}}{ }^{24}$ $=45.14$ ( $c=1.01$ in $\mathrm{CHCl}_{3}$ ); IR (nujol) 1753, 1737, 1720, 1631, 1609, $1567 \mathrm{~cm}^{-1}$; ${ }^{1} \mathrm{H} \mathrm{NMR}(400 \mathrm{MHz}$, $\left.\mathrm{CDCl}_{3}\right) \delta 1.00$ (d, $\left.J=6.3 \mathrm{~Hz}, 3 \mathrm{H}\right) ; 1.02$ (d, $\left.J=6.3 \mathrm{~Hz}, 3 \mathrm{H}\right), 1.33$ (s, 9H), 1.54 (s, 9H), 1.82-1.93 (m, 1H), 2.07-2.27 (m, 4H), 2.84-2.96 (m, 1H), 3.23 (s, 3H), 3.23-3.29 (m, 2H), 3.37 (s, 3H), 3.80 (s, 3H), 4.48 (d, $J=8.7 \mathrm{~Hz}, 1 \mathrm{H}), 6.73$ (d, $J=1.7 \mathrm{~Hz}, 1 \mathrm{H}), 6.75$ (dd, $J=7.8,1.7 \mathrm{~Hz}, 1 \mathrm{H}), 7.20$ (d, $J=7.8$ $\mathrm{Hz}, 1 \mathrm{H}) ;{ }^{13} \mathrm{C}-\mathrm{APT}\left\{{ }^{1} \mathrm{H}\right\} \mathrm{NMR}\left(100 \mathrm{MHz}, \mathrm{CDCl}_{3}\right) \delta$ 24.4, 24.9, 25.6, 28.1, 29.7, 35.0, 37.6, 41.5, 42.7, 51.5, 55.1, 59.1, 64.4, 70.6, 71.8, 81.0, 109.5, 117.5, 126.5, 136.0, 139.6, 158.4, 169.2, 170.3, 171.8; $\operatorname{HRMS}\left(\mathrm{ESI}^{+}\right) \mathrm{m} / \mathrm{z}[\mathrm{M}+\mathrm{H}]^{+}$calcd for $\mathrm{C}_{29} \mathrm{H}_{46} \mathrm{NO}_{7} 520.3269$, found 520.3281 . 
4.1.25.

(2S,4S,5R)-1-(4-(tert-Butyl)-3-methoxybenzoyl)-2-isobutyl-5-(methoxycarbonyl)-4-

(methoxymethyl)pyrrolidine-2-carboxylic acid (23)

To a solution of compound $22(52.0 \mathrm{mg}, 0.1 \mathrm{mmol})$ in dichloromethane $(1.2 \mathrm{~mL})$ at $0{ }^{\circ} \mathrm{C}$ was added trifluoroacetic acid $(0.4 \mathrm{~mL})$ and the resulting solution was stirred at $0{ }^{\circ} \mathrm{C}$ for 14 hours. The reaction mixture was diluted with dichloromethane $(15 \mathrm{~mL})$, neutralised with saturated aqueous sodium hydrogen carbonate solution and carefully acidified at $\mathrm{pH} 1$ with $1 \mathrm{M}$ hydrochloric acid. The organic layer was separated and the aqueous layer was extracted with dichloromethane (2 x $20 \mathrm{~mL})$. The combined organic extracts were washed with water $(10 \mathrm{~mL})$, dried over anhydrous $\mathrm{MgSO}_{4}$, filtered and evaporated under reduced pressure to give compound 23 (44.0 mg, 97\% yield) as a brown solid. M.p. = $107^{\circ} \mathrm{C} ;[\alpha]_{\mathrm{D}}{ }^{24}=-13.35\left(c=1.06 \mathrm{in} \mathrm{CHCl}_{3}\right.$ ); IR (nujol) 3500-2400, 1753, 1717, 1628, $1564 \mathrm{~cm}^{-1} ;{ }^{1} \mathrm{H}$ NMR (400 MHz, $\left.\mathrm{CDCl}_{3}\right) \delta 1.02(\mathrm{~d}, J=6.6 \mathrm{~Hz}, 6 \mathrm{H}), 1.34(\mathrm{~s}, 9 \mathrm{H}), 1.75-1.88(\mathrm{~m}, 1 \mathrm{H}), 2.08(\mathrm{dd}, J=$ 14.5, 7.2 Hz, 1H), 2.20 (dd, $J=13.6,7.0 \mathrm{~Hz}, 1 \mathrm{H}$ ), 2.36 (dd, $J=14.5,4.8 \mathrm{~Hz}, 1 \mathrm{H}), 2.57$ (dd, $J=13.6$, $11.4 \mathrm{~Hz}, 1 \mathrm{H}), 2.77-2.91$ (m, 1H), 3.23 (s, 3H), 3.27 (dd, $J=9.9,6.8 \mathrm{~Hz}, 1 \mathrm{H}), 3.33$ (dd, $J=9.9,4.6 \mathrm{~Hz}$, 1H), 3.54 (s, 3H), 3.81 (s, 3H), 4.64 (d, $J=8.1 \mathrm{~Hz}, 1 \mathrm{H}), 6.74-6.8$ (m, 2H), 7.25 (d, $J=7.9 \mathrm{~Hz}, 1 \mathrm{H})$; ${ }^{13} \mathrm{C}-\mathrm{APT}\left\{{ }^{1} \mathrm{H}\right\}$ NMR $\left(100 \mathrm{MHz}, \mathrm{CDCl}_{3}\right) \delta 24.2,24.8,24.8,29.5,35.2,36.3,41.4,42.3,52.9,55.3,59.1$, 65.5, 70.4, 72.7, 109.8, 117.7, 126.9, 134.0, 141.3, 158.8, 172.5, 173.0, 173.0; HRMS(ESI) m/z $[\mathrm{M}+\mathrm{Na}]^{+}$calcd for $\mathrm{C}_{25} \mathrm{H}_{37} \mathrm{NNaO}_{7} 486.2463$, found 486.2448.

\subsubsection{6. tert-Butyl (2S,4S,5S)-1-(4-(tert-butyl)-3-methoxybenzoyl)-2-isobutyl-4-(methoxymethyl)-5-} vinylpyrrolidine-2-carboxylate (24)

To a suspension of methyl triphenylphosphonium bromide (428.7 mg, $1.2 \mathrm{mmol}$ ) in dry toluene (9 mL) at $0{ }^{\circ} \mathrm{C}$ and under argon atmosphere was added potassium tert-butoxide (112.2 $\mathrm{mg}, 1.0 \mathrm{mmol}$ ) and the mixture was stirred at room temperature for 2 hours. Then, a solution of aldehyde 7 (98.0 mg, 0.2 mmol) in dry toluene ( $3 \mathrm{~mL}$ ) was added dropwise and the reaction was allowed to proceed for 24 hours. The reaction was quenched with saturated aqueous ammonium chloride solution (10 mL) and extracted with ethyl ether (2 x $20 \mathrm{~mL})$. The combined organic extracts were dried over anhydrous $\mathrm{MgSO}_{4}$, filtered and evaporated under reduced pressure and the residue was purified by flash chromatography (eluent: diethyl ether/hexane, 1/1) to afford compound 24 (88.6 mg, 91\% yield) as a white solid. M.p. $=162{ }^{\circ} \mathrm{C}$; $[\alpha]_{\mathrm{D}}{ }^{24}=-27.86\left(c=0.96\right.$ in $\mathrm{CHCl}{ }_{3}$ ); IR (nujol) 3076, 1728, 1653, 1610, $1567 \mathrm{~cm}^{-1}$; ${ }^{1} \mathrm{H}$ NMR (400 MHz, $\mathrm{CDCl}_{3}$ ) $\delta 1.01$ (d, $\left.J=6.6 \mathrm{~Hz}, 3 \mathrm{H}\right), 1.05$ (d, $\left.J=6.5 \mathrm{~Hz}, 3 \mathrm{H}\right), 1.33$ (s, 9H), 1.52 (s, 9H), 1.82-1.92 (m, 1H), 1.90 (dd, $J=13.1,13.1 \mathrm{~Hz}, 1 \mathrm{H}), 2.04$ (dd, $J=14.8,3.7 \mathrm{~Hz}, 1 \mathrm{H}$ ), 2.15 (dd, $J=13.1,6.7 \mathrm{~Hz}, 1 \mathrm{H}), 2.29$ (dd, $J=14.8,8.2 \mathrm{~Hz}, 1 \mathrm{H}), 2.75-2.87$ (m, 1H), 3.20 (d, $J=7.1 \mathrm{~Hz}$, 
2H), 3.24 (s, 3H), 3.79 (s, 3H), 4.35 (dd, $J=17.2,1.6 \mathrm{~Hz}, 1 \mathrm{H}), 4.52$ (dd, $J=9.4,8.0 \mathrm{~Hz}, 1 \mathrm{H}$ ), 4.79 (dd, $J=10.2,1.6 \mathrm{~Hz}, 1 \mathrm{H}), 5.87$ (ddd, $J=17.2,10.2,9.4 \mathrm{~Hz}, 1 \mathrm{H}), 6.77$ (d, $J=1.7 \mathrm{~Hz}, 1 \mathrm{H}), 6.83$ (dd, $J=7.9$, $1.7 \mathrm{~Hz}, 1 \mathrm{H}), 7.18$ (d, $J=7.9 \mathrm{~Hz}, 1 \mathrm{H}), 9.6 \mathrm{~Hz}, 1 \mathrm{H}) ; 6.77$ (d, J=1.6 Hz, 1H); 6.83 (dd, J=7.9, 1.6 Hz, 1H); 7.18 (d, J=7.9 Hz, 1H), ${ }^{13} \mathrm{C}-\mathrm{APT}\left\{{ }^{1} \mathrm{H}\right\}$ NMR (100 MHz, CDCl) $\delta$ 24.1, 24.6, 25.8, 28.1, 29.7, 35.0, 37.9, 41.8, 41.9, 55.2, 59.1, 66.1, 69.8, 72.5, 81.2, 110.5, 117.6, 118.2, 126.0, 134.0, 136.5, 139.7, 158.2, 169.9, 173.3; HRMS(ESI $\left.{ }^{+}\right) \mathrm{m} / \mathrm{z}[\mathrm{M}+\mathrm{H}]^{+}$calcd for $\mathrm{C}_{29} \mathrm{H}_{46} \mathrm{NO}_{5}$ 488.3371, found 488.3370.

4.1.27. tert-Butyl (2S,4S,5S)-1-(4-(tert-butyl)-3-methoxybenzoyl)-5-ethyl-2-isobutyl-4(methoxymethyl)pyrrolidine-2-carboxylate (25)

A solution of compound 24 (48.7 mg, $0.1 \mathrm{mmol})$ in ethanol (5 mL) was hydrogenated with $\mathrm{Pd} / \mathrm{C} 10 \%$ (20 mg) as catalyst at room temperature for 12 hours. The catalyst was removed by filtration through a short Celite ${ }^{\circledR}$ pad and the filtrate evaporated to dryness to afford compound 25 (45.5 mg, 93\% yield) as a white solid. M.p. $=152{ }^{\circ} \mathrm{C}$; $[\alpha]_{\mathrm{D}}{ }^{24}=-8.40\left(c=1.04\right.$ in $\mathrm{CHCl}_{3}$ ); IR (nujol) 1728, 1621, $1567 \mathrm{~cm}^{-1} ;{ }^{1} \mathrm{H}$ NMR (400 MHz, $\mathrm{CDCl}_{3}$ ) $\delta 0.46(\mathrm{t}, J=7.5 \mathrm{~Hz}, 3 \mathrm{H}), 1.00$ (d, $\left.J=6.6 \mathrm{~Hz}, 3 \mathrm{H}\right), 1.01$ (d, $\left.J=6.6 \mathrm{~Hz}, 3 \mathrm{H}\right)$, 1.34 (s, 9H), 1.44-1.58 (m, 2H), 1.49 (s, 9H), 1.78-1.92 (m, 1H), 1.87 (dd, $J=12.7,12.7 \mathrm{~Hz}, 2 \mathrm{H}$ ), 1.99 (dd, $J=15.1,3.9 \mathrm{~Hz}, 1 \mathrm{H}), 2.09$ (dd, $J=12.7,6.5 \mathrm{~Hz}, 1 \mathrm{H}$ ), 2.31 (dd, $J=15.1,7.7 \mathrm{~Hz}, 1 \mathrm{H}$ ), 2.78-2.91 (m, 1H), 3.29 (s, 3H), 3.26-3.39 (m, 2H), 3.82 (s, 3H), 4.06-4.16 (m, 1H), 6.90-6.95 (m, 2H), 7.22 (d, $J=8.3 \mathrm{~Hz}, 1 \mathrm{H}) ;{ }^{13} \mathrm{C}-\mathrm{APT}\left\{{ }^{1} \mathrm{H}\right\} \mathrm{NMR}\left(100 \mathrm{MHz}, \mathrm{CDCl}_{3}\right) \delta 11.9,24.3,24.5,25.6,25.8$, 28.1, 29.7, 35.0, 37.3, 41.6, 42.1, 55.2, 58.9, 63.9, 69.1, 71.8, 80.9, 110.8, 118.6, 126.2, 136.6, 139.9, 158.5, 169.5, 173.5; HRMS(ESI ${ }^{+}$) $/ z$ [M+H] ${ }^{+}$calcd for $\mathrm{C}_{29} \mathrm{H}_{48} \mathrm{NO}_{5} 490.3527$, found 490.3540 .

4.1.28.

(2S,4S,5S)-1-(4-(tert-Butyl)-3-methoxybenzoyl)-5-ethyl-2-isobutyl-4-

(methoxymethyl)pyrrolidine-2-carboxylic acid (26)

To a solution of compound $25(24.5 \mathrm{mg}, 0.05 \mathrm{mmol})$ in dichloromethane $(0.6 \mathrm{~mL})$ at $0{ }^{\circ} \mathrm{C}$ was added trifluoroacetic acid $(0.2 \mathrm{~mL})$ and the resulting solution was stirred at $0{ }^{\circ} \mathrm{C}$ for 14 hours. The reaction mixture was diluted with dichloromethane $(15 \mathrm{~mL})$, neutralised with saturated aqueous sodium hydrogen carbonate solution and carefully acidified at $\mathrm{pH} 1$ with $1 \mathrm{M}$ hydrochloric acid. The organic layer was separated and the aqueous layer was extracted with dichloromethane (2 x $10 \mathrm{~mL})$. The combined organic extracts were washed with water $(10 \mathrm{~mL})$, dried over anhydrous $\mathrm{MgSO}_{4}$, filtered and evaporated under reduced pressure to give compound 26 (21.0 mg, 97\% yield) as a brown oil. [ $\alpha]_{\mathrm{D}}{ }^{24}=$ -106.76 (c = 1.00 in $\mathrm{CHCl}_{3}$ ); IR (neat) 3500-2300, 1740, 1635, 1607, $1542 \mathrm{~cm}^{-1} ;{ }^{1} \mathrm{H} \mathrm{NMR}(400 \mathrm{MHz}$, $\left.\mathrm{CDCl}_{3}\right) \delta 0.66(\mathrm{t}, J=7.4 \mathrm{~Hz}, 3 \mathrm{H}), 0.98(\mathrm{~d}, J=6.6 \mathrm{~Hz}, 3 \mathrm{H}) ; 1.00(\mathrm{~d}, J=6.6 \mathrm{~Hz}, 3 \mathrm{H}), 1.37$ (s, 9H), 
1.30-1.40 (m, 2H), 1.74-1.84 (m, 2H), 2.16-2.26 (m, 1H), 2.40-2.47 (m, 1H), 2.64-2.76 (m, 2H), 3.31 (s, 3H), 3.31 (dd, $J=9.6,9.6 \mathrm{~Hz}, 1 \mathrm{H}), 3.41$ (dd, $J=9.6,4.8 \mathrm{~Hz}, 1 \mathrm{H}), 3.86$ (s, 3H), 4.35 (ddd, $J=$ 10.0, 4.8, $4.8 \mathrm{~Hz}, 1 \mathrm{H}), 6.94$ (dd, $J=7.9,1.7 \mathrm{~Hz}, 1 \mathrm{H}), 6.98$ (d, $J=1.7 \mathrm{~Hz}, 1 \mathrm{H}), 7.29$ (d, $J=7.9 \mathrm{~Hz}, 1 \mathrm{H})$; ${ }^{13} \mathrm{C}-\mathrm{APT}\left\{{ }^{1} \mathrm{H}\right\} \mathrm{NMR}\left(100 \mathrm{MHz}, \mathrm{CDCl}_{3}\right) \delta 10.8,22.8,23.9,24.7,25.0,29.6,35.3,35.6,40.1,42.4,55.4$, 59.2, 66.0, 71.7, 72.2, 111.6, 119.5, 126.9, 134.2, 142.3, 159.0, 174.5, 175.0; HRMS(ESI ${ }^{+}$m/z $[\mathrm{M}+\mathrm{Na}]^{+}$calcd for $\mathrm{C}_{25} \mathrm{H}_{39} \mathrm{NNaO}_{5} 456.2721$, found 456.2741.

\subsubsection{9. tert-Butyl (2S,4S,5R)-5-(acetoxymethyl)-1-(4-(tert-butyl)-3-methoxybenzoyl)-2-isobutyl-4-} (methoxymethyl)pyrrolidine-2-carboxylate (27)

A solution of compound 7 (97.9 $\mathrm{mg}, 0.2 \mathrm{mmol})$ in ethanol $(2 \mathrm{~mL})$ was reacted with sodium borohydride (75.7 mg, $2 \mathrm{mmol}$ ) for 16 hours at room temperature. The reaction was quenched with saturated aqueous ammonium chloride solution $(2 \mathrm{~mL})$ and concentrated under reduced pressure. The residue was partitioned between dichloromethane $(20 \mathrm{~mL})$ and water $(10 \mathrm{~mL})$, the organic layer was separated and the aqueous layer extracted with dichloromethane $(2 \times 10 \mathrm{~mL})$. The combined organic extracts were dried over anhydrous $\mathrm{MgSO}_{4}$, filtered and evaporated under reduced pressure to afford a residue containing the crude alcohol. To a stirred solution of the crude alcohol in pyridine (5 mL) was successively added DMAP (12.2 mg, $0.1 \mathrm{mmol})$ and acetic anhydride (2.04, $20.0 \mathrm{mmol})$ and the resulting mixture was stirred at room temperature for 18 hours. Then, the reaction mixture was evaporated under reduced pressure and the residue was partitioned between dichloromethane (20 mL) and water $(10 \mathrm{~mL})$. The organic layer was separated and the aqueous layer extracted with dichloromethane (2 x $10 \mathrm{~mL}$ ). The combined organic extracts were dried over anhydrous MgSQ filtered and evaporated under reduced pressure. The crude product was purified by flash chromatography (eluent: diethyl ether/hexane, 1/1) to afford compound 27 (103.5 mg, 97\% yield) as a white solid. M.p. $=79{ }^{\circ} \mathrm{C}$; $[\alpha]_{\mathrm{D}}{ }^{24}=14,16\left(c=1.25\right.$ in $\mathrm{CHCl} \quad 3$ ); IR (nujol) 1736, 1622, $1566 \mathrm{~cm}^{-1} ;{ }^{1} \mathrm{H}$ NMR (400 MHz, CDCl $) \delta 0.99$ (d, $J=6.6 \mathrm{~Hz}, 3 \mathrm{H}), 1.00$ (d, $J=6.6 \mathrm{~Hz}, 3 \mathrm{H}), 1.33$ (s, 9H), 1.48 (s, 9H), 1.75 (s, 3H), 1.77-1.88 (m, 1H), 1.90 (dd, $J=13.2,13.2$ Hz, 1H), 1.99 (dd, $J=14.9,3.7$ Hz, 1H), 2.17 (dd, $J=13.2,6.9 \mathrm{~Hz}, 1 \mathrm{H}), 2.31$ (dd, $J=14.9,8.1 \mathrm{~Hz}, 1 \mathrm{H}$ ), 2.83-2.95 (m, 1H), 3.29 (s, 3H), 3.31 (dd, $J$ = 9.5, $6.8 \mathrm{~Hz}, 1 \mathrm{H}$ ), 3.38 (dd, $J=9.5,7.5 \mathrm{~Hz}, 1 \mathrm{H}$ ), 3.82 (s, 3H), 3.89 (dd, $J=11.6,5.2 \mathrm{~Hz}, 1 \mathrm{H}$ ), 4.23 (dd, $J=11.6,7.3 \mathrm{~Hz}, 1 \mathrm{H}), 6.91-6.96$ (m, 2H), 7.22 (d, $J=7.8 \mathrm{~Hz}, 1 \mathrm{H}) ;{ }^{13} \mathrm{C}-\mathrm{APT}\left\{{ }^{1} \mathrm{H}\right\} \mathrm{NMR}(100 \mathrm{MHz}$, $\left.\mathrm{CDCl}_{3}\right) \delta 20.7,24.2,24.4,25.8,28.0,29.6,35.0,37.3,41.3,41.3,55.1,59.1,60.3,63.5,69.4,71.4$, 81.3, 110.7, 118.4, 126.4, 135.8, 140.2, 158.6, 169.4, 170.3, 173.0; HRMS(ESI ${ }^{+}$) $\mathrm{m} / \mathrm{z}[\mathrm{M}+\mathrm{H}]^{+}$calcd for $\mathrm{C}_{30} \mathrm{H}_{48} \mathrm{NO}_{7}$ 534.3426, found 534.3447. 
4.1.30.

(2S,4S,5R)-5-(Acetoxymethyl)-1-(4-(tert-butyl)-3-methoxybenzoyl)-2-isobutyl-4(methoxymethyl)pyrrolidine-2-carboxylic acid (28)

To a solution of compound 27 (53.4 $\mathrm{mg}, 0.1 \mathrm{mmol})$ in dichloromethane $(1.2 \mathrm{~mL})$ at $0{ }^{\circ} \mathrm{C}$ was added trifluoroacetic acid $(0.4 \mathrm{~mL})$ and the resulting solution was stirred at $0{ }^{\circ} \mathrm{C}$ for 6 hours. The reaction mixture was diluted with dichloromethane $(15 \mathrm{~mL})$, neutralised with saturated aqueous sodium hydrogen carbonate solution and carefully acidified at $\mathrm{pH} 1$ with $1 \mathrm{M}$ hydrochloric acid. The organic layer was separated and the aqueous layer was extracted with dichloromethane (2 x $20 \mathrm{~mL})$. The combined organic extracts were washed with water $(10 \mathrm{~mL})$, dried over anhydrous $\mathrm{MgSO}_{4}$, filtered and evaporated under reduced pressure to give compound 28 (46.7 mg, 98\% yield) as a brownish oil. $[\alpha]_{D}{ }^{24}$ $=-72.69\left(c=1.06\right.$ in $\left.\mathrm{CHCl}_{3}\right)$; IR (neat) 3700-2200, 1739, 1638, 1609, $1564 \mathrm{~cm}^{-1} ;{ }^{1} \mathrm{H} \mathrm{NMR}(400 \mathrm{MHz}$, $\left.\mathrm{CDCl}_{3}\right) \delta 1.00$ (d, $\left.J=6.6 \mathrm{~Hz}, 3 \mathrm{H}\right), 1.00$ (d, $\left.J=6.6 \mathrm{~Hz}, 3 \mathrm{H}\right), 1.36$ (s, 9H), 1.75-1.86 (m, 1H), 1.88 (dd, $J=13.8,5.6 \mathrm{~Hz}, 1 \mathrm{H}), 2.02$ (s, 3H), 2.22 (dd, $J=11.6,5.9 \mathrm{~Hz}, 1 \mathrm{H}), 2.36$ (dd, $J=13.8,5.7 \mathrm{~Hz}, 1 \mathrm{H})$, 2.67-2.84 (m, 2H), 3.29 (s, 3H), 3.29 (dd, $J=9.6,9.6$ Hz, 1H), 3.48 (dd, $J=9.6,4.7$ Hz, 1H), 3.78 (dd, $J=12.2,3.8 \mathrm{~Hz}, 1 \mathrm{H}), 3.86$ (s, 3H), 4.06 (dd, $J=12.2$, $3.8 \mathrm{~Hz}, 1 \mathrm{H}), 4.53$ (ddd, $J=7.3,3.8,3.8 \mathrm{~Hz}, 1 \mathrm{H}$ ), 6.90 (dd, $J=7.9,1.7 \mathrm{~Hz}, 1 \mathrm{H}), 6.96$ (d, $J=1.7 \mathrm{~Hz}, 1 \mathrm{H}), 7.29(\mathrm{~d}, J=7.9 \mathrm{~Hz}, 1 \mathrm{H}) ; \quad{ }^{13} \mathrm{C}-\mathrm{APT}\left\{{ }^{1} \mathrm{H}\right\} \mathrm{NMR}$ $\left(100 \mathrm{MHz} \mathrm{CDCl}_{3}\right) \delta 21.0,24.0,24.6,25.0,29.5,35.2,36.6,38.4,42.7,55.3,59.3,62.4,62.8,71.6$, 74.0, 110.6, 118.2, 127.0, 133.8, 141.9, 159.0, 170.8, 173.9, 174.7; HRMS(ESI $\left.{ }^{+}\right) \mathrm{m} / \mathrm{z}[\mathrm{M}+\mathrm{Na}]^{+}$ $\mathrm{C}_{26} \mathrm{H}_{39} \mathrm{NNaO}_{7}$ 500.2619, found 500.2603.

\subsubsection{1. tert-Butyl (2S,4S,5R)-5-((allyloxy)methyl)-1-(4-(tert-butyl)-3-methoxybenzoyl)-2-isobutyl-4-} (methoxymethyl)pyrrolidine-2-carboxylate (29)

A solution of compound 7 (97.9 $\mathrm{mg}, 0.2 \mathrm{mmol})$ in ethanol $(2 \mathrm{~mL})$ was reacted with sodium borohydride (75.7 $\mathrm{mg}, 2 \mathrm{mmol})$ for 16 hours at room temperature. The reaction was quenched with saturated aqueous ammonium chloride solution (2 mL) and concentrated under reduced pressure. The residue was partitioned between dichloromethane $(20 \mathrm{~mL})$ and water $(10 \mathrm{~mL})$, the organic layer was separated and the aqueous layer extracted with dichloromethane (2 x $10 \mathrm{~mL}$ ). The combined organic extracts were dried over anhydrous $\mathrm{MgSO}_{4}$, filtered and evaporated under reduced pressure to afford a residue containing the crude alcohol. To a stirred solution of the crude alcohol in dry THF (5 mL) under argon at $0{ }^{\circ} \mathrm{C}$ was added sodium hydride (16.0 $\mathrm{mg}$ of a $60 \%$ dispersion in mineral oil, $0.4 \mathrm{mmol}$ ) and the mixture was stirred at room temperature for $15 \mathrm{~min}$. Then, allylbromide (173 ml, $242 \mathrm{mg}, 2.0$ mmol) was added and the slurry was stirred for 18 hours at room temperature. The resulting reaction 
mixture was quenched with saturated aqueous $\mathrm{NLCl}$ solution $(10 \mathrm{~mL})$ and the organic solvent was evaporated under reduced pressure. The aqueous phase was extracted with dichloromethane (3 x 20 $\mathrm{mL}$ ) and the combined organic layers were dried over anhydrous MgS $\mathrm{O}$ filtered and concentrated under reduced pressure. The crude product was purified by flash chromatography (eluent: diethyl ether/hexane, 1/1) to provide compound 29 (101.0 mg, 95\% yield) as a white solid. M.p. $=97^{\circ} \mathrm{C} ;[\alpha]_{\mathrm{D}}{ }^{24}$ $=20.90\left(c=1.15\right.$ in $\mathrm{CHCl}_{3}$ ); IR (nujol) 1725, 1624, $1566 \mathrm{~cm}^{-1} ;{ }^{1} \mathrm{H}$ NMR (400 MHz, CDCl $\left.{ }_{3}\right) \delta 0.99$ (d, $J=6.6 \mathrm{~Hz}, 3 \mathrm{H}), 1.02$ (d, $J=6.5 \mathrm{~Hz}, 3 \mathrm{H}), 1.33$ (s, 9H), 1.48 (s, 9H), 1.78-1.88 (m, 1H), 1.89 (dd, $J=$ 13.1, $13.1 \mathrm{~Hz}, 1 \mathrm{H}), 1.98$ (dd, $J=14.8,3.5 \mathrm{~Hz}, 1 \mathrm{H}), 2.22$ (dd, $J=13.1,6.8 \mathrm{~Hz}, 1 \mathrm{H}), 2.29$ (dd, $J=14.8$, 8.4 Hz, 1H), 2.79-2.91 (m, 1H), 3.17 (dd, $J=10.9,2.7 \mathrm{~Hz}, 1 \mathrm{H}), 3.27$ (dd, $J=9.6,7.8 \mathrm{~Hz}, 1 \mathrm{H}$ ), 3.30 (s, 3H), 3.35-3.42 (m, 1H), 3.43-3.50 (m, 1H), 3.56 (dd, $J=9.6,6.3 \mathrm{~Hz}, 1 \mathrm{H}), 3.57$ (dd, $J=10.9,10.9 \mathrm{~Hz}$, 1H), 3.83 (s, 3H), 4.31 (ddd, $J=9.8,7.0,2.7 \mathrm{~Hz}, 1 \mathrm{H}$ ), 4.90 (ddd, $J=17.2$, 3.3, $1.5 \mathrm{~Hz}, 1 \mathrm{H}$ ), 4.97 (dq, $J$ = 10.4, 2.9, $1.3 \mathrm{~Hz}, 1 \mathrm{H}), 5.49$ (dddd, $J=17.2,10.7,5.4,5.4 \mathrm{~Hz}, 1 \mathrm{H}), 6.90$ (d, $J=1.7 \mathrm{~Hz}, 1 \mathrm{H}), 6.95$ (dd, $J=7.9,1.7 \mathrm{~Hz}, 1 \mathrm{H}), 7.25(\mathrm{~d}, J=7.9 \mathrm{~Hz}, 1 \mathrm{H}) ; \quad{ }^{13} \mathrm{C}-\mathrm{APT}\left\{{ }^{1} \mathrm{H}\right\} \mathrm{NMR}\left(100 \mathrm{MHz}, \mathrm{CDCl}_{3}\right) \delta 24.0,24.4$, 25.8, 28.1, 29.6, 35.0, 38.1, 41.3, 41.7, 55.1, 59.0, 60.7, 69.2, 69.4, 71.1, 72.1, 81.0, 110.4, 116.6, 118.3, 126.5, 134.5, 135.9, 140.1, 158.6, 169.2, 173.2; HRMS(ESI ${ }^{+}$) $m / z[M+H]^{+}$calcd for $\mathrm{C}_{31} \mathrm{H}_{50} \mathrm{NO}_{6}$ 532.3633, found 532.3646.

\subsubsection{2. (2S,4S,5R)-5-((Allyloxy)methyl)-1-(4-(tert-butyl)-3-methoxybenzoyl)-2-isobutyl-4-} (methoxymethyl)pyrrolidine-2-carboxylic acid (30)

To a solution of compound $29(53.2 \mathrm{mg}, 0.1 \mathrm{mmol})$ in dichloromethane $(1.2 \mathrm{~mL})$ at $0{ }^{\circ} \mathrm{C}$ was added trifluoroacetic acid $(0.4 \mathrm{~mL})$ and the resulting solution was stirred at $0{ }^{\circ} \mathrm{C}$ for 6 hours. The reaction mixture was diluted with dichloromethane $(15 \mathrm{~mL})$, neutralised with saturated aqueous sodium hydrogen carbonate solution and carefully acidified at $\mathrm{pH} 1$ with $1 \mathrm{M}$ hydrochloric acid. The organic layer was separated and the aqueous layer was extracted with dichloromethane (2 x $20 \mathrm{~mL})$. The combined organic extracts were washed with water $(10 \mathrm{~mL})$, dried over anhydrous $\mathrm{MgSO}_{4}$, filtered and evaporated under reduced pressure to give compound 30 (47.1 mg, 99\% yield) as a brownish oil. [ $\alpha]_{D}{ }^{24}$ $=-52.62\left(c=1.05\right.$ in $\left.\mathrm{CHCl}_{3}\right)$; IR (neat) 3700-2100, 1739, 1641, 1608, $1550 \mathrm{~cm}^{-1} ;{ }^{1} \mathrm{H} \mathrm{NMR}(400 \mathrm{MHz}$, $\left.\mathrm{CDCl}_{3}\right) \delta 1.00$ (d, $\left.J=6.7 \mathrm{~Hz}, 3 \mathrm{H}\right) ; 1.01$ (d, $\left.J=6.6 \mathrm{~Hz}, 3 \mathrm{H}\right), 1.35$ (s, 9H), 1.75-1.88 (m, 1H), 1.97 (dd, $J=14.2,6.0 \mathrm{~Hz}, 1 \mathrm{H}), 2.20$ (dd, $J=13.3,7.8 \mathrm{~Hz}, 1 \mathrm{H}), 2.30$ (dd, $J=14.2,5.6 \mathrm{~Hz}, 1 \mathrm{H}), 2.62$ (dd, $J=$ 13.3, $13.3 \mathrm{~Hz}, 1 \mathrm{H}), 2.71-2.84$ (m, 1H), 3.20-3.28 (m, 2H), 3.30 (s, 3H), 3.32 (dd, $J=9.5,9.5 \mathrm{~Hz}, 1 \mathrm{H}$ ), 3.42 (dd, $J=9.5,5.6 \mathrm{~Hz}, 1 \mathrm{H}), 3.79-3.83$ (m, 2H), 3.84 (s, 3H), 4.45 (ddd, $J=7.4,4.8,4.8 \mathrm{~Hz}, 1 \mathrm{H}$ ), 5.12-5.16 (m, 1H), 5.16-5.19 (m, 1H), 5.79 (dddd, $J=17.8,9.8,5.9,5.9$ Hz, 1H), 6.90 (dd, $J=7.9$, 
$1.7 \mathrm{~Hz}, 1 \mathrm{H}), 6.95$ (d, $J=1.7 \mathrm{~Hz}, 1 \mathrm{H}), 7.26$ (d, $J=7.9 \mathrm{~Hz}, 1 \mathrm{H}) ;{ }^{13} \mathrm{C}-\mathrm{APT}\left\{{ }^{1} \mathrm{H}\right\} \mathrm{NMR}\left(100 \mathrm{MHz}, \mathrm{CDCl}_{3}\right)$ S 24.4, 24.6, 24.9, 29.6, 35.2, 36.6, 39.0, 42.5, 55.3, 59.2, 63.2, 68.4, 71.8, 72.5, 72.7, 111.0, 118.3,

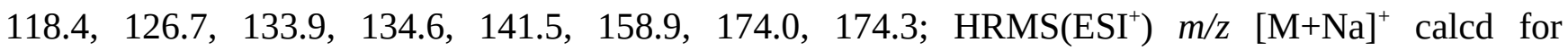
$\mathrm{C}_{27} \mathrm{H}_{41} \mathrm{NNaO}_{6}$ 498.2827, found 498.2841.

4.1.33. tert-Butyl (2S,4S,5R)-1-(4-(tert-butyl)-3-methoxybenzoyl)-2-isobutyl-5(((methoxycarbonyl)oxy)methyl)-4-(methoxymethyl)pyrrolidine-2-carboxylate (31)

A solution of compound $7(97.9 \mathrm{mg}, 0.2 \mathrm{mmol})$ in ethanol $(2 \mathrm{~mL})$ was reacted with sodium borohydride (75.7 mg, $2 \mathrm{mmol}$ ) for 16 hours at room temperature. The reaction was quenched with saturated aqueous ammonium chloride solution ( $2 \mathrm{~mL}$ ) and concentrated under reduced pressure. The residue was partitioned between dichloromethane $(20 \mathrm{~mL})$ and water $(10 \mathrm{~mL})$, the organic layer was separated and the aqueous layer extracted with dichloromethane (2 x $10 \mathrm{~mL})$. The combined organic extracts were dried over anhydrous $\mathrm{MgSO}_{4}$, filtered and evaporated under reduced pressure to afford a residue containing the crude alcohol. To a stirred solution of the crude alcohol and DMAP (12.2 mg, $0.1 \mathrm{mmol})$ in a mixture of dry dichloromethane $(2 \mathrm{~mL})$ and dry pyridine $(2 \mathrm{~mL})$ under argon at $0^{\circ} \mathrm{C}$ was added dropwise methyl chloroformate $(2.32 \mathrm{~mL}, 30.0 \mathrm{mmol})$ and the mixture was stirred at room temperature for 2 hours. Then, the reaction mixture was diluted with dichloromethane (30 mL) and washed with water (2 x $10 \mathrm{~mL}$ ). The organic layer was dried over anhydrous Mg\$,Ofiltered and concentrated under reduced pressure. The crude product was purified by flash chromatography (eluent: diethyl ether/hexane, 1/1) to give compound 31 (105.5 mg, 96\% yield) as a white solid. M.p. $=78{ }^{\circ} \mathrm{C}$; $[\alpha]_{\mathrm{D}}{ }^{24}=18.01(c=1.10$ in CHG) $)$; IR (nujol) 1754, 1727, 1614, $1566 \mathrm{~cm} ;{ }^{1} \mathrm{H} \mathrm{NMR}(400 \mathrm{MHz}$, $\left.\mathrm{CDCl}_{3}\right) \delta 1.00$ (d, $\left.J=6.6 \mathrm{~Hz}, 3 \mathrm{H}\right), 1.01$ (d, $\left.J=6.6 \mathrm{~Hz}, 3 \mathrm{H}\right), 1.33$ (s, 9H), 1.50 (s, 9H), 1.77-1.90 (m, 1H), 1.96 (dd, $J=13.1,13.1 \mathrm{~Hz}, 1 \mathrm{H}) ; 1.99$ (dd, $J=15.1,4.0 \mathrm{~Hz}, 1 \mathrm{H}$ ), 2.18 (dd, $J=13.1,6.9 \mathrm{~Hz}, 1 \mathrm{H}$ ), 2.32 (dd, $J=15.1,7.8 \mathrm{~Hz}, 1 \mathrm{H}), 2.82-2.95$ (m, 1H), 3.28 (s, 3H), 3.32 (dd, $J=9.6,6.3 \mathrm{~Hz}, 1 \mathrm{H}$ ), 3.40 (dd, $J=9.6,7.3 \mathrm{~Hz}, 1 \mathrm{H}$ ), 3.60 (s, 3H), 3.83 (s, 3H), 3.94 (dd, $J=11.2,4.6 \mathrm{~Hz}, 1 \mathrm{H}$ ), 4.30 (dd, $J=11.2$, $8.1 \mathrm{~Hz}, 1 \mathrm{H}), 4.52$ (dd, $J=7.6,7.6,4.7 \mathrm{~Hz}, 1 \mathrm{H}), 6.90$ (dd, $J=7.9,1.7 \mathrm{~Hz}, 1 \mathrm{H}), 6.93$ (d, $J=1.7 \mathrm{~Hz}, 1 \mathrm{H})$, $7.22(\mathrm{~d}, J=7.9 \mathrm{~Hz}, 1 \mathrm{H}) ;{ }^{13} \mathrm{C}-\mathrm{APT}\left\{{ }^{1} \mathrm{H}\right\} \mathrm{NMR}\left(100 \mathrm{MHz}, \mathrm{CDCl}_{3}\right) \delta$ 24.3, 24.4, 25.8, 28.0, 29.6, 35.0, 37.2, 41.3, 41.3, 54.7, 55.0, 59.0, 60.1, 66.5, 69.3, 71.2, 81.4, 110.7, 118.1, 126.4, 135.6, 140.2, 155.1, 158.6, 169.5, 173.0; HRMS(ESI $\left.{ }^{+}\right) \mathrm{m} / \mathrm{z}[\mathrm{M}+\mathrm{H}]^{+}$calcd for $\mathrm{C}_{40} \mathrm{H}_{48} \mathrm{NO}_{8}$ 550.3375, found 550.3393.

4.1.34. (2S,4S,5R)-1-(4-(tert-Butyl)-3-methoxybenzoyl)-2-isobutyl-5-(((methoxycarbonyl)oxy)methyl)4-(methoxymethyl)pyrrolidine-2-carboxylic acid (32) 
To a solution of compound 31 (55.0 $\mathrm{mg}, 0.1 \mathrm{mmol})$ in dichloromethane $(1.2 \mathrm{~mL})$ at $0{ }^{\circ} \mathrm{C}$ was added trifluoroacetic acid $(0.4 \mathrm{~mL})$ and the resulting solution was stirred at $0{ }^{\circ} \mathrm{C}$ for 6 hours. The reaction mixture was diluted with dichloromethane $(15 \mathrm{~mL})$, neutralised with saturated aqueous sodium hydrogen carbonate solution and carefully acidified at $\mathrm{pH} 1$ with $1 \mathrm{M}$ hydrochloric acid. The organic layer was separated and the aqueous layer was extracted with dichloromethane (2 x $20 \mathrm{~mL}$ ). The combined organic extracts washed with water $(10 \mathrm{~mL})$, dried over anhydrous MgS@ filtered and evaporated under reduced pressure to give compound 32 (48.4 mg, 98\% yield) as a brownish solid. M.p. $=81^{\circ} \mathrm{C} ;[\alpha]_{\mathrm{D}}{ }^{24}=-72.29\left(c=1.08\right.$ in $\mathrm{CHCl}_{3}$ ); IR (nujol) 3700-2300, 1757, 1739, 1638, $1562 \mathrm{~cm}^{-}$ 1, ${ }^{1} \mathrm{H}$ NMR (400 MHz, CDÇ) $\delta 0.99$ (d, $\left.J=6.6 \mathrm{~Hz}, 3 \mathrm{H}\right), 0.99$ (d, $\left.J=6.5 \mathrm{~Hz}, 3 \mathrm{H}\right), 1.35$ (s, 9H), 1.73-1.84 (m, 1H), 1.86 (dd, $J=13.8,5.6 \mathrm{~Hz}, 1 \mathrm{H}), 2.24$ (dd, $J=12.7,6.7 \mathrm{~Hz}, 1 \mathrm{H}$ ), 2.36 (dd, $J=13.8$, $5.6 \mathrm{~Hz}, 1 \mathrm{H}), 2.69$ (dd, $J=12.7,12.7 \mathrm{~Hz}, 1 \mathrm{H}), 2.70-2.83$ (m, 1H), 3.29 (s, 3H), 3.30 (dd, $J=9.6,8.6$ Hz, 1H), 3.46 (dd, $J=9.6,5.0$ Hz, 1H), 3.66 (s, 3H), 3.80 (dd, $J=11.7,6.9$ Hz, 1H), 3.86 (s, 3H), 4.16 (dd, $J=11.7,4.0 \mathrm{~Hz}, 1 \mathrm{H}$ ), 4.55 (ddd, $J=6.9,6.9,4.0 \mathrm{~Hz}, 1 \mathrm{H}), 6.86$ (dd, $J=7.9,1.7 \mathrm{~Hz}, 1 \mathrm{H}$ ), 7.02 (d, $J$ $=1.7 \mathrm{~Hz}, 1 \mathrm{H}), 7.26(\mathrm{~d}, J=7.9 \mathrm{~Hz}, 1 \mathrm{H}) ; \quad{ }^{13} \mathrm{C}-\mathrm{APT}\left\{{ }^{1} \mathrm{H}\right\} \mathrm{NMR}\left(100 \mathrm{MHz}, \mathrm{CDCl}{ }_{3}\right) \delta 24.0,24.6,24.9$, 29.5, 35.2, 36.1, 38.5, 42.5, 55.0, 55.2, 59.2, 62.4, 65.8, 71.1, 73.0, 111.3, 118.0, 126.7, 134.0, 141.6, 155.2, 158.9, 173.9, 174.9; $\mathrm{HRMS}\left(\mathrm{ESI}^{+}\right) \mathrm{m} / \mathrm{z}[\mathrm{M}+\mathrm{Na}]^{+}$calcd for $\mathrm{C}_{26} \mathrm{H}_{39} \mathrm{NNaO}_{8}$ 516.2568, found 516.2580 .

\subsubsection{5. tert-Butyl (2S,4S,5R)-1-(4-(tert-butyl)-3-methoxybenzoyl)-5-(fluoromethyl)-2-isobutyl-4-} (methoxymethyl)pyrrolidine-2-carboxylate (33)

A solution of compound $7(97.9 \mathrm{mg}, 0.2 \mathrm{mmol})$ in ethanol $(2 \mathrm{~mL})$ was reacted with sodium borohydride $(75.7 \mathrm{mg}, 2 \mathrm{mmol}$ ) for 16 hours at room temperature. The reaction was quenched with saturated aqueous ammonium chloride solution $(2 \mathrm{~mL})$ and concentrated under reduced pressure. The residue was partitioned between dichloromethane $(20 \mathrm{~mL})$ and water $(10 \mathrm{~mL})$, the organic layer was separated and the aqueous layer extracted with dichloromethane $(2 \times 10 \mathrm{~mL})$. The combined organic extracts were dried over anhydrous $\mathrm{MgSO}_{4}$, filtered and evaporated under reduced pressure to afford a residue containing the crude alcohol. To a stirred solution of the crude alcohol and triethylamine (40.5 $\mathrm{mg}, 0.4 \mathrm{mmol})$ in dry dichloromethane $(2 \mathrm{~mL})$ under argon at $-20{ }^{\circ} \mathrm{C}$ was added dropwise DAST (53 $\mathrm{ml}, 0.4 \mathrm{mmol}$ ). After the addition, the reaction mixture was warmed to room temperature and stirred for 14 hours. Then, the resulting mixture was quenched by adding saturated aqueous $\mathrm{NaHCO}_{3}$ solution (10 $\mathrm{mL})$ and extracted with dichloromethane (3 x $20 \mathrm{~mL})$. The combined organic layers were dried over anhydrous $\mathrm{MgSO}_{4}$, filtered and concentrated under reduced pressure. The crude product was purified 
by flash chromatography (eluent: diethyl ether/hexane, 1/1) to afford compound 33 (51.3 mg, 52\% yield) as a white solid. M.p. $=136{ }^{\circ} \mathrm{C} ;[\alpha]_{\mathrm{D}}{ }^{24}=7.11\left(c=1.09\right.$ in $\left.\mathrm{CHCl}{ }_{3}\right)$; IR (nujol) 1736, 1622, 1567 $\mathrm{cm}^{-1}$; ${ }^{1} \mathrm{H}$ NMR (400 MHz, $\mathrm{CDCl}_{3}$ ) $\delta 1.01$ (d, $\left.J=6.6 \mathrm{~Hz}, 3 \mathrm{H}\right), 1.03$ (d, $\left.J=6.6 \mathrm{~Hz}, 3 \mathrm{H}\right), 1.35$ (s, 9H), 1.50 (s, 9H), 1.80-1.90 (m, 1H), 1.93 (dd, $J=13.1,13.1 \mathrm{~Hz}, 1 \mathrm{H}$ ), 2.00 (dd, $J=14.9$, $3.8 \mathrm{~Hz}, 1 \mathrm{H}$ ), 2.22 (dd, $J=13.1,6.9 \mathrm{~Hz}, 1 \mathrm{H}$ ), 2.32 (dd, $J=14.9,8.1 \mathrm{~Hz}, 1 \mathrm{H}), 2.87-2.99$ (m, 1H), 3.32 (s, $3 \mathrm{H}$ ), 3.37 (ddd, $J=9.3,6.9,1.8 \mathrm{~Hz}, 1 \mathrm{H}$ ), 3.50 (ddd, $J=9.3,7.1,1.8 \mathrm{~Hz}, 1 \mathrm{H}$ ), 3.83 (s, 3H), 4.22 (ddd, $J=45.9,8.9,2.9$ Hz, 1H), 4.47 (dd, $J=42.5,8.3,8.3 \mathrm{~Hz}, 1 \mathrm{H}), 4.43-4.51$ (m, 1H), 6.91 (d, $J=1.4 \mathrm{~Hz}, 1 \mathrm{H}), 6.94$ (dd, $J=$ 7.9, $1.4 \mathrm{~Hz}, 1 \mathrm{H}), 7.25$ (d, $J=7.9 \mathrm{~Hz}, 1 \mathrm{H}) ;{ }^{13} \mathrm{C}-\mathrm{APT}\left\{{ }^{1} \mathrm{H}\right\} \mathrm{NMR}\left(100 \mathrm{MHz}, \mathrm{CDCl}_{3}\right) \delta$ 24.2, 24.4, 25.8, 28.1, 29.7, 35.1, 37.6, 41.2, 41.4, 55.1, 59.2, 60.7 (d, $J=23.7 \mathrm{~Hz}$ ), 69.5, 71.6 (d, $J=5.1 \mathrm{~Hz}$ ), 81.3, 81.6 (d, $J=174.1 \mathrm{~Hz}), 110.2,118.1,126.7,135.6,140.4,158.7,169.3,173.1 ; \mathrm{HRMS}\left(\mathrm{ESI} \quad{ }^{+}\right) \mathrm{m} / \mathrm{z}[\mathrm{M}+\mathrm{H}]^{+}$ calcd for $\mathrm{C}_{28} \mathrm{H}_{45} \mathrm{FNO}_{5}$ 494.3277, found 494.3296.

4.1.36. (2S,4S,5R)-1-(4-(tert-Butyl)-3-methoxybenzoyl)-5-(fluoromethyl)-2-isobutyl-4(methoxymethyl)pyrrolidine-2-carboxylic acid (34)

To a solution of compound $33(49.4 \mathrm{mg}, 0.1 \mathrm{mmol})$ in dichloromethane $(1.2 \mathrm{~mL})$ at $0{ }^{\circ} \mathrm{C}$ was added trifluoroacetic acid $(0.4 \mathrm{~mL})$ and the resulting solution was stirred at $0{ }^{\circ} \mathrm{C}$ for 6 hours. The reaction mixture was diluted with dichloromethane $(15 \mathrm{~mL})$, neutralised with saturated aqueous sodium hydrogen carbonate solution and carefully acidified at $\mathrm{pH} 1$ with $1 \mathrm{M}$ hydrochloric acid. The organic layer was separated and the aqueous layer was extracted with dichloromethane (2 x $20 \mathrm{~mL})$. The combined organic extracts were washed with water $(10 \mathrm{~mL})$, dried over anhydrous $\mathrm{MgSO}_{4}$, filtered and evaporated under reduced pressure to give compound 34 (43.3 mg, 99\% yield) as a brownish oil. [ $\alpha]_{\mathrm{D}}{ }^{24}$ $=-79.74\left(c=1.05\right.$ in $\mathrm{CHCl}_{3}$ ); IR (neat) 3700-2300, 1739, 1711, 1631, 1607, $1564 \mathrm{~cm}^{-1} ;{ }^{1} \mathrm{H}$ NMR (400 $\left.\mathrm{MHz}, \mathrm{CDCl}_{3}\right) \delta 1.01$ (d, $\left.J=6.5 \mathrm{~Hz}, 6 \mathrm{H}\right), 1.36(\mathrm{~s}, 9 \mathrm{H}), 1.76-1.87$ (m, 1H), 1.92 (dd, $J=14.0,5.8 \mathrm{~Hz}$, 1H), 2.25 (dd, $J=13.4,7.7 \mathrm{~Hz}, 1 \mathrm{H}), 2.37$ (dd, $J=14.0,5.7 \mathrm{~Hz}, 1 \mathrm{H}), 2.66$ (dd, $J=13.4,13.4 \mathrm{~Hz}, 1 \mathrm{H}$ ), 2.72-2.86 (m, 1H), 3.31 (s, 3H); 3.34 (dd, $J=9.6,9.6 \mathrm{~Hz}, 1 \mathrm{H}), 3.47$ (dd, $J=9.6,5.4 \mathrm{~Hz}, 1 \mathrm{H}$ ), 3.85 (s, 3H), 4.27 (dd, $J=47.0,4.9 \mathrm{~Hz}, 2 \mathrm{H}), 4.52$ (dddd, $J=21.9,7.2,4.9,4.9 \mathrm{~Hz}, 1 \mathrm{H}), 6.89$ (dd, $J=7.9,1.7$ $\mathrm{Hz}, 1 \mathrm{H}), 6.94$ (d, $J=1.7 \mathrm{~Hz}, 1 \mathrm{H}), 7.29$ (d, $J=7.9 \mathrm{~Hz}, 1 \mathrm{H}) ; \quad{ }^{13} \mathrm{C}-\mathrm{APT}\left\{{ }^{1} \mathrm{H}\right\} \mathrm{NMR}\left(100 \mathrm{MHz}, \mathrm{CDCl}_{3}\right) \delta$ 24.2, 24.6, 24.9, 29.6, 35.2, 36.3, 38.6 (d, $J=1.9$ HZ), 42.4, 55.3, 59.2, 63.1 (d, $J=18,5 \mathrm{~Hz}), 71.3$, 73.0, 82.0 (d, $J=174.3 \mathrm{~Hz}), 110.6,118.2,127.0$, 134.0, 141.8, 159.1, 174.1, 174.5; HRMS(ESI $\left.\quad{ }^{+}\right) \mathrm{m} / \mathrm{z}$ $[\mathrm{M}+\mathrm{Na}]^{+}$calcd for $\mathrm{C}_{24} \mathrm{H}_{36} \mathrm{FNNaO}_{5} 460.2470$, found 460.2485 . 
4.1.37. tert-Butyl (2S,4S,5R)-5-(azidomethyl)-1-(4-(tert-butyl)-3-methoxybenzoyl)-2-isobutyl-4(methoxymethyl)pyrrolidine-2-carboxylate (35)

A solution of compound $7(195.8 \mathrm{mg}, 0.4 \mathrm{mmol})$ in ethanol $(6 \mathrm{~mL})$ was reacted with sodium borohydride (151.4 mg, $4 \mathrm{mmol}$ ) for 16 hours at room temperature. The reaction was quenched with saturated aqueous ammonium chloride solution $(6 \mathrm{~mL})$ and concentrated under reduced pressure. The residue was partitioned between dichloromethane $(20 \mathrm{~mL})$ and water $(10 \mathrm{~mL})$, the organic layer was separated and the aqueous layer extracted with dichloromethane (2 x $10 \mathrm{~mL})$. The combined organic extracts were dried over anhydrous $\mathrm{MgSO}_{4}$, filtered and evaporated under reduced pressure to afford a residue containing the crude alcohol. To a stirred solution of the crude alcohol and triethylamine (121.5 mg, $1.2 \mathrm{mmol})$ in dry dichloromethane $(20 \mathrm{~mL})$ under argon at $0{ }^{\circ} \mathrm{C}$ was added methanesulfonyl chloride (93 ml, $1.2 \mathrm{mmol}$ ) and the reaction mixture was stirred at $0{ }^{\circ} \mathrm{C}$ for 2 hours. Then the resulting mixture was quenched by the addition of a saturated aqueous NaHCO ${ }_{3}$ solution $(10 \mathrm{~mL})$, the organic layer was separated and the aqueous layer extracted with dichloromethane $(2 \times 10 \mathrm{~mL})$. The combined organic exracts were dried over anhydrous $\mathrm{MgSO}_{4}$, filtered and concentrated under reduced pressure. The crude product was used in the next step without further purification. A mixture of crude mesylate, $\mathrm{NaI}$ (60.0 mg, 0,4 mg) and $\mathrm{NaN}_{3}(260.1 \mathrm{mg}, 4.0 \mathrm{mmol})$ in dry DMF (6 mL) was stirred under argon at $80{ }^{\circ} \mathrm{C}$ for 14 hours. The solvent was removed at reduced pressure, the residue partitioned between ethyl ether $(20 \mathrm{~mL})$ and water $(10 \mathrm{~mL})$, the organic layer separated and the aqueous layer extracted with ethyl ether ( 2 x $20 \mathrm{~mL}$ ). The combined organic extracts were dried over anhydrous $\mathrm{MgSO}_{4}$, filtered and evaporated under reduced pressure. The crude product was purified by flash chromatography (eluent: diethyl ether/hexane, 1/1) to afford compound 35 (200.5 mg, 97\% yield) as a white solid. M.p. = 113 ${ }^{\circ} \mathrm{C} ;[\alpha]_{\mathrm{D}}^{24}=5.73\left(c=1.20\right.$ in $\mathrm{CHCl}_{3}$ ); IR (nujol) 2104, 1731, 1626, $1566 \mathrm{~cm}^{-1} ;{ }^{1} \mathrm{H} \mathrm{NMR}(400 \mathrm{MHz}$, $\left.\mathrm{CDCl}_{3}\right) \delta 1.00$ (d, $\left.J=6.6 \mathrm{~Hz}, 3 \mathrm{H}\right), 1.02$ (d, $\left.J=6.5 \mathrm{~Hz}, 3 \mathrm{H}\right), 1.34$ (s, 9H), 1.49 (s, 9H), 1.78-1.89 (m, 1H), 1.88 (dd, $J=13.1,13.1 \mathrm{~Hz}, 1 \mathrm{H}), 1.98$ (dd, $J=14.9,3.7 \mathrm{~Hz}, 1 \mathrm{H}), 2.17$ (dd, $J=13.1,6.8 \mathrm{~Hz}, 1 \mathrm{H}$ ), 2.30 (dd, $J=14.9,8.1 \mathrm{~Hz}, 1 \mathrm{H}), 2.83-2.96$ (m, 1H), 3.17 (dd, $J=13.0,9.4 \mathrm{~Hz}, 1 \mathrm{H}), 3.25$ (dd, $J=13.0$, $3.6 \mathrm{~Hz}, 1 \mathrm{H}), 3.31$ (s, 3H), 3.33 (dd, $J=9.5,6.4 \mathrm{~Hz}, 1 \mathrm{H}), 3.42$ (dd, $J=9.5,7.3 \mathrm{~Hz}, 1 \mathrm{H}), 3.84$ (s, 3H), 4.36-4.44 (m, 1H), 6.93 (d, $J=1.7 \mathrm{~Hz}, 1 \mathrm{H}), 6.96$ (dd, $J=7.9,1.7 \mathrm{~Hz}, 1 \mathrm{H}), 7.27$ (d, $J=7.9 \mathrm{~Hz}, 1 \mathrm{H}$ ); ${ }^{13} \mathrm{C}-\mathrm{APT}\left\{{ }^{1} \mathrm{H}\right\} \mathrm{NMR}\left(100 \mathrm{MHz}, \mathrm{CDCl}_{3}\right) \delta$ 24.1, 24.4, 25.8, 28.1, 29.6, 35.1, 37.2, 41.4, 41.6, 51.3, 55.2, 59.0, 60.9, 69.4, 71.3, 81.4, 110.1, 118.2, 126.7, 135.4, 140.8, 158.8, 169.2, 173.1; HRMS(ESI ${ }^{+}$) $\mathrm{m} / \mathrm{z}$ $[\mathrm{M}+\mathrm{H}]^{+}$calcd for $\mathrm{C}_{28} \mathrm{H}_{45} \mathrm{~N}_{4} \mathrm{O}_{5}$ 517.3385, found 517.3401. 
(methoxymethyl)pyrrolidine-2-carboxylic acid (36)

To a solution of compound $35(51.7 \mathrm{mg}, 0.1 \mathrm{mmol})$ in dichloromethane $(1.2 \mathrm{~mL})$ at $0{ }^{\circ} \mathrm{C}$ was added trifluoroacetic acid $(0.4 \mathrm{~mL})$ and the resulting solution was stirred at $0{ }^{\circ} \mathrm{C}$ for 6 hours. The reaction mixture was diluted with dichloromethane $(15 \mathrm{~mL})$, neutralised with saturated aqueous sodium hydrogen carbonate solution and carefully acidified at pH 1 with $1 \mathrm{M}$ hydrochloric acid. The organic layer was separated and the aqueous layer was extracted with dichloromethane (2 x $20 \mathrm{~mL})$. The combined organic extracts were washed with water $(10 \mathrm{~mL})$, dried over anhydrous $\mathrm{MgSO}_{4}$, filtered and evaporated under reduced pressure to give compound 36 (45.6 mg, 99\% yield) as a brownish oil. [ $\alpha]_{D}^{24}$ $=-58.82$ ( $c=1.00$ in CHG); IR (neat) 3700-2400, 2102, 1738, 1712, 1639, 1607, 1564 çᄁn ${ }^{1} \mathrm{H}$ NMR (400 MHz, $\left.\mathrm{CDCl}_{3}\right) \delta 1.00(\mathrm{~d}, J=6.7 \mathrm{~Hz}, 3 \mathrm{H}), 1.00$ (d, $\left.J=6.6 \mathrm{~Hz}, 3 \mathrm{H}\right), 1.36(\mathrm{~s}, 9 \mathrm{H}), 1.75-1.86$ (m, 1H), 1.92 (dd, $J=14.1,5.9 \mathrm{~Hz}, 1 \mathrm{H}), 2.24$ (dd, $J=13.6,7.6 \mathrm{~Hz}, 1 \mathrm{H}), 2.34$ (dd, $J=14.1,5.6 \mathrm{~Hz}$, 1H), 2.63 (dd, $J=13.6,13.6 \mathrm{~Hz}, 1 \mathrm{H}), 2.73-2.85$ (m, 1H), 3.18 (dd, $J=12.9,7.3 \mathrm{~Hz}, 1 \mathrm{H}), 3.24$ (dd, $J=$ 12.9, $5.5 \mathrm{~Hz}, 1 \mathrm{H}), 3.28$ (dd, $J=9.6,9.6 \mathrm{~Hz}, 1 \mathrm{H}$ ), 3.31 (s, 3H), 3.45 (dd, $J=9.6,5.3 \mathrm{~Hz}, 1 \mathrm{H}$ ), 3.87 (s, 3H), 4.45-4.52 (m, 1H), 6.91 (dd, $J=7.9,1.7 \mathrm{~Hz}, 1 \mathrm{H}), 7.02$ (d, $J=1.7 \mathrm{~Hz}, 1 \mathrm{H}), 7.30$ (d, $J=7.9 \mathrm{~Hz}$, $1 \mathrm{H}) ;{ }^{13} \mathrm{C}-\mathrm{APT}\left\{{ }^{1} \mathrm{H}\right\}$ NMR $\left(100 \mathrm{MHz}, \mathrm{CDCl}_{3}\right) \delta 24.2$, 24.5, 24.9, 29.5, 35.2, 35.8, 39.2, 42.3, 51.0, 55.4, 59.2, 62.7, 71.1, 72.3, 111.0, 118.5, 126.8, 134.0, 142.0, 159.2, 174.2, 174.7; HRMS(ESI ${ }^{+}$m/z $[\mathrm{M}+\mathrm{Na}]^{+}$calcd for $\mathrm{C}_{24} \mathrm{H}_{36} \mathrm{~N}_{4} \mathrm{NaO}_{5}$ 483.2577, found 483.2581.

\subsubsection{9. tert-Butyl (2S,4S,5R)-5-(acetamidomethyl)-1-(4-(tert-butyl)-3-methoxybenzoyl)-2-isobutyl-4-} (methoxymethyl)pyrrolidine-2-carboxylate (37)

A mixture of compound 35 (103.4 mg, $0.2 \mathrm{mmol})$ and 10\% Pd/C (20 mg) in ethyl acetate (5 mL) was stirred at room temperature under hydrogen atmosphere for 2 hours. The reaction mixture was filtered through a Celite ${ }^{\circledR}$ pad and concentrate under reduced pressure to afford a residue containing the crude amine. To a stirred solution of the crude amine in toluene $(5 \mathrm{~mL})$ at room temperature was subsequently added triethylamine (101.2 mg, $1.0 \mathrm{mmol}$ ) and acetic anhydride (102.1 mg, $1.0 \mathrm{mmol}$ ) and the reaction mixture was stirred at $100{ }^{\circ} \mathrm{C}$ for 4 hours. The reaction was quenched with water (10 $\mathrm{mL}$ ) and extracted with dichloromethane (3 x $20 \mathrm{~mL})$. The combined organic extracts were dried over anhydrous $\mathrm{MgSO}_{4}$, filtered and evaporated under reduced pressure. The crude product was purified by flash chromatography (eluent: diethyl ether) to give compound 37 (69.3 mg, 65\% yield) as a colourless oil. $[\alpha]_{\mathrm{D}}{ }^{24}=43.81$ ( $c=1.07$ in $\mathrm{CHCl}_{3}$ ); IR (nujol) 3304, 1727, 1700, 1678, 1639, $1564 \mathrm{~cm}^{-1} ;{ }^{1} \mathrm{H}$ NMR $\left(400 \mathrm{MHz}, \mathrm{CDCl}_{3}\right) \delta 1.01$ (d, $\left.J=6.6 \mathrm{~Hz}, 6 \mathrm{H}\right), 1.33$ (s, 9H), 1.55 (s, 9H), 1.78-1.88 (m, 1H), 1.86 (dd, $J$ 
= 12.8, $12.8 \mathrm{~Hz}, 1 \mathrm{H}), 1.89$ (s, 3H), 2.01 (dd, $J=14.9,4.0 \mathrm{~Hz}, 1 \mathrm{H}), 2.14$ (dd, $J=12.8,7.2 \mathrm{~Hz}, 1 \mathrm{H}$ ), 2.26 (dd, $J=14.9,7.1 \mathrm{~Hz}, 1 \mathrm{H}), 2.78$ (dd, $J=14.8,3.4 \mathrm{~Hz}, 1 \mathrm{H}$ ), 2.84-2.98 (m, 1H), 3.30 (dd, $J=9.3,9.3$ Hz, 1H), 3.32 (s, 3H); 3.34 (dd, $J=9.3,6.1 \mathrm{~Hz}, 1 \mathrm{H}$ ), 3.54 (ddd, $J=14.8,8.3,2.6 \mathrm{~Hz}, 1 \mathrm{H}), 3.83$ (s, 3H), 4.36-4.44 (m, 1H), 6.87-6.92 (m, 2H), 7.22 (d, $J=8.5 \mathrm{~Hz}, 1 \mathrm{H}), 7.92$ (d, J=8.3 Hz, 1H); ${ }^{13} \mathrm{C}-\mathrm{APT}\left\{{ }^{1} \mathrm{H}\right\}$ NMR (100 MHz, $\left.\mathrm{CDCl}_{3}\right) \delta$ 23.2, 24.5, 24.7, 25.7, 28.1, 29.6, 35.0, 38.3, 39.3, 41.1, 42.1, 55.3, 59.2, 60.7, 70.4, 71.5, 82.7, 110.0, 117.9, 126.6, 135.5, 140.5, 158.8, 169.4, 169.9, 175.4; $\left.\operatorname{HRMS(ESI~}{ }^{+}\right) \mathrm{m} / \mathrm{z}$ $[\mathrm{M}+\mathrm{H}]^{+}$calcd for $\mathrm{C}_{30} \mathrm{H}_{49} \mathrm{~N}_{2} \mathrm{O}_{6} 533.3585$, found 533.3578 .

4.1.40. (2S,4S,5R)-5-(Acetamidomethyl)-1-(4-(tert-butyl)-3-methoxybenzoyl)-2-isobutyl-4(methoxymethyl)pyrrolidine-2-carboxylic acid (38)

To a solution of compound $37(53.3 \mathrm{mg}, 0.1 \mathrm{mmol})$ in dichloromethane $(1.2 \mathrm{~mL})$ at $0{ }^{\circ} \mathrm{C}$ was added trifluoroacetic acid $(0.4 \mathrm{~mL})$ and the resulting solution was stirred at $0{ }^{\circ} \mathrm{C}$ for 6 hours. The reaction mixture was diluted with dichloromethane $(15 \mathrm{~mL})$, neutralised with saturated aqueous sodium hydrogen carbonate solution and carefully acidified at $\mathrm{pH} 1$ with $1 \mathrm{M}$ hydrochloric acid. The organic layer was separated and the aqueous layer was extracted with dichloromethane (2 x $20 \mathrm{~mL})$. The combined organic extracts were washed with water $(10 \mathrm{~mL})$, dried over anhydrous $\mathrm{MgSO}_{4}$, filtered and evaporated under reduced pressure to give compound 38 (45.3 mg, 95\% yield) as a brownish solid. M.p. $=85^{\circ} \mathrm{C} ; \mathrm{\alpha}_{\mathrm{D}}{ }^{24}=-28.00$ (c=1.02 in $\mathrm{CHCl}_{3}$ ); IR (nujol) 3600-2200, 3279, 1730, 1711, 1627, $1563 \mathrm{~cm}^{-1}$; ${ }^{1} \mathrm{H}$ NMR (400 MHz, $\mathrm{CDCl}_{3}$ ) $\delta 1.00$ (d, $\left.J=6.6 \mathrm{~Hz}, 6 \mathrm{H}\right), 1.34$ (s, 9H), 1.76-1.88 (m, 1H), 1.83 (s, 3H), 2.06 (dd, $J=14.4,6.5 \mathrm{~Hz}, 1 \mathrm{H}$ ), 2.21 (dd, $J=13.4,8.0 \mathrm{~Hz}, 1 \mathrm{H}$ ), 2.24 (dd, $J=14.4,5.0 \mathrm{~Hz}$, 1H), 2.43 (dd, $J=13.4,13.4 \mathrm{~Hz}, 1 \mathrm{H}), 2.74-2.87$ (m, 1H), 3.12 (ddd, $J=14.4,8.9,5.6 \mathrm{~Hz}, 1 \mathrm{H}$ ), 3.24 (ddd, $J=14.4,4.8,4.8 \mathrm{~Hz}, 1 \mathrm{H}), 3.33$ (s, 3H), 3.36-3.46 (m, 2H), 3.82 (s, 3H), 4.45-4.52 (m, 1H), 6.82 (bt, $J=4.8 \mathrm{~Hz}, 1 \mathrm{H}), 6.93$ (dd, $J=7.9,1.7 \mathrm{~Hz}, 1 \mathrm{H}$ ), 7.06 (d, $J=1.7 \mathrm{~Hz}, 1 \mathrm{H}), 7.26$ (d, $J=7.9 \mathrm{~Hz}, 1 \mathrm{H}$ ); ${ }^{13} \mathrm{C}-\mathrm{APT}\left\{{ }^{1} \mathrm{H}\right\}$ NMR $\left(100 \mathrm{MHz}, \mathrm{CDCl}_{3}\right) \delta 23.2,24.5,24.8,24.8,29.6,35.2,36.8,39.5,40.0,42.1,55.3$, 59.2, 62.2, 71.0, 71.7, 110.9, 118.2, 126.7, 134.5, 141.3, 158.9, 170.9, 172.5, 176.0; HRMS(ESI ${ }^{+}$) m/z $[\mathrm{M}+\mathrm{Na}]^{+}$calcd for $\mathrm{C}_{26} \mathrm{H}_{40} \mathrm{~N}_{2} \mathrm{NaO}_{6}$ 499.2779, found 499.2797.

\subsection{Biological assays}

\subsubsection{Cells and replicon system.}

The highly permissive cell clone Huh /-Lunet, as well as HuH 7 cells containing subgenomic (HCV) replicons I389luc-ubi-neo/NS3-3'/5.1 (Huh 5-2), I377NS3-3'/wt (Huh 9-13), or I389/hygro-ubi-NS33'/5.1 (a kind gift from Dr. V. Lohmann and Dr. R. Bartenschaler) has been described [18]. Briefly, 
this system allowed the efficient propagation of genetically modified HCV RNAs (replicons) in a human hepatoma cell line (Huh). The amount of RNA that has been transcribed and translated is determined through the quantification of a reporter contained the replicon system (luciferase). The amount of luminescence detected (after adding the substrate specific for this enzyme) is proportional to the virus replication rate. Cells were grown in a DMEM supplemented with $10 \%$ heat-inactivated fetal bovine serum 1 x non-essential amino acids, $100 \mathrm{IU} / \mathrm{mL}$ penicillin, $100 \mu \mathrm{g} / \mathrm{mL}$ streptomycin and 250 $\mu \mathrm{g} / \mathrm{mL}$ geneticin (G418).

\subsubsection{Antiviral and cytostatic assays with Huh 5-2 cells}

Antiviral and cytostatic assays were performed according to the protocol already described in Abian et al [19]. The 50\% effective concentration (EC50) was defined as the concentration of compound that reduced the luciferase signal by $50 \%$ and the 50\% cytotoxic concentration (CC50) was determined employing the dose-response equation (i.e., Hill equation).

\subsubsection{Geometry optimization and calculation of molecular descriptors}

Structures of the compounds were optimized at the quantum level with the DFT (Density Functional Theory) functional b3lyp/6-31+g(d,p) using GaussView 5.0.8 and Gaussian09 [24]. Charge zero (0) and a multiplicity of one (1) were settled, in the Gaussian input files, for all the compounds. The Homo and Lumo energies (in a.u.) of the optimized structures were extracted from the .log Gaussian output files, and used to calculate the reactivity $(\mathrm{Re})$ of compounds as:

$$
R e=\frac{!}{!}=\frac{!}{\frac{(! " \# ! ! " \# " * ! ! ! ! " \#)}{!}}=\frac{! \text { !!"\#\$ }}{(! " \# \$ ! ! " \# " ~)}
$$

where, $\eta$, is the chemical hardness, and 27.2114 is the conversion rate from a.u. to $\mathrm{eV}$ units.

Thirty-five additional molecular descriptors, including steric ones (e.g. molecular weight, sum of atomic van der Waals volumes, radius of gyration, molecular eccentricity, spherocity, etc.), constitutional ones (e.g. heteroatom percentages, rotatable bond fraction, etc.), ring ones (e.g. cyclomatic number, total ring size, aromatic ratio, etc.), molecular properties (e.g. hydrophilic factor, molar refractivity, octanol-water partition coefficient, etc.) and a consensus drug-like score were calculated with the DRAGON 6.0 program [25]. 


\section{Acknowledgments}

This work was financially supported by the Instituto de Salud Carlos III and European Union (ERDF/ESF, 'Investing in your future') (PI15/00663), Miguel Servet Program from the Instituto de la Salud Carlos III (CPII13/00017 to O.A.) and the Gobierno de Aragón-FSE (B01 research groups), Centro de Investigacion Biomédica en Red en Enfermedades Hepaticas y Digestivas (CIBERehd) and Asociación Española de Gastroenterologia (AEG) and grants FU2016-78232-P (MINECO, Spain) and E45_17R (Gobierno de Aragón, Spain). R.C-G thanks the MECD for an FPU grant (FPU13/3870). R.C-G thanks the DGA for an EPIF grant.

\section{REFERENCES}

[1] (a) Petruzziello, A.; Marigliano, S.; Loquercio, G.; Cozzolino, A.; Cacciapuoti C. Global Epidemiology of Hepatitis C Virus Infection: An up-Date of the Distribution and Circulation of Hepatitis C Virus Genotypes. World J. Gastroenterol. 2016; 22, 7824-7840. DOI: 10.3748/wjg.v22.i34.7824. (b) The Polaris Observatory HCV Collaborators. Global Prevalence and Genotype Distribution of Hepatitis C Virus Infection in 2015: A Modelling Study. Lancet Gastroenterol. Hepatol. 2017, 2, 161-176. DOI: http://dx.doi.org/10.1016/ S2468-1253(16)30181-9. [2] (a) Yamane, D.; McGivern, D. R.; Masaki, T.; Lemon, S. M. Liver injury and disease pathogenesis in chronic hepatitis C. Curr. Top. Microbiol. Immunol. 2013, 369, 263-288. DOI: 10.1007/978-3-64227340-7_11. (b) Mitchell, J. K.; Lemon, S. M.; McGivern, D. R. How Do Persistent Infections with Hepatitis C Virus Cause Liver Cancer?. Curr. Opin. Virol. 2015, 14, 101-108. DOI: 10.1016/j.coviro.2015.09.003. (c) Manns, M. P.; Buti, M.: Gane, E.; Pawlotsky, J. M.; Razavi, H.; Terrault, N.; Younossi, Z. Hepatitis C Virus Infection. Nat. Rev. Dis. Prim. 2017, 3, Article number 17006. DOI: 10.1038/nrdp.2017.6. (d) Irshad, M.; Gupta, P.; Irshad, K. Molecular Basis of Hepatocellular Carcinoma Induced by Hepatitis C Virus Infection. World J. Hepatol. 2017, 9, 13051314

[3] Global Hepatitis Report 2017. Geneva: World Health Organization; 2017.

https://www.who.int/hepatitis/publications/global-hepatitis-report2017/en/, 2017 (accessed 13 December 2018)

[4] Kolykhalov, A. A.; Mihalik, K.; Feinstone, S. M.; Rice, C. M. Hepatitis C Virus-Encoded Enzymatic Activities and Conserved RNA Elements in the 3 Nontranslated Region Are Essential for Virus Replication In Vivo. J. Virol. 2000, 74, 2046-2051. DOI: 10.1128/JVI.74.4.2046-2051.2000. 
[5] (a) Wu, J. Z.; Hong, Z. Targeting NS5B RNA-Dependent RNA Polymerase for Anti-HCV Chemotherapy. Curr. Drug Targets Infect. Disord. 2003, 3 (2003) 207-219. DOI: 10.2174/1568005033481114. (b) De Francesco, R.; Tomei, L.; Altamura, S.; Summa, V.; Migliaccio, G. Approaching a New Era for Hepatitis C Virus Therapy: Inhibitors of the NS3-4A Serine Protease and the NS5B RNA-Dependent RNA Polymerase. Antivir. Res. 2003, 58, 1-16. DOI: 10.1016/S01663542(03)00028-7. (c) Beaulieu, P.; Tsantrizos, Y. Inhibitors of the HCV NS5B Polymerase: New Hope for the Treatment of Hepatitis C Infections. Curr. Opin. Investig. Drugs 2004, 5, 838-850. (d) Wu, J. Z.; Yao, N.; Walker, M.; Hong, Z. Recent Advances in Discovery and Development of Promising Therapeutics against Hepatitis C Virus NS5B RNA-Dependent RNA Polymerase. Mini-Rev. Med. Chem. 2005, 5, 1103-1112. DOI: 10.2174/138955705774933310. (e) Koch, U.; Narjes, F. Recent Progress in the Development of Inhibitors of the Hepatitis C Virus RNA-dependent RNA Polymerase. Curr. Top. Med. Chem. 2007, 7, 1302-1329. DOI: 10.2174/156802607781212211. (f) Burton, J. R.; Everson, G. T. HCV NS5B Polymerase Inhibitors. Clin. Liver. Dis. 2009, 13, 453-465. DOI: 10.1016/j.cld.2009.05.001.

[6] (a) Beaulieu, P. L. Recent Advances in the Development of NS5B Polymerase Inhibitors for the Treatment of Hepatitis C Virus Infection. Expert Opin. Ther. Pat. 2009, 19, 145-164. DOI: 10.1517/13543770802672598. (b) Legrand-Abravel, F.; Nicot, F.; Izopet, J. New NS5B Polymerase Inhibitors for Hepatitis C. Expert. Opin. Investig, Drugs, 2010, 19, 963-975. DOI: 10.1517/13543784.2010.500285. (c) Watkins, W. J.; Ray, A. S.; Chong, L. S. HCV NS5B Polymerase Inhibitors. Curr. Opin. Drug Discov. Devel. 2010, 13, 441-465. (d) Patil, V. M.; Gupta, S. P.; Samanta, S.; Masand, N. Current Perspective of HCV NS5B Inhibitors: A Review. Curr. Med. Chem. 2011, 18, 5564-5597. DOI: 10.2174/092986711798347234. (e) Varshney, J.; Sharma, P. K; Sharma, A. A Review on an Update of NS5B Polymerase Hepatitis C Virus Inhibitors. Eur. Rev. Med. Pharmacol. Sci. 2012, 16, 667-671. (f) Sofia, M. J.; Chang, W.; Furman, P. A.; Mosley, R. T.; Ross, B. S. Nucleoside, Nucleotide, and Non-Nucleoside Inhibitors of Hepatitis C Virus NS5B RNA-Dependent RNA-Polymerase. J. Med. Chem. 2012, 55, 2481-2531. DOI: 10.1021/jm201384j. (g) Soriano, V; Vispo, E.; de Mendoza, C.; Labarga, P.; Fernandez-Montero, J. V.; Poveda, E.; Treviño, A.; Barreiro, P. Hepatitis C Therapy With HCV NS5B Polymerase Inhibitors. Expert Opin. Pharmacother. 2013, 14, 1161-1170. DOI: 10.1517/14656566.2013.795543. (h) Zhao, C.; Wang, Y.; Ma, S. Recent advances on the synthesis of hepatitis C virus NS5B RNA-dependent RNA-polymerase inhibitors. Eur. J. Med. Chem. 2015, 102, 188-214. DOI: 10.1016/j.ejmech.2015.07.046. (h) Polamreddy, P.; Vishwakarma, V.; Gundla, R. A review on anti-HCV agents targeting active site and allosteric sites on non-structural 
protein 5B [NS5B]. Int. J. Pharm. Pharm. Sci. 2016, 8, 1-18. DOI: 10.22159/ijpps.2016v8i11.13965.

(i) Shan, L. H.; Liu, Y.; Li, Y- H.; Liu, H. M.; Ke, Y. New Non-Nucleocide NS5B Protein Inhibitors for the Treatment of Chronic Hepatitis C Infection. Curr. Top. Med. Chem. 2016 16. 1392-1401. DOI: $10.2174 / 1568026616666151120113933$.

[7] (a) Burton, G.; Ku, T. W.; Carr, T. J.; Kiesow, T.; Sarisky, R. T.; Lin-Goerke, J.; Baker, A.; Earnshaw, D. L.; Hofmann, G. A.; Keenan R. M.; Dhanak, D. Identification of small molecule inhibitors of the hepatitis C virus RNA-dependent RNA polymerase from a pyrrolidine combinatorial mixture. Bioorg. Med. Chem. Lett. 2005, 15, 1553-1556. DOI:10.1016/j.bmcl.2005.01.076. (b) Burton, G.; Ku, T. W.; Carr, T. J.; Kiesow, T.; Sarisky, R. T.; Lin-Goerke, J.; Hofmann, G. A.; Slater, M. J.; Haigh, D.; Dhanak, D.; Johnson, V. K.; Parry, N. R.; Thommes, P. Studies on acyl pyrrolidine inhibitors of HCV RNA-dependent RNA polymerase to identify a molecule withreplicon antiviral activity. Bioorg. Med. Chem. Lett. 2007, 17, 1930-1933. DOI:10.1016/j.bmcl.2007.01.034. (c) Slater, M. J.; Amphlett, E. M.; Andrews, D. M.; Bravi, G.; Burton, G.; Cheasty, A. G.; Corfield, J. A.; Ellis, M. R.; Fenwick, R. H.; Fernandes, S.; Guidetti, R.; Haigh, D.; Hartley, C. D.; Howes, P. D.; Jackson, D. L.; Jarvest, R. L.; Lovegrove, V. L. H.; Medhurst, K. J.; Parry, N. R.; Price, H.; Shah, P.; Singh, O. M. P.; Stocker, R.; Thommes, P.; Wilkinson C.; Wonacott, A. J. Optimization of Novel Acyl Pyrrolidine Inhibitors of Hepatitis C Virus RNA-Dependent RNA Polymerase Leading to a Development Candidate. J. Med. Chem. 2007, 50, 897-900. DOI: 10.1021/jm061207r.

[8] Haudecoeur, R.; Peuchmaur, M.; Ahmed-Belkacem, A.; Pawlotsky, J. M.; Boumendjel, A. Structure-Activity Relationships in the Development of Allosteric Hepatitis C Virus RNA-Dependent RNA Polymerase Inhibitors: Ten Years of Research. Med. Res. Rew. 2013, 33, 934-984. DOI 10.1002/med.21271.

[9] (a) Nájera, C. Sansano, J. M. 1,3-Dipolar Cycloadditions: Applications to the Synthesis of Antiviral Agents. Org. Biomol. Chem. 2009, 7, 4567-4581. DOI: 10.1039/b913066g. (b) Döndas, H. A.; Retamosa, M. de G.; Sansano, J. M. Current Trends towards the Synthesis of Bioactive Heterocycles and Natural Products Using 1,3-Dipolar Cycloadditions (1,3-DC) with Azomethine Ylides. Synthesis 2017, 2819-2851 and references herein. DOI: 10.1055/s-0036-1588423.

[10] Nájera, C.; Retamosa, M. de G.; Sansano, J. M.; de Cózar, A. Cossío, F. P. Diastereoselective 1,3Dipolar Cycloaddition Reactions between Azomethine Ylides and Chiral Acrylates Derived from Methyl (S)- and (R)-Lactate - Synthesis of Hepatitis C Virus RNA-Dependent RNA Polymerase Inhibitors. Eur. J. Org. Chem. 2007, 5038-5049. DOI: 10.1002/ejoc.200700267. [11] (a) Agbodjan, A. A.; Cooley, B. E.; Copley, R. C. B.; Corfield, J. A.; Flanagan, R. C.; Glover, B. 
N.; Guidetti, R.; Haigh, D.; Howes, P. D.; Jackson, M. M.; Matsuoka, R. T.; Medhurst, K. J.; Millar, A.; Sharp, M. J.; Slater, M. J.; Toczko, J. F. Xie, S. Asymmetric Synthesis of an $N$-Acylpyrrolidine for Inhibition of HCV Polymerase. J. Org. Chem. 2008, 73, 3094-3102. DOI: 10.1021/jo800062c. (b) Flanagan, R. C.; Xie, S. Millar, A. A Catalyzed and Highly Selective Ester Reduction in the Synthesis of an N-Acylpyrrolidine: Safe Design through Reaction Calorimetry and Modeling. Org. Process Res. Dev. 2008, 12, 1307-1312. DOI: 10.1021/op8001799. (c) Tsubogo, T.; Saito, S.; Seki, K.; Yamashita, Y.; Kobayashi, S. Development of Catalytic Asymmetric 1,4-Addition and [3 + 2] Cycloaddition Reactions Using Chiral Calcium Complexes. J. Am. Chem. Soc. 2008, 130, 13321-12223. DOI: 10.1021/ja8032058. (d) Nájera, C.; Retamosa, M. de G.; Martín-Rodríguez, M.; Sansano, J. M.; de Cózar A.; Cossío, F. P. Synthesis of Prolines by Enantioselective 1,3-Dipolar Cycloaddition of Azomethine Ylides and Alkenes Catalyzed by Chiral Phosphoramidite-Silver(I) Complexes. Eur. J. Org. Chem. 2009, 5622-5634. DOI: 10.1002/ejoc.200900774. (e) Martín-Rodríguez, M.; Nájera, C.; Sansano, J. M.; de Cózar, A. Cossío, F. P. Chiral Gold(I) vs Chiral Silver Complexes as Catalysts for the Enantioselective Synthesis of the Second Generation GSK-hepatitis C Virus Inhibitor. Beilstein J. Org. Chem. 2011, 7, 988-996. DOI: 10.3762/bjoc.7.111. (f) Chabour, I.; Castelló, L. M.; ManceboAracil, J.; Martín-Rodríguez, M.; Retamosa, M. de G.; Nájera, C.; Sansano, J. M. Dual Chiral Silver Catalyst in the Synthetic Approach to the Core of Hepatitis C Virus Inhibitor GSK 625433 Using Enantioselective 1,3-Dipolar Cycloaddition of Azomethine Ylides and Electrophilic Alkenes. Tetrahedron: Asymmetry 2017, 28, 1424-1429. DOI: 10.1016/j.tetasy.2017.08.011.

[12] See, for example: (a) Etayo, P.; Badorrey, R.; Díaz-de-Villegas, M. D.; Gálvez, J. A. Efficient Stereodivergent Synthesis of cis-(2R,4S)- and trans-(2R,4R)-4-Phosphonomethyl-2piperidinecarboxylic Acids from the Same Chiral Imine Derived from $(R)$-Glyceraldehyde. Synlett 2006, 2799-2803. DOI: 10.1055/s-2006-950272. (b) Etayo, P.; Badorrey, R.; Díaz-de-Villegas, M. D.; Gálvez, J. A. Asymmetric Homologation of Ketones. A New Entry to Orthogonally Protected (2R,4R)-Piperidine2,4-dicarboxylic Acid. J. Org. Chem. 2008, 73, 8594-8597. DOI: 10.1021/jo801515k. (c) Etayo, P.; Badorrey, R.; Díaz-de-Villegas, M. D.; Gálvez, J. A. Asymmetric Synthesis of a Novel Conformationally Constrained D-Lysine Analogue with a Piperidine Skeleton. Eur. J. Org. Chem. 2008, 3474-3478. DOI: 10.1002/ejoc.200800069. (d) Allepuz, A. C.; Badorrey, R.; Díaz-de-Villegas, M. D.; Gaĺvez, J. A. Asymmetric Synthesis of ES-285, an Anticancer Agent Isolated from Marine Sources. Eur. J. Org. Chem. 2009, 6172-6178. DOI: 10.1002/ejoc.200900828. (e) Badorrey, R.; Portaña, E.; Gálvez, J. A.; Díaz-de-Villegas, M. D. Stereocontrolled Synthesis of Orthogonally Protected 2-Substituted 4-Aminopiperidines. Org. Biomol. Chem. 2009, 7, 2912-2918. DOI: 
10.1039/b904948g. (f) Etayo, P.; Badorrey, R.; Díaz-de-Villegas, M. D.; Gálvez, J. A.; López-Ram-deVíu, P. An Expeditious Method for the First Asymmetric Synthesis of Dexoxadrol from the Chiral Pool. Synlett 2010, 1775-1778. DOI: 10.1055/s-0030-1258110. (g) Gálvez, J. A.; Díaz-de-Villegas, M. D.; Badorrey, R.; López-Ram-de-Víu, P. Switch in Regioselectivity of Epoxide Ring-opening by Changing the Organometallic Reagent. Org. Biomol. Chem. 2011, 9, 8155-8162. DOI: 10.1039/c1ob06216f. (h) Díez, J. A.; Gálvez, J. A.; Díaz-de-Villegas, M. D.; Badorrey, R.; Bartholomewb, B.; Nash R. J. Stereoselective Synthesis and Biological Evaluation of D-Fagomine, D3-epi-Fagomine and D-3,4-epi-Fagomine Analogs from D-Glyceraldehyde Acetonide as a Common Building Block. Org. Biomol. Chem. 2012, 10, 9278-9286. DOI: 10.1039/c2ob26732b.

[13] Gálvez, J. A.; Díaz-de-Villegas, M. D.; Alías, M.; Badorrey, R. Chiral Iminoesters Derived from D-Glyceraldehyde in [3 + 2] Cycloaddition Reactions. Asymmetric Synthesis of a Key Intermediate in the Synthesis of Neuramidinase Inhibitors. J. Org. Chem. 2013, 78, 11404-11413. DOI: 10.1021/j0401967a.

[14] Swamy, N. R.; Venkateswarlu, Y. A Mild and Efficient Method for Chemoselective Deprotection of Acetonides by Bismuth(III) Trichloride. Tetrahedron Lett. 2002, 43, 7549-7552. DOI: 10.1016/S0040-4039(02)01809-9.

[15] Abiko, A.; Roberts, J. C.; Takemasa, T.; Masamune, S. $\mathrm{KMnO}_{4}$ Revisited: Oxidation of Aldehydes to Carboxylic Acids in the tert-Butyl Alcohol-aqueous $\mathrm{NaH}{ }_{2} \mathrm{PO}_{4}$ System. Tetrahedron Lett. 1986, 27, 4537-4540. DOI: 10.1016/S0040-4039(00)84997-7.

[16] Merritt, E. A.; Bagley, M. C. Holzapfel-Meyers-Nicolaou Modification of the Hantzsch Thiazole Synthesis. Synthesis 2007, 3535-3541. DOI: 10.1055/s-2007-990851.

[17] Talukdar, S.; Hsu, J. L.; Chou, T. C.; Fang, J. M. Direct Transformation of Aldehydes to Nitriles Using Iodine in Ammonia Water. Tetrahedron Lett. 2001, 42, 1103-1105. DOI: 10.1016/S00404039(00)02195-X.

[18] Spero, D. M.; Kapadia, S. R. Enantioselective Synthesis of $\alpha, \alpha$-Disubstituted Amino Acid Derivatives via Enzymatic Resolution: Preparation of a Thiazolyl-substituted $\alpha$-Methyl $\alpha$-Benzyl Amine J. Org. Chem. 1996, 61, 7398-7401. DOI: 10.1021/jo9610671.

[19] (a) Blight, K. J.; Mc Keating, J. A.; Rice, C. M. Highly Permissive Cell Lines for Subgenomic and Genomic Hepatitis C Virus RNA Replication. J. Virol. 2002, 76, 13001-13004. DOI: 10.1128/JVI.76.24.13001-13014.2002. (b) Lohmann, V.; Kormer, F.; Koch, J.; Herian, U.; Theilmann, L.; Bartenschlager, R. Replication of Subgenomic Hepatitis C Virus RNAs in a Hepatoma Cell Line. Science 1999, 285, 110-113. DOI: 10.1126/science.285.5424.110. 
[20] Abian, O.; Vega, S.; Sancho, J.; Velazquez-Campoy, A. Allosteric Inhibitors of the NS3 Protease from the Hepatitis C Virus. PLoS One. 2013, 8, e69773. DOI: 10.1371/journal.pone.0069773.

[21] Residual solvent signals set according to Fulmer, G. R.; Miller, A. J. M.; Sherden, N. H.; Gottlieb, H. E.; Nudelman, A.; Stolz, B. M.; Bercaw, J. E.; Goldberg, K. I. NMR Chemical Shifts of Trace Impurities: Common Laboratory Solvents, Organics, and Gases in Deuterated Solvents Relevant to the Organometallic Chemist. Organometallics 2010, 29, 2176-2179. DOI: 10.1021/om100106e.

[22] Hellriegel, C.; Rück, A. Technical Aspects of Quantitative NMR for the Certification of Organic Reference Materials. Analytix 2012, No 4, 8-9.

[23] Crude bromoacetaldehyde was prepared according to Huang, S.; Qing, J.; Wang, S.; Wang, H.;

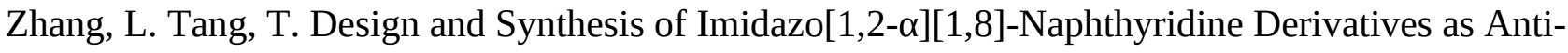
HCV Agents Via Direct C-H Arylation. Org. Biomol. Chem. 2014, 12, 2344-2348, DOI: 10.1039/c3ob42525h, and its purity was determined by ${ }^{1} \mathrm{H}-\mathrm{RMN}$ using TMB as an internal standard. [24] Frisch, M. J.; Trucks, G. W.; Schlegel, H. B.; Scuseria, G. E.; Robb, M. A.; Cheeseman, J. R.; Scalmani, G.; Barone, V.; Mennucci, B.; Petersson, G. A.; Nakatsuji, H.; Caricato, M.; Li, X.; Hratchian, H. P.; Izmaylov, A. F.; Bloino, J.; Zheng, G.; Sonnenberg, J. L.; Hada, M.; Ehara, M.; Toyota, K.; Fukuda, R.; Hasegawa, J.; Ishida, M.; Nakajima, T.; Honda, Y.; Kitao, O.; Nakai, H.; Vreven, T.; Montgomery, J. A. Peralta, J. E.; Ogliaro, F.; Bearpark, M.; Heyd, J. J.; Brothers, E.; Kudin, K. N.; Staroverov, V. N.; Kobayashi, R.; Normand, J.; Raghavachari, K.; Rendell, A.; Burant, J. C.; Iyengar, S. S.; Tomasi, J.; Cossi, M.; Rega, N.; Millam, J. M.; Klene, M.; Knox, J. E.; Cross, J. B.; Bakken, V.; Adamo, C.; Jaramillo, J.; Gomperts, R.; Stratmann, R. E.; Yazyev, O.; Austin, A. J.; Cammi, R.; Pomelli, C.; Ochterski, J. W.; Martin, R. L.; Morokuma, K.; Zakrzewski, V. G.; Voth, G. A.; Salvador, P.; Dannenberg, J. J.; Dapprich, S.; Daniels, A. D.; Farkas, O.; Foresman, J. B.; Ortiz, J. V.; Cioslowski, J; Fox, D. J. Gaussian 09, Revision A.01, Gaussian Inc., Wallingford CT, 2009. [25] Todeschini, R.; Consonni, W. Molecular Descriptors for Chemoinformatics, Wiley-VCH Verlag GmbH \& Co. KGaA, 2010.

\section{Supplementary data}

Copies of ${ }^{1} \mathrm{H}$ NMR and ${ }^{13} \mathrm{C}$ NMR spectra of all compounds, X-ray crystallographic data (ORTEP) for compound 4a (PDF), copies of antiviral activity and cell viability graphs of compounds 13, 15, 16, 18, 19, 23, 26, 28, 30, 32, 34, 36 and 38, and figures for binding poses of GSK3082 and compounds 13, 15, 16, 18, 19, 21, 23, 26, 28, 30, 32, 34, 36 and 38. $\mathrm{X}$-ray crystallographic data for compound $\mathbf{4 a}$ (CIF). 